\title{
INVESTIGATING DESIGN PERFORMANCE OF INTERDISCIPLINARY UNDERGRADUATE ENGINEERING STUDENT TEAMS
}

\author{
A Thesis \\ Presented to the faculty of the School of Engineering and Applied Science \\ University of Virginia
}

In Partial Fulfillment of the Requirements of the Degree

Master of Science Systems Engineering

by

Matthew E. McFarland

May 2014 


\section{APPROVAL SHEET}

The thesis is submitted in partial fulfillment of requirements of the degree of Master of Science Systems Engineering

Matthew E. McFarland, Author This thesis has been read and approved by the examining Committee:

\begin{tabular}{c}
\hline $\begin{array}{c}\text { Prof. Reid Bailey } \\
\text { Thesis Advisor }\end{array}$ \\
\hline Prof. Peter A. Beling \\
Committee Chair \\
\hline Prof. Joanne B. Dugan \\
Committee Member \\
\hline Prof. Nancy L. Deutsch \\
Committee Member
\end{tabular}

Accepted for the School of Engineering and Applied Science:

\begin{tabular}{c}
\hline James H. Aylor \\
Dean, School of Engineering and \\
Applied Science
\end{tabular}

May 2014 


\section{ACKNOWLEDGMENTS}

First, I would like to thank Professor Reid Bailey for introducing me to the research field of engineering education. Three years ago when I first began my graduate career at the University of Virginia, I was interested in expanding my knowledge of engineering and Professor Bailey provided the opportunity I was looking for through the creation of this research study. I would also like to thank my committee, Professor Peter Beling, Professor Nancy Deutsch and Professor Joanne Dugan for also helping turn my three years of graduate work on this research study into a truly meaningful learning experience. Lastly, I would like to thank my family, the driving source behind pursuing this degree, and friends for continuing to support and motivate me, from both near and far, as I tackled the challenges of graduate school. 


\section{ABSTRACT}

While interdisciplinary teamwork and design are centrally important to modern engineering practice, many traditional engineering programs do not have interdisciplinary design collaboration built into their engineering curriculum. This gap in engineering curricula has caused disconnect between engineering education and current engineering practice. Efforts in engineering education to address this issue have resulted in the establishment of interdisciplinary engineering programs at many universities, including the Technology Leaders Program at the University of Virginia. This study aims to uncover insights into interdisciplinary collaboration and engineering design through research on undergraduate engineering students from this program, with the purpose of improving the understanding of how students become proficient at interdisciplinary design. To facilitate this goal, this study used the method of video analysis to observe both students from this program and their undergraduate engineering peers not in the program working in interdisciplinary teams on an engineering design activity.

In this thesis, chapters 1 and 2 provide context for the motivation and purpose of this research by introducing the engineering education research area, presenting the research questions of interest and explaining relevant literature and prior works relating to this study. Chapters 3 through 5 present the methodology used in the gathering and preparation of data for analysis, and the engineering design framework used in developing a coding scheme for the assessment of data. Chapters 6 through 9 present the major findings of this study and their importance to the overall purpose of this research. 
Chapter 6 provides context for what happened during this study from an overall study perspective. It presents the amount of time student teams spent working across stages of the engineering design framework and across various team structures. Team structure refers to the utilization of various subgroups by student teams during this activity to accomplish work. Major findings from this chapter show activities related to prototyping and testing play a large role in engineering design with over half the time in this study attributed to those activities. Findings also show student teams tend to spend the same amount of time working in a single group as they do in some combination of subgroups. This chapter also presents a rich description for what type of activities are involved in an engineering design activity and how they relate to the engineering design framework used in this study. The findings of this chapter are important to understanding the nature of interdisciplinary collaboration and engineering design in the context of this study.

Chapter 7 builds on the findings of chapter 6 by evaluating how group composition affected the behavior of student teams in this study. Group composition refers to the makeup of student teams in this study. Each team consisted of two electrical and computer engineering students, and two systems engineering students but varied with the number of students from the Technology Leaders Programs. A similar analysis to chapter 6 is completed looking at the overall time spent working in each design stage and team structure as well as studying the frequency of activities in each of the design stages. Major findings from this chapter show the time spent in each design stage was different among teams with different group compositions. Findings also show the use of team structure varied across group compositions as well. 
Chapter 8 explores the relationship between team structure and engineering design. In this chapter both overall team structure and subgroup team structures are analyzed to draw inferences about impact on engineering design. Major findings from this chapter show the choice of team structure was an indicator for which design stage a team was currently operating in. This chapter also analyzes the relationship between team structure and engineering design at the group composition level investigating the influence of varying group compositions on both areas. Findings show group composition did not influence this relationship.

Chapter 9 is the only chapter to analyze team structure and engineering design at the individual team level. This chapter studies the behavior over time of each team in reference to design stage and team structure use. It presents several patterns of navigation through the engineering design framework and team structure use. The findings in this chapter give perspective to how the results presented in chapter 6 were represented across all eleven groups. Major findings from this chapter show student groups follow several distinct patterns of behavior when working on an engineering design activity.

Chapter 10 draws on the inferences from each of these chapters to present answers to the research questions of interest and presents future work that could follow this study. 


\section{Table of Contents}

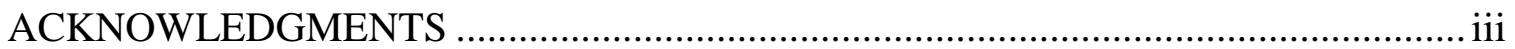

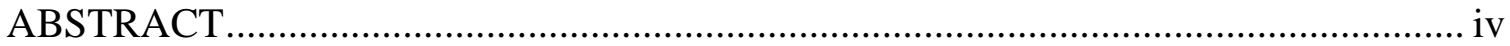

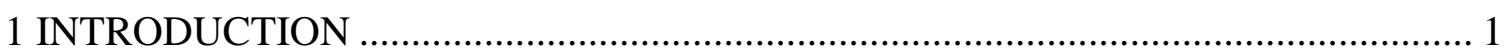

1.1 Technology Leaders Program ................................................................... 4

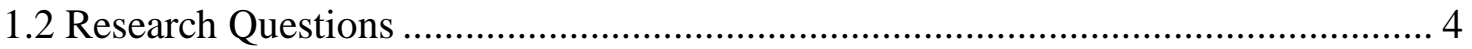

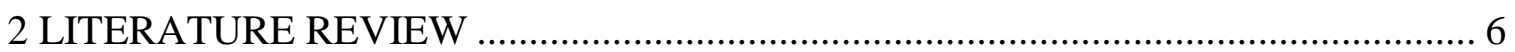

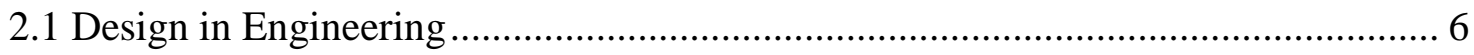

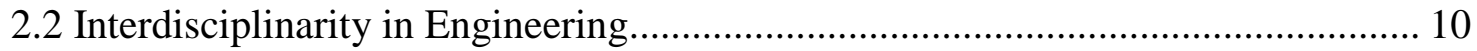

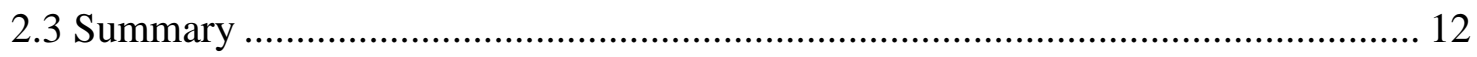

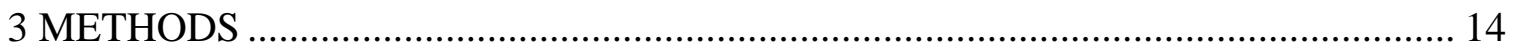

3.1 Researcher Paradigm \& Approach .................................................................. 14

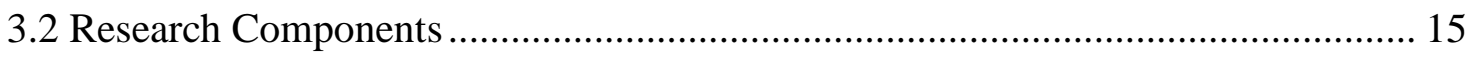

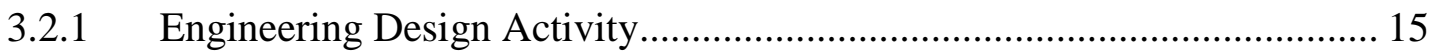

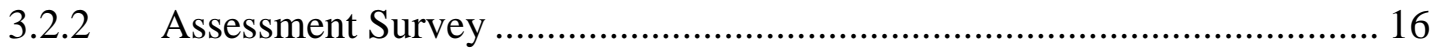

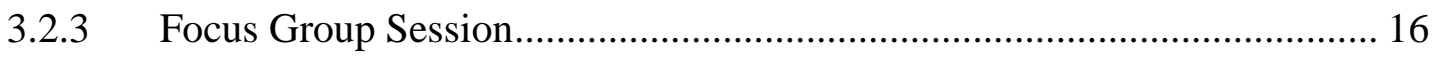

3.3 Recruitment of Participants ........................................................................ 17

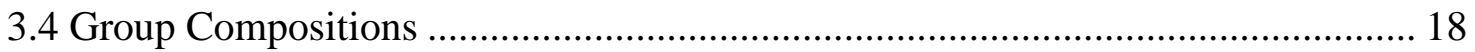

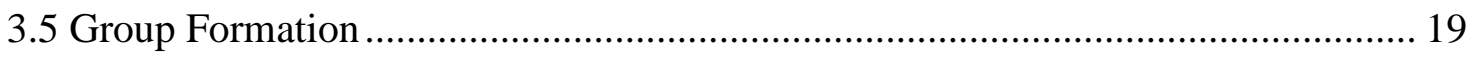

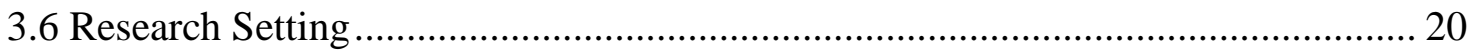

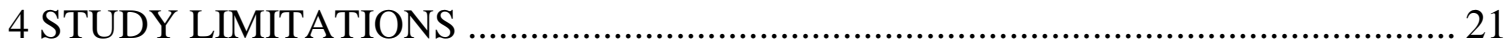

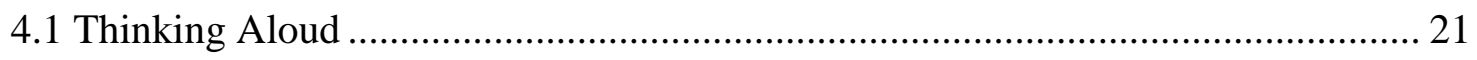

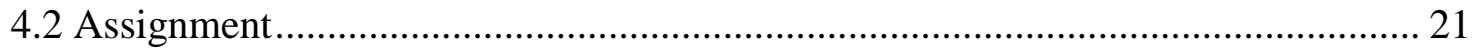

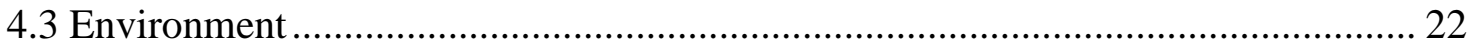

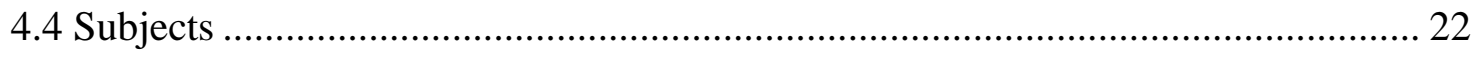

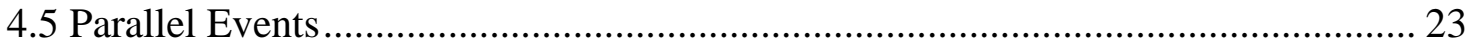

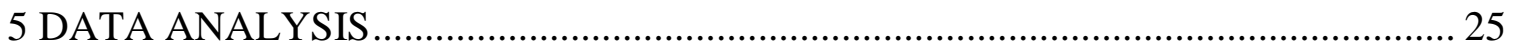

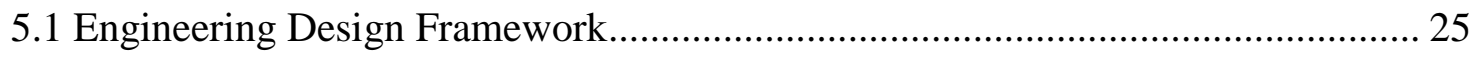

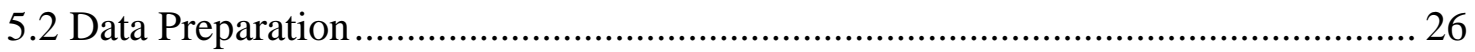




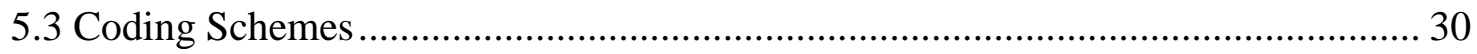

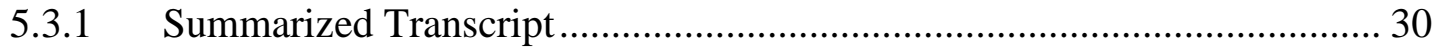

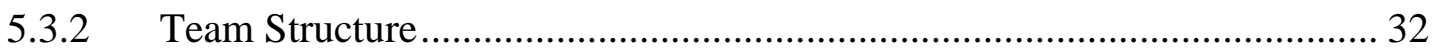

5.3.3 Time Distribution ................................................................................... 33

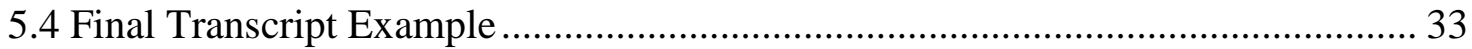

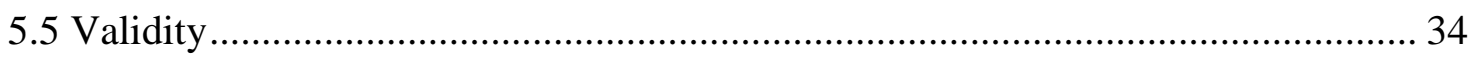

6 CONTEXTS OF DESIGN STAGE AND TEAM STRUCTURE.................................. 35

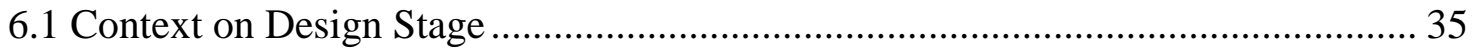

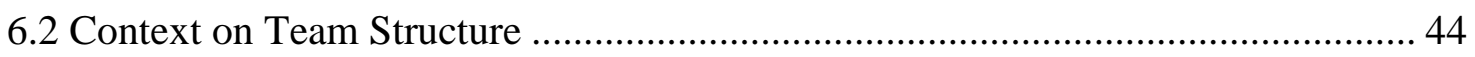

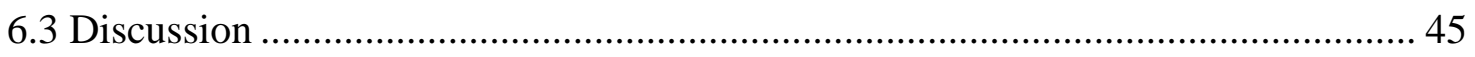

7 INFLUENCE OF GROUP COMPOSITION ON STUDENT BEHAVIOR .................. 47

7.1 Influences on Design Stage in Reference to Time ................................................. 48

7.2 Influences on Design Stage in Reference to Activity …………………................. 49

7.3 Influences on Team Structure in Reference to Time.............................................. 57

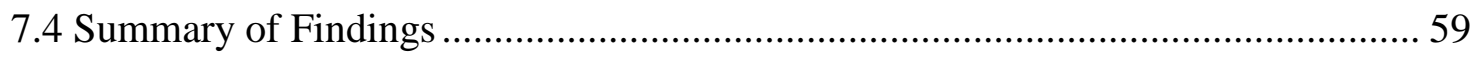

8 RELATIONSHIP BETWEEN TEAM STRUCTURE AND DESIGN STAGE ............ 61

8.1 Relationship between Team Structure.................................................................. 61

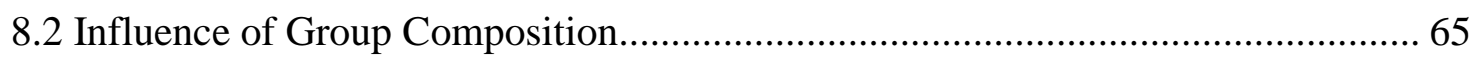

9 PATTERNS IN DESIGN STAGE USE AND TEAM STRUCTURE........................... 72

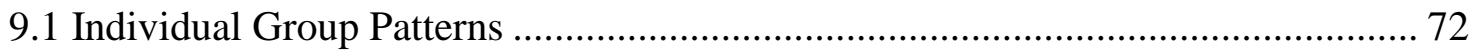

9.2 Observed Patterns through Design Stages .......................................................... 73

9.3 Observed Patterns through Team Structure …………………………………...... 74

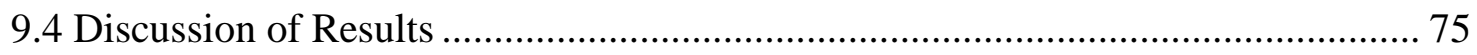

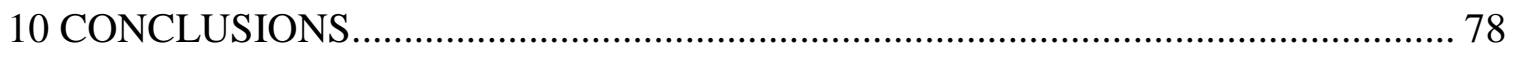

10.1 Response to Research Questions of Interest ………............................................ 78

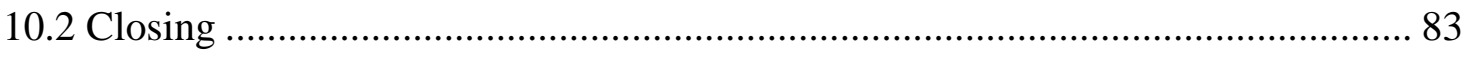

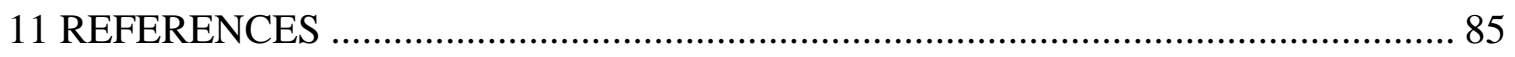

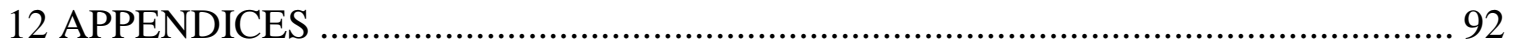

APPENDIX A: Study Room Set-up Description and Layout...................................... 92 APPENDIX B: Design Activity Prompt and Cavalier Daily Additional Information.. 93 viii 
APPENDIX C: Inter-rater Reliability using Cohen's Kappa.................................... 97

APPENDIX D: Patterns of Activity for Each Group ............................................. 98

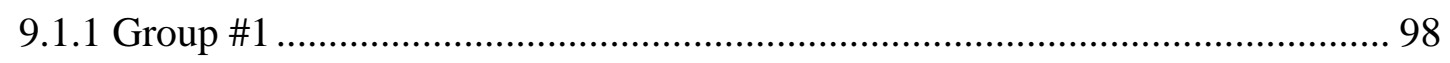

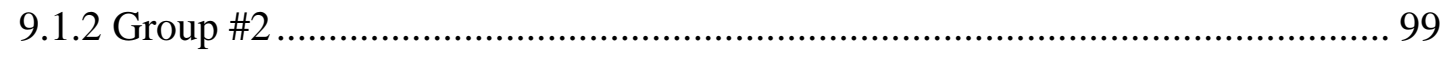

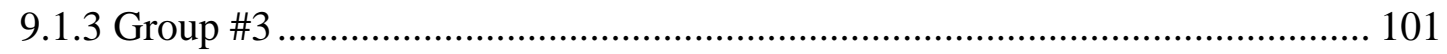

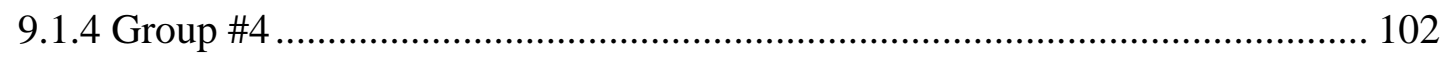

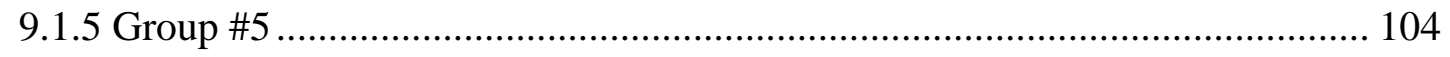

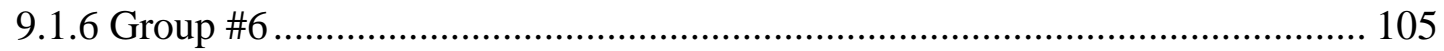

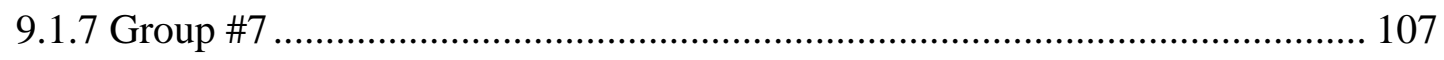

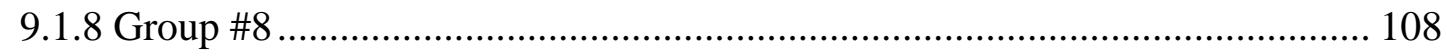

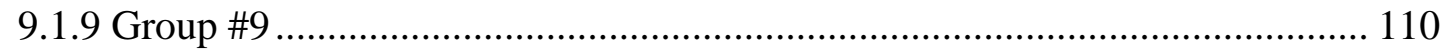

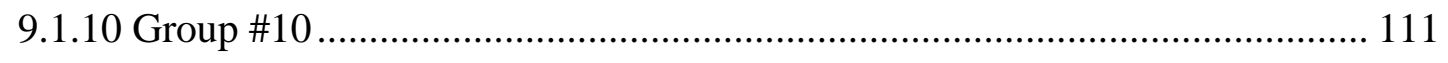

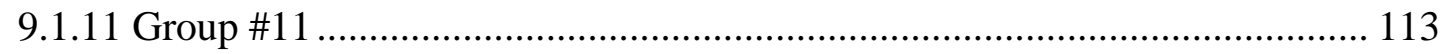




\section{INTRODUCTION}

Over the last 5 decades, the average engineering curriculum has largely been based on an "engineering science" model in which the analytical and mathematical elements of engineering are strictly of focus [1]. This implies that all challenges faced in engineering can be condensed and modeled as solvable math equations. This model, however, poses a threat to the current methods of engineering practice by giving the notion that all serious engineering is done in the language of mathematics [2]. While the engineering science model approach has a clear role in a design process, the model neglects to show that engineering also involves "working between technical and non-technical considerations ... and managing trade-offs where solutions are judged by interdisciplinary criteria" [3]. Therefore, in instituting this model in engineering curricula, those factors that make engineering design as much of a social activity as a mathematical process are neglected [2]. Neglected factors include the "systems methodology" and "engineering design" related processes such as need identification, problem formulation, development of alternatives, and analysis and decision-making using prototypes and judgment. Also neglected are social aspects such as cultural and environmental influences and processes such as working with a group of individuals. All of these factors, plus many more, are what drive the demands of technology and product innovation today. These demands have evolved the current practice of engineering in such a way that there now exists disconnect between engineering education and engineering practice. This disconnect has resulted in today's engineering students lacking the key skills needed to be successful engineers [4]. 
There have been many prominent calls to reduce the distance between engineering education and engineering practice, with perhaps the most notable being from the National Academy of Engineering's Engineer of 2020 project [5], [6]. As a result, engineering education is starting to change.

One key area of change in engineering education is the inclusion of interdisciplinary knowledge and teamwork skills into engineering curricula. According to the National Academy of Engineering, the need to experience interdisciplinary collaborations is growing due to the increasing complexity and scale of systems-based engineering problems. As a result the future of engineering education must emphasize preparing engineers who can deal with complexity, innovate on demand and bridge disciplinary boundaries [6]. "Where disciplinary approaches to design are situated in specific bodies of knowledge, cross-disciplinary approaches focus on the nature of the problem, integrating several perspectives to synthesize a collective whole." [3]. Therefore the ability to exhibit interdisciplinary knowledge is vital to the development of the modern engineer. In the context of this study, interdisciplinary knowledge will refer to the common understanding among engineers which centers around teamwork and the dynamics of completing team projects with individuals from other disciplines [7], [8].

Another major area of recent change in engineering education is design. As articulated by Dym and Levitt, engineering design is "the systematic, intelligent generation and evaluation of specifications for artifacts whose form and function achieve stated 
objectives and satisfy specified constraints" [9]. Although design is widely considered as the most distinguishing and fundamental activity of engineering [1], most curricula have it either isolated in the senior year or sometimes also in the first year. It was once thought that first year students did not have the capacity to comprehend engineering design before completing the fundamental coursework of engineering. Now, as the engineering curriculum has progressed, first year design courses, known as the cornerstone engineering courses, have become staple courses across engineering programs in the United States [1]. Similarly, fourth year design courses, referred to as capstone courses, have seen increased development over time through integration of industry-sponsored projects with real world applications into the coursework. However, these capstone courses serve as the only standard opportunity across engineering education for undergraduate engineering students to showcase their engineering education.

In summary, while interdisciplinary teamwork and design are centrally important to modern engineering practice, many traditional engineering programs do not have interdisciplinary design collaboration built into their engineering curriculum; instead their programs are mainly analytical and theoretical, leaving little room for students to develop professional practices. Many programs also approach engineering design from an engineering science model; focusing on analytical approaches to design within single engineering disciplines. This disconnect between engineering education and engineering practice has been recognized and a growing number of curricula are being created to address it; included in such programs are those at Harvey Mudd [10], James Madison [11], Purdue's EPIC [12] and Multidisciplinary Engineering programs [12], [13], and the 
Technology Leaders Program at the University of Virginia [14]. Unfortunately, there is a lack of research available into how to best educate students in interdisciplinary design around which these programs can be built. This study aims to uncover insights into interdisciplinary collaboration and engineering design through research on undergraduate engineering students from an interdisciplinary engineering program at University of Virginia.

\subsection{Technology Leaders Program}

An interdisciplinary undergraduate engineering program at the University of Virginia, the Technology Leaders Program, provides a case study for this research. This interdisciplinary program consists of collaboration between the Electrical and Computer Engineering (ECE) and Systems Engineering (SIE) departments. It is comprised of a three year curriculum that fosters a learning environment in which electrical, computer and systems engineering students collaborate to engage in the designing, prototyping and testing of engineering systems. The value added of a TLP student is grounded in their ability to engage both systems integration and domain-specific engineering work. At the end of the curriculum, graduates should be more able to "design systems requiring the integration of knowledge and skills from" electrical, computer and systems engineering and "collaborate on interdisciplinary teams" [14].

\subsection{Research Questions}

The long-term goal of this research is to improve understanding of how students become proficient at interdisciplinary design; the purpose of this improved understanding is to 
inform the creation of curricula to develop graduates with those skills. To facilitate this goal, the primary research method was to observe engineering students from the Technology Leaders Program and their peers not in the program working on interdisciplinary teams on an engineering design activity. A mixed-methods approach was used to address two main objectives, interdisciplinary collaboration and engineering design, to answer the following research questions:

1) How do interdisciplinary teams engage in the engineering design process? Is there a difference in how teams of differing student composition engage in the engineering design process?

2) How do interdisciplinary teams distribute their time with respect to the engineering design stages and team structure? Is there a difference in the distribution of time when comparing teams of differing student compositions?

3) When interdisciplinary teams split into subgroups, how do those subgroups contribute to the engineering design stages? Are those subgroups determined by majors, curriculum or other factors?

4) What patterns of behavior with respect to design stage and team structure do interdisciplinary teams exhibit during an engineering design activity? 


\section{LITERATURE REVIEW}

The motivation for this study was in part due to the literature regarding the evaluation of interdisciplinary work, interdisciplinary design and the absence of research in how to best educate students in interdisciplinary design. This section explores prior studies in these areas and discusses them in relation to student experiences and engineering education as a whole.

\subsection{Design in Engineering}

Atman has conducted several studies using Verbal Protocol Analysis (VPA) to observe and compare the design process of undergraduate students, specifically first and fourth year students [15]-[18]. In her studies, participants individually worked through openended design questions with limited information provided upfront. However, participants were not selected based on major and did not commence in any physical implementation of their designs. Results from her studies show there are noticeable differences between first and fourth year students design processes, particularly in the amount of information gathered, transition behavior and their progression through design steps. These studies give valuable insight to design as it relates to teamwork but did not include the implementation of design into a prototype. These studies also did not give insight into design as it relates to interdisciplinarity in engineering. 
The Delft Protocol Workshop [19] and Design Thinking Research Symposia: Design Meeting Protocols (DTRS7) [20] were two significant workshops aimed at studying engineering design activities and knowledge.

The Delft Protocol Workshop brought together a group of researchers all versed in protocol analysis to analyze a standard set of data collected by Cross et al [19]. The data was a recorded collection of both individual designers and a three-person team of designers designing a fastening device for a backpack to go on a mountain bike. The experimental setup was similar to the setup of this study with information being distributed upon request and participants completing a short follow-up interview after the activity. However, in Cross' study only individual participants were instructed to think aloud and complete a short initial think aloud exercise. The groups in this study were not instructed in the same manner to do the same but instead expected to talk aloud in communication with other members of the group. Also, participants of Cross' study were all professionals with varying years of engineering design experience. Examples of what researchers did with the data include formulating comparisons and dissimilarities between team and individual performance in design [21], [22], characterizing aspects of a team [23] and looking at the relationship between the ways design ideas mutate and evolve within a group [24], [25].

The Design Thinking Research Symposia: Design Meeting Protocols (DTRS7) also brought together researchers from around the world but for the purpose of showing how analyzing design meetings can increase the understanding of design as a social process 
[20]. Researchers were provided with a standard set of films of design meetings from two design firms, one specializing in architecture and the other in engineering design. The architectural project was to design a crematorium whereas the engineering project was to design a digital pen. The data set consisted of video/audio footage of a total four meetings, two each from both projects. Researchers who participated chose to conduct analysis on any of the four meetings. There were two ways researchers approached the data sets, either from a data driven approach or a theory driven approach. A theory driven approach entailed imposing or testing a particular theory about design on the data whereas a data driven approach entailed constructing all arguments from the data. In addition to using one of these approaches, many researchers also developed, applied or extended a coding scheme to classify the data. Atman was one of two researchers who took a data driven approach and used a coding scheme in an analysis on the engineering design team meetings. She analyzed the data set for the purpose of understanding how designers integrate context of conversation into the design process [18]. She developed a time-based description of conversation in terms of activities occurred, topics discussed and focus of discussions. Her same methodology was applied in several other studies relating to undergraduate engineering students and serves as the basis for the coding scheme developed for this study. Badke-Schaub et al. conducted an analysis in a similar way using a three-categorization system of Content, Cognitive Acts, and Strategies to classify each statement. She also developed network maps observing how often each team member spoke to each other [26]. Other studies from this collection of work analyzed how references to objects, whether intermediary or analogous, play a role in design [27]-[29]. 
Other researchers who have studied engineering design and design teams include Dong, Song, and Olson. Dong's research characterizes the performance of engineering design teams using computational text analysis. Results developed a mechanism for instructors to monitor and manage team performance and nuances in real time [30]. Song examined documentation, presentation material, and e-mail communication of student designers to plot the semantic coherence of those materials over the product design cycle. Results showed that high performing design teams cycle between divergent and convergent patterns of thinking and questioning [31]. Olson conducted a study on small group design meetings. The purpose of the study was to observe and discover what design discussions unfold during ten face-to-face meetings with two groups of professional software engineers from different organizations. The study grouped observations into three areas: activity categories, usage of time, and negative / positive alternatives. Results of the study found that design meetings, although as an observer seem scattered and disorganized, are actually quite organized with most of the discussion centering around design issues, alternatives, criteria and their supporting clarifications. Results also showed the pattern of activity in terms of time spent were similar across all ten group meetings [32].

In summary, much of prior work in design focuses specifically on the design process and the way about which individuals with varying backgrounds develop a solution. The prior work presented however does not delve into the implementation of design solutions as physical prototypes. This study both targeted students of specific engineering disciplines and seeks to understand how those students implement their designs solutions. 


\subsection{Interdisciplinarity in Engineering}

While most research in interdisciplinarity is in the humanities, a growing body of work in interdisciplinarity in engineering is emerging. Within engineering, Richter explored and uncovered mixed results about the learning barriers students face in interdisciplinary contexts. One study looked at a student's ability to recognize relationships between the student's major and interdisciplinary topics as well as identify connections between their own field and other's fields in terms of contributions, viewpoints and expertise [7]. Results from this study show students exhibit a disciplinary egocentrism, the inability to think beyond their discipline, and this is a cognitive barrier faced when interacting in the interdisciplinary setting. In another study, Richter used a scenario-based instrument to measure a student's ability to identify and value contributions of multiple disciplines and measure a student's understanding of the need for broad based interdisciplinary collaboration [33]. Results from this study show students do exhibit awareness for the need of interdisciplinary collaboration and the ability to value the contributions of multiple disciplines. These results do potentially conflict with the findings of Richter's other study about student learning barriers. However neither set of results give insight into how students of differing disciplines contribute in a team setting.

Lattuca and Borrego also conducted research on barriers to interdisciplinary learning in students, Lattuca from a pedagogical view and Borrego through literature analysis. Lattuca explored the various theories and definitions used by scholars to define interdisciplinarity. Results from her study revealed varying and conflicting definitions of interdisciplinarity used by engineering administrators and faculty across engineering 
education. These conflicting definitions potentially hamper the development of a student's interdisciplinary competence [34]. Borrego explored and identified five categories of learning outcomes for interdisciplinary graduate education by comparing literature of interdisciplinary studies with content analysis of successful National Science Foundation proposals [35].

Coso conducted a study for the purpose of measuring undergraduate students' interdisciplinary understanding. She specifically focused on second-year students' development as interdisciplinary engineers within an interdisciplinary undergraduate engineering (IUE) program. Her study sought to characterize students' perceptions of interdisciplinarity and determine if students' perceptions of interdisciplinary vary with gender or disciplinary affiliation. Among her findings are that students from differing majors (i.e. Systems Engineering and Electrical and Computer Engineering) do not show a disciplinary identity in their second year, that students believed that the benefits of an interdisciplinary approach outweigh the challenges associated with interdisciplinary teamwork, and that their perceptions of interdisciplinarity are based off previous engineering team-based projects [36]. Additionally, her work highlighted the tight connection between interdisciplinarity and teamwork in engineering; this is in contrast to the humanities, where interdisciplinarity can be a goal for a single individual [37].

Other research work of interest to this study centers on interdisciplinary teamwork. Within the design literature, Cross identified teamwork as important to a professional design activity and becoming of greater importance in product design. Cross also 
characterized teamwork as having six elements, which include gathering and sharing info, analyzing and understanding the design problem, and ways of developing and adopting design concepts [23]. Interdisciplinary teams exhibit these elements as well as excellence in communication with technical and public audiences, the ability to communicate using technology, and understanding of complexities associated with global market and social context [5].

Borrego, through research in cross-disciplinary engineering collaborations developed a three-step process to what she referred to as "true interdisciplinary approach" to research [38]. However, results from her interdisciplinary research suggest engineers are unlikely to participate in truly interdisciplinary work and instead trust in the expertise of others' doing their own work [39], [40]. This particular observation is of direct interest to this study and the body of research known as Science of Team Science (SciTs). Science of Team Science (SciTs) is a growing body of research on multi/inter/trans disciplinary research and research teams. SciTS seeks to understand cross-disciplinary research by examining how teams organize, communicate and conduct research. Although SciTs is fast growing field of interest more research needs to be conducted in order to validate its claims for team science [41], [42].

\subsection{Summary}

Research in interdisciplinary collaboration and engineering design are two important areas in the understanding of how students become proficient at interdisciplinary design. Although studies conducted on design teams resulted in significant findings, the studies 
presented did not include implementation of design solutions in their methods. Also, the participants in these studies were not determined based on discipline.

In addition, there exists prior work in the humanities on students navigating interdisciplinary situations; however, in the field of engineering this work is limited. Out of the work that does exist it primarily has been conducted through the use of interviews, "critical incident interviews" [37], scenario-based cases and surveys. This study instead used the method of video analysis to investigate those interdisciplinary team interactions between students. Moreover, prior video analysis of engineering design teams has not focused on interdisciplinary teams. Therefore, the purpose of this study was to build on the research presented on the role of interdisciplinarity and design in engineering through video analysis of interdisciplinary design teams. 


\section{METHODS}

\subsection{Researcher Paradigm \& Approach}

The theoretical framework of this study fell under the realm of post-positivism. The researcher used deduction and induction to acquire knowledge about the student research subjects. Background experience as an undergraduate engineering student in a traditional engineering curriculum and prior engineering internship experiences provided foundational knowledge for the researcher. This foundational knowledge lead the researcher to believe differences exist between the TLP and non-TLP students and to investigate what ways the groups of students are different in relation to interdisciplinary design collaborations.

The most appropriate approach to understanding these differences and responding to the research questions was a mixed methods approach consisting of the grounded theory and case study methods. Although the researcher entered the study expecting that there was a difference between the two approaches to engineering education, this viewpoint was too general to be a valid hypothesis. The grounded theory method approach allowed for the researcher to first collect data and then, during analysis and coding of data, to identify concepts and emerging categories. The researcher used the case study method to fabricate an environment in which individual cases were created. This resulted in the creation of different teams which could be compared in a cross-case comparison. The student subjects had the opportunity to experience interdisciplinary interactions and to capture those interactions as desired data to answer the research questions. 


\subsection{Research Components}

Students in this study participated in a design activity in interdisciplinary teams of four. During the design activity students were asked to follow the Verbal Protocol Analysis method of thinking aloud while working through the activity. This method was used in a way similar to how design has been studied by many others including Atman [15]-[18] and Cross, Christaans and Dorst [19]. Following the activity, students also participated in a focus group and completed a post-activity survey. A pilot study was conducted in spring of 2012. A second set of participants completed the protocol in spring of 2013. Both studies were approved by the Institutional Review Board.

\subsubsection{Engineering Design Activity}

Participants completed a three-hour activity in which they work as a team to develop and model a prototype for a newspaper counter for the college newspaper, the Cavalier Daily. The newspaper counter must be designed using the materials provided and constructed as an addition to the current Cavalier Daily newspaper distribution boxes. The students were presented with information about the Cavalier Daily Newspaper and a list of requirements for the desired prototype established by Cavalier Daily. The students were then instructed to act as engineering consultants and develop a solution based on those requirements. In addition to a Cavalier Daily newspaper distribution box, the students were provided with several electronic sensors manufactured by Phidgets and SunSPOT as well as various construction materials (tape, cardboard, scissors, paper, etc.) to construct the desired prototype. Students were also provided with four laptop computers outfitted with Microsoft Office and Integrated Development Environments to configure the 
electrical sensors. During the three-hour activity, the researcher acted as a representative of Cavalier Daily answering questions and providing any information requested of the client by the students. The problem chosen for this Engineering Design Activity required skills related to the Electrical Engineering, Computer Engineering, and Systems Engineering majors. This engineering problem was complex enough to allow students to fully engage in the engineering design process and simple enough to complete prototyping within the given three-hour time frame. The entire activity was recorded using multiple video cameras and tape recorders. See Appendices A and B for the activity prompt, Cavalier Daily additional information and room set-up.

\subsubsection{Assessment Survey}

Following the Engineering Design Activity, each student was required to complete an electronic Assessment Survey. The purpose of this survey was to capture individual thoughts about the study that were not expressed during the Engineering Design Activity. Questions on the survey asked participants to explain the distribution of work and the level of contribution each participant displayed during the Design Activity. Participants were asked whether their individual contributions to the project were valued by the other participants on their team. Participants were also asked to list the individual contributions of each team member.

\subsubsection{Focus Group Session}

Each team of students participated in a forty-five minute focus group session immediately following the assessment survey. During this session, teams were asked a series of 
questions about thoughts behind their actions taken during the activity and thoughts on the overall team interaction. The questions sought to develop an understanding of the general thought process displayed during the activity with specific questions focusing on

the team's overall approach toward developing a solution. Other questions asked during this session prompted the students with a topic relating to either technical features or project requirements. These questions were asked to observe how individual students contribute to discussions on specific topics (e.g., do electrical engineering students tend to contribute differently to questions about the electronics than systems engineering students do?). In addition, the researcher asked questions about specific things observed during the three hours that warranted further explanation or exploration by the students. The entire session was recorded using video cameras and tape recorders.

\subsection{Recruitment of Participants}

All students were recruited using two electronic surveys. The first survey was distributed to all 4th year engineering students in Systems Engineering and Electrical and Computer Engineering departments to collect the major and year of interested participants. Only second semester 4th year students were accepted for the study. The second survey was administered to eligible students who respond to the first survey and used to identify their availability for participation in the research study. A separate survey will be administered to 4th year TLP students to identify their availability to participate in the research study as well. All students were asked to consent to participation in the study and received $\$ 100$ for successful completion of the entire study. 
The pilot study included twenty-three fourth year undergraduate engineering students as participants from the following majors: twelve Systems and Information Engineering (SIE), ten Electrical and Computer Engineering (ECE), one Computer Science (CS). Eleven of the twenty-three students were a part of the Technology Leaders Program. Eleven students were traditional curriculum students not associated with the Technology Leaders Program. One of the eleven students withdrew from the Technology Leaders Program after completing the first year of the program.

The spring 2013 study included nineteen fourth year undergraduate engineering students as participants from the following majors: ten Systems and Information Engineering (SIE), nine Electrical and Computer Engineering (ECE). Ten of the nineteen students were a part of the Technology Leaders Program. Nine students were traditional curriculum students not associated with the Technology Leaders Program.

Table 3.3 shows the breakdown of all participants by curriculum, gender, and major.

Table 3.3 Breakdown of Study Participants

\begin{tabular}{|c|c|c|c|c|c|}
\hline Curriculum & Male & Female & ECE & SIE & CS \\
\hline Traditional & 13 & 8 & 10 & 11 & \\
\hline TLP & 14 & 7 & 9 & 11 & 1 \\
\hline
\end{tabular}

\subsection{Group Compositions}

Students were divided into groups of four. Each group had two SIE students, two ECE students and make up one of five group structures depending on the number of TLP students available to participate in the study. The five group structures are as follows: 
- GC1 - Four TLP students (two SIE, two ECE)

- GC2 - Two traditional students (one SIE, one ECE), two TLP students (one SIE, one ECE),

- GC3 - Two traditional students (both ECE), two TLP students (both SIE)

- GC4 - Two traditional students (both SIE), two TLP students (both ECE)

- GC5 - Four traditional students (two SIE, two ECE)

Table 4.3 shows the breakdown of groups in the study by composition. One GC4 group and one GC5 group only had three students to complete the study (noted by the *).

Table 3.4 Breakdown of Study Groups by Composition

\begin{tabular}{|c|c|c|c|c|c|}
\hline Composition & GC1 & GC2 & GC3 & GC4 & GC5 \\
\hline \# of Groups & 2 & 3 & 2 & $2 *$ & $2^{*}$ \\
\hline
\end{tabular}

\subsection{Group Formation}

TLP students were not solicited through the same general survey as the other students. Instead, all $4^{\text {th }}$ year TLP students in the program were asked to participate in this study via email. Since there were a finite number of TLP students participating, those students were placed in groups first before placing non-TLP students. The TLP students were paired into groups based on major and capstone team advisor. The intent was to separate those students who worked on the same capstone team to minimize the amount of prior experience each student had working together. Once availability was obtained from the paired TLP students, non-TLP students who matched in availability and were on different capstone teams were selected to complete the design activity groups. 


\subsection{Research Setting}

Both studies took place inside a classroom designed for interactive learning. The room setup included three six foot tables, four desk chairs, various arts and craft materials, loose-leaf paper, mechanical pencils, two white boards and one replica of the newspaper distribution box. Two cameras were positioned in adjacent corners of the room to capture the overall and main table view student participants working during the pilot study. A tape recorder was positioned on the main table to capture any discussion between the students that were not picked up by the cameras. Refer to appendix A for the drawing of room layout. 


\section{STUDY LIMITATIONS}

\subsection{Thinking Aloud}

The act of participants thinking aloud could have influenced the work of each individual. This act was abnormal for participants not used to working on a team. From pilot study observations, abnormality can be inferred in the number of times where extended periods of silence occur and participants were reminded to continue thinking aloud. However, in the previous studies presented in Section 3.2 thinking aloud did not influence the thought process of the student[43]. Also, when one participant thought aloud it could hinder another participant from doing the same since two people generally do not talk at the same time in a group. This could also deter a participant who had a similar thought from expressing it or cause another participant to change their thoughts before expressing them.

\subsection{Assignment}

Only one assignment/prompt was used. The assignment presented in the Design Activity was selected because it best mirrored similar group assignments conducted in the Technology Leaders Program. A tradeoff between time allotted, reality of problem and material suitable to majors involved was considered when selecting an assignment. The assignment was designed to be relatively simple, to not require specialist knowledge and to be solvable in the given timeframe. A more complex assignment could uncover further differences between participants by fostering more collaboration and requiring the use of specialist knowledge by participants. 


\subsection{Environment}

The environment in which participants work was a classroom. Although a classroom was not uncommon to participants, it may have been an atypical environment for participants to conduct this nature of work. Participants were also limited to the materials provided to them for the study. Participants did not have the opportunity to observe the object of the assignment in its natural environment, which can limit their thought process. Furthermore, they only had three hours to complete their work whereas a real design project would occur over a longer period of time.

\subsection{Subjects}

Although all participants were from one of two majors, each participant's curriculum and educational training varied slightly. Some participants were more familiar with the materials provided than others which may lead those individuals to take on certain roles and tasks during the activity. The wide range of participant Grade Point Averages (only known to the researcher) could have influenced individual actions of participants. Table 6.4 shows the breakdown of GPAs by group.

Table 4.4.1 Breakdown of Student GPAs by Group

\begin{tabular}{|c|c|c|c|c|c|c|c|c|c|c|c|c|}
\hline $\begin{array}{c}\text { GPA } \\
\text { RANGE }\end{array}$ & G1 & G2 & G3 & G4 & G5 & G6 & G7 & G8 & G9 & G10 & G11 & TOTAL \\
\hline $0.00-2.49$ & - & 1 & 1 & - & - & 1 & - & - & - & - & - & 3 \\
\hline $2.50-2.99$ & 1 & 1 & - & - & 2 & 1 & 1 & - & 1 & - & - & 7 \\
\hline $3.00-3.49$ & 1 & 2 & 3 & 3 & 1 & 2 & 1 & 1 & 3 & 2 & 2 & 21 \\
\hline $3.50-4.00$ & 2 & - & - & 1 & - & - & 2 & 3 & - & 2 & 1 & 11 \\
\hline
\end{tabular}


Participants from the Technology Leaders Program may have had prior coursework experience working together in groups. The TLP students also were also self-selected into the program meaning each student chose to participate in the program. In addition, the TLP students of the pilot study had experience using the same hardware and software in prior coursework. The TLP students of the spring 2013 study had not used the software or hardware in their prior coursework. There was one student in this study who participated in the TLP for one semester before leaving the program. This participant was coded as a non-TLP student. Her prior involvement in the Technology Leaders Program may have influenced her actions taken during this study but due to her short time in the program this was not a concern. Another participant in the study was a TLP student majoring in Computer Science. Her statements were coded as a TLP student ECE student.

Also, there exists the possibility of a Demand-Characteristic Effect which states participants may "form an interpretation of the experiment's purpose and unconsciously change their behavior to fit that interpretation" [44]. This theory may be applicable to the all participants who may act atypical due to belief the Engineering Design Activity is calling upon them to act in a certain way.

\subsection{Parallel Events}

There were periods where parallel events occurred. For example, two students were constructing materials in the distribution box while two students were coding or two students were coding, one student was testing electrical sensors while one student was 
sitting quietly. Concurrent events could have affected the coding of groups based on design task and also made it difficult to hear all conversations. The coding of concurrent events is addressed in the description of each coding scheme affected (Section 5.3). 


\section{DATA ANALYSIS}

\subsection{Engineering Design Framework}

To answer the research questions of interest, the coding framework selected for this study needed to map all conversations and activities observed in segments back to stages of engineering design process. The framework selected was based on a coding scheme developed by Atman of the University of Washington [18]. However, it was adapted to account for prototyping and testing of a physical product (the Atman scheme ended with conceptual designs), and to aggregate several categories from the Atman scheme into a less granular, more generalized stages of design. The following figure shows the adapted coding scheme:

Figure 5.1.1 Engineering Design Stages Coding Scheme

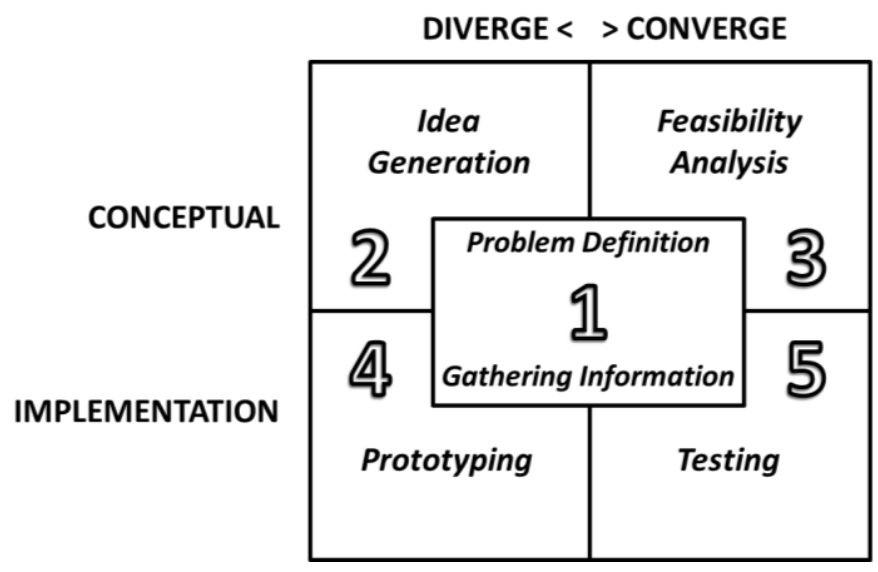

This framework is divided into two dimensions - conceptual versus implementation and diverge versus converge - which determine the location of the stages in the diagram. First, each stage is characterized by whether the actions and conversations that occur 
within it are either abstract/generalized thinking of the mind (conceptual) or as practical implementation of thoughts and ideas (implementation) [45]. Each stage is also characterized as either an expansion from a small to a broad view of an idea or topic (diverge) or moving from a broad viewpoint to a specific focus (converge). Divergence is associated with activities like brainstorming, ideation, building, and prototyping. Convergence is associated with activities such as analysis, selection, evaluation, and testing.

Altogether, five stages comprise this framework. Stage 1 focuses on conversations or actions pertaining to defining requirements, project scoping, and gathering information about a particular project or the needs of stakeholders. Stage 2 focuses on conceptual conversations about new ideas for solutions or designs that pertain to the prototype, including brainstorming and other forms of idea generation (which could be applied prior to any implementation or in response to testing or implementation problems). Stage 3 focuses on conceptual conversations about the feasibility of a proposed solution, including analysis, evaluation, simulations, and multi-attribute selection of a concept. Stage 4 focuses on actions and conversations associated with the constructing of a prototype including building and software coding. Stage 5 focuses on actions or conversations associated with the testing of an implemented system or prototype.

\subsection{Data Preparation}

The first step in data preparation was to merge the audio and video data together. The audio recording for each group was overlaid on its respective video recording using 
VSDC Free Video Editor [46]. To make analysis of video easier, a timer was also added to each video using the same software.

To create a transcript of the events occurring in each design activity, summarized paragraphs detailing events of each team, such as actions taken or statements made, were recorded and separated while watching each video. Section breaks were inserted between paragraphs based on when a design stage a team was functioning in changed or when there was a change in team structure (working as a single group versus in subgroups). At each section break, time was also recorded to make referencing of segments easier in analysis. This resulted in the creation of a transcript which included, for each segment, a video identification number, a start time, a stop time, time elapsed and a summary of events. Figure 5.2.1 shows an example of a summarized video transcript.

Figure 5.2.1 Summarized Video Transcript

\begin{tabular}{|l|l|l|l|l|l|}
\hline Video & Start & Stop & Elapsed & Summary \\
\hline 7.1 & $0: 00: 00$ & $0: 03: 23$ & $0: 03: 23$ & $\begin{array}{l}\text { [Bradley], [Carla], [Olivia] and [Patricia] starts off reading } \\
\text { the prompt individually and writing notes on their sheets. }\end{array}$ \\
\hline 7.2 & $0: 03: 23$ & $0: 07: 04$ & $0: 03: 41$ & $\begin{array}{l}\text { [Bradley] begins to re-read aloud the requirements from the } \\
\text { activity prompt to the group, each group member contributes } \\
\text { pointing out different requirements. Determine the creation } \\
\text { of the optimal distribution plan and power is out of scope. } \\
\text { [Carla] begins to rank aloud the requirements for the project. } \\
\text { The group begins reading through specs to determine what } \\
\text { sensors are provided. }\end{array}$ \\
\hline 7.23 & $0: 53: 51$ & $0: 54: 36$ & $0: 00: 45$ & $\begin{array}{l}\text { l--- } \\
\text { [Patricia] updates [Carla] on the } \\
\text { issues of sensitivity faced with } \\
\text { and [Carla] begin brainstorming } \\
\text { ways to use the remaining } \\
\text { sensors to count individual } \\
\text { newspapers. }\end{array}$ & $\begin{array}{l}\text { [Bradley] and [Olivia] are } \\
\text { testing the RFID sensor } \\
\text { and I believe distance } \\
\text { sensor) inside the } \\
\text { distribution box. }\end{array}$ \\
\hline--- & --- & --- & --- & & \multicolumn{3}{|c|}{} \\
\hline 7.47 & $2: 36: 06$ & $2: 37: 01$ & $0: 01: 05$ & $\begin{array}{l}\text { [Bradley] and [Carla] look up } \\
\text { pricing for an Arduino board } \\
\text { and other materials used. }\end{array}$ & $\begin{array}{l}\text { [Olivia] and [Patricia] } \\
\text { continue to work on } \\
\text { finalizing the code for the } \\
\text { prototype. }\end{array}$ \\
\hline
\end{tabular}




\begin{tabular}{|l|l|l|l|l|}
\hline 7.48 & $2: 37: 01$ & $2: 37: 11$ & $0: 00: 10$ & $\begin{array}{l}\text { The group informs the client they have finished with their } \\
\text { prototype. }\end{array}$ \\
\hline
\end{tabular}

To check the validity of the summaries written, each transcript was reviewed by a second reviewer. The reviewer was tasked to read each transcript in conjunction with watching its respective video and to offer feedback on the following areas: the accuracy of the summary (i.e. what happened, who said it, is there context missing, etc.), the accuracy of the time recorded (within a few seconds), and the length of the segments (i.e. if subsequent statements should be combined or if long segments should be split). Following this review, a second iteration was done by the principle researcher in conjunction with watching the videos to incorporate feedback from the second reviewer.

To evaluate whether the transcripts were ready to be coded and to begin refining the selected coding scheme, a sample of approximately 30 segments were selected at random to be jointly coded by the principle researcher and a second coder. From doing so, challenges to coding emerged that required the researcher to do a third iteration over the transcripts. The challenges discovered were summaries either (1) containing certain key words that were very general and representative of multiple design stage processes without further context added or (2) describing team activities representative of multiple design stage processes. The following Figures 5.2.2 and 5.2.3 are examples of those challenges.

Figure 5.2.2: A segment containing general key words.

Before 3rd Iteration:

\begin{tabular}{|l|l|l}
6.47 & $\begin{array}{l}\text { Josh] begins to write the results up on the board. [Josh] asks [Herman] if it can work in java. } \\
\text { [Herman] explains the situation with the software, suggests to try and translate visual studio }\end{array}$ \\
\hline
\end{tabular} 
into java but doesn't think will be too successful. [Herman] suggests writing out code instead.

After 3rd Iteration:

\begin{tabular}{|l|l|}
\hline 6.47 & $\begin{array}{l}\text { [Josh] begins to write the results up on the board from testing of the two force sensors. [Josh] } \\
\text { asks [Herman] if it can work in java. [Herman] explains he cannot find code sample in Java } \\
\text { and is waiting for visual studio to download. [Herman] suggests trying translating visual }\end{array}$ \\
$\begin{array}{l}\text { studio into Java but doesn't think he will be too successful. [Herman] suggests writing out how } \\
\text { the pseudo code would work instead. }\end{array}$
\end{tabular}

In the "before" segment the words "results", "situation" and "code" are all general terms.

After completing the 3rd iteration, the resulting "after" segment included context added

(text in bold and underlined) to further describe the previously highlighted general terms.

Figure 5.2.3: A segment describing activities representative of multiple design stages.

\section{Before 3rd Iteration:}

\begin{tabular}{|l|l|}
\hline \multirow{7}{*}{4.14} & $\begin{array}{l}\text { [Vivian] looks for the maximum number of papers. The client points out to take note of the } \\
\text { different types of distribution points. [Eric] confirms that the distribution box points are the } \\
\text { ones that only matter. [Vivian] determines the max based on the data provided and points out } \\
\text { its more than the sensors can handle. [Eric] wonders if the weighted would be divided in two or } \\
\text { if both would max out. [Dennis] clarifies with [Vivian] that the force sensor isn't good to use of } \\
\text { weight measurement, instead supposed to be used as a button. [Dennis] thinks could use the } \\
\text { RFID to see if someone is reaching inside the box. [William] suggests using the distance sensor } \\
\text { to measure the distance of the stack from the top of the box. [Vivian] reads the specs on the } \\
\text { distance sensor, says it's not enough of a range (but doesn't actually measure). [Dennis] } \\
\text { physically shows what he suggests to [Vivian]. [Dennis] suggests putting contraption inside } \\
\text { that measures the right height. }\end{array}$ \\
\hline
\end{tabular}

After 3rd Iteration:

\begin{tabular}{|l|l|}
\hline 4.14 & $\begin{array}{l}\text { [Vivian] looks for the maximum number of papers. The client points out to take note of the } \\
\text { different types of distribution points. [Eric] confirms that the distribution box points are the } \\
\text { ones that only matter. [Vivian] determines the max based on the data provided and points out } \\
\text { its more than the sensors can handle. [Eric] wonders if the weighted would be divided in two or } \\
\text { if both would max out. }\end{array}$ \\
\hline 4.15 & $\begin{array}{l}\text { [Dennis] clarifies with [Vivian] that the force sensor isn't good to use of weight measurement, } \\
\text { instead supposed to be used as a button. [Dennis] thinks could use the RFID to see if someone } \\
\text { is reaching inside the box. [William] suggests using the distance sensor to measure the distance } \\
\text { of the stack from the top of the box. [Vivian] reads the specs on the distance sensor, says it's } \\
\text { not enough of a range (but doesn't actually measure). [Dennis] physically shows what he } \\
\text { suggests to [Vivian]. [Dennis] suggests putting contraption inside that measures the right } \\
\text { height. }\end{array}$ \\
\hline
\end{tabular}


The "before" segment describes the student team functioning in two different design stage processes, gathering information about the product and generating ideas for a solution. After iteration, the "before" segment was split into two segments, each summarizing one of the two design stage processes.

After completing three iterations of review for each video transcript, 11 video transcripts totaling 583 segments were created. These segments were combined into one transcript and decontextualized through order randomization before applying a coding scheme.

\subsection{Coding Schemes}

To accomplish the objectives of this study, all data collected was analyzed by doing the following:

1. Converted segmented videos into summarized transcripts,

2. For each transcript segment,
a. Recorded the start and end time,
b. Recorded the design stage
c. Recorded the team structure

\subsubsection{Summarized Transcript}

All statements recorded during the activity were identified by speaker and paraphrased in the context of conversation. Each statement is assigned a number according to its relation to the engineering design stages. In the same manner, physical actions (nonconversational) undertaken by individual students are also transcribed and assigned a 
number according to its relation to the engineering design stages. Physical actions observed included the writing of code, configuring of electrical hardware, constructing of materials for configuration of electrical hardware, and testing of implemented system.

The coding scheme is as follows:

- Numbers one (1) through five (5) were assigned to statements that corresponded directly with one of the engineering design stages.

- Six (6) was assigned to statements that represented three or more design stages.

- Zero (0) was assigned to statements that are irrelevant to the study.

After conducting the first round of coding, it was found that teams would sometimes rapidly oscillate between two different design stages. For example, while brainstorming potential solutions for a prototype, a group would often critique whether or not the proposed idea was feasible before moving on to the next idea. In this particular case, separating the segment into multiple segments to represent stage 2 and stage 3 exclusively was avoided. Instead the segment was coded as oscillating between both stage 2 and stage 3. Cases with segments such as this one existed in pairs of any combination of design stages and emerged from coding of all transcript segments.

All segments were randomized and assigned two codes, one signifying the design stage it represented and the other to describe the structure of the team during that segment. Table 5.3.1 shows how the Codes for design stages from the previously described framework were assigned. 
Table 5.3.1: Coding Notation Used for Design Stages

\begin{tabular}{|l|c|}
\hline Segment Condition & $\begin{array}{c}\text { Example } \\
\text { Code }\end{array}$ \\
\hline $\begin{array}{l}\text { If a segment consisted of one or multiple activities primarily representative of a single design } \\
\text { stage, coded as the number of its respective stage. }\end{array}$ & 2 \\
\hline $\begin{array}{l}\text { If a segment consisted of oscillations between two activities representative of two different } \\
\text { design stages, coded as two numbers respective of the design stages }\end{array}$ & $2 \$ 3$ \\
\hline $\begin{array}{l}\text { If a segment consisted of multiple activities representative of multiple design stages, coded as } \\
\text { a six. }\end{array}$ & 6 \\
\hline $\begin{array}{l}\text { If a segment consisted of one or multiple activities unrelated to any design stages, coded as a } \\
\text { zero. }\end{array}$ & 0 \\
\hline Subgroup segments were coded in the same manner, but with two codes separated. & $2 \mid 3$ \\
\hline
\end{tabular}

\subsubsection{Team Structure}

Team structure was observed to determine if a particular structure a group chose to work in correlated with the selected tasks done during that time period. Codes for team structure were applied in the following way:

Table 5.3.2: Coding Notation Used for Team Structure

\begin{tabular}{|c|c|c|c|}
\hline Code & \multicolumn{3}{|l|}{ Explanation of Team Structure } \\
\hline $4 s$ & \multicolumn{3}{|l|}{ All four students working in a single group. } \\
\hline 31e & \multicolumn{2}{|c|}{ Three students (two SIE, one ECE) working in a subgroup. } & $\begin{array}{l}\text { One ECE student } \\
\text { working alone. }\end{array}$ \\
\hline $31 \mathrm{~s}$ & \multicolumn{2}{|c|}{ Three students (two ECE, one SIE) working in a subgroup. } & $\begin{array}{l}\text { One SIE student } \\
\text { working alone. }\end{array}$ \\
\hline $22 \mathrm{~m}$ & $\begin{array}{l}\text { Two students (one SIE, one ECE) working in } \\
\text { a subgroup. }\end{array}$ & \multicolumn{2}{|c|}{$\begin{array}{l}\text { Two students (one SIE, one ECE) working in } \\
\text { a subgroup. }\end{array}$} \\
\hline $22 s$ & $\begin{array}{llllll}\begin{array}{l}\text { Two students (two } \\
\text { subgroup. }\end{array} & \text { SIE) working in a } & \\
\end{array}$ & $\begin{array}{l}\text { Two students (two } \\
\text { subgroup. }\end{array}$ & ECE) working in a \\
\hline 211e & $\begin{array}{l}\text { Two students (two ECE) working in a } \\
\text { subgroup. }\end{array}$ & $\begin{array}{l}\text { One SIE student } \\
\text { working alone. }\end{array}$ & $\begin{array}{l}\text { One SIE student } \\
\text { working alone. }\end{array}$ \\
\hline $211 \mathrm{~m}$ & $\begin{array}{l}\text { Two students (one SIE, one ECE) working in } \\
\text { a subgroup. }\end{array}$ & $\begin{array}{l}\text { One ECE student } \\
\text { working alone. }\end{array}$ & $\begin{array}{l}\text { One SIE student } \\
\text { working alone. }\end{array}$ \\
\hline 211s & \begin{tabular}{llllll|}
$\begin{array}{l}\text { Two students (two } \\
\text { subgroup. }\end{array}$ & SIE) working in a & \\
\end{tabular} & $\begin{array}{l}\text { One ECE student } \\
\text { working alone. }\end{array}$ & $\begin{array}{l}\text { One ECE student } \\
\text { working alone. }\end{array}$ \\
\hline $1111 s$ & \begin{tabular}{|l|l|}
$\begin{array}{l}\text { One SIE student } \\
\text { working alone. }\end{array}$ & $\begin{array}{l}\text { One SIE student } \\
\text { working alone. }\end{array}$
\end{tabular} & $\begin{array}{l}\text { One ECE student } \\
\text { working alone. }\end{array}$ & $\begin{array}{l}\text { One ECE student } \\
\text { working alone. }\end{array}$ \\
\hline
\end{tabular}




\subsubsection{Time Distribution}

Time is observed to determine how long each group spends in each engineering design stage and team structure. Time distribution is recorded in minutes and also coded on a numerical scale of 1 through 5, which corresponds to the five stages of the engineering design process. Segments where the activities of the group are irrelevant to the study or are unclear to the researcher are assigned a 0 . Segments where the group is multitasking or conducting activities in more than one stage concurrently are assigned a 6 . Comparisons in time distribution are made between groups to determine if group composition has any impact on the distribution of time in engineering design stages.

\subsection{Final Transcript Example}

Applying codes for both design stage and team structure to all transcript segments resulted in one transcript with 583 coded segments like the ones shown in the following table:

Table 5.4.1: Example of Coding Notation Applied to Segments

\begin{tabular}{|l|l|l|l|}
\hline Video & $\begin{array}{l}\text { Design } \\
\text { Stage }\end{array}$ & $\begin{array}{l}\text { Team } \\
\text { Structure }\end{array}$ & Summary \\
\hline $\mathbf{9 . 0 3}$ & 2 & $4 \mathrm{~s}$ & $\begin{array}{l}\text { [Tasha] suggests going through the function of each sensor. [Vince] } \\
\text { talks about the interface kit and its functionality. [Vince] suggests a } \\
\text { way for using the RFID, [Calvin] also suggests an idea for the RFID. } \\
\text { [Tasha] suggests placing one of the sensors inside the door. [Calvin] } \\
\text { starts checking the box to see how to place the sensor inside the box. }\end{array}$ \\
\hline $\mathbf{6 . 0 2}$ & $2 \$ 3$ & $4 \mathrm{~s}$ & $\begin{array}{l}\text { [Herman] questions if more than one sensor should be used in the } \\
\text { prototype. [Josh] suggests the thin force sensor would work. [Herman] } \\
\text { questions its limitations and if it would work. [Zach] suggests to } \\
\text { measure one newspaper but [Xavier] doesn't think it would be } \\
\text { accurate enough and would leave large amount of error. [Herman] } \\
\text { suggests using a sensor to just count the door opening each day. [Josh] } \\
\text { talks through the usage of force sensors over time, reading the } \\
\text { limitations of both the thin and the large force sensor, rule out the large } \\
\text { force sensor. [Herman] then suggests the RFID. [Xavier] confirms will } \\
\text { need to use more than one sensor to measure, then asks about } \\
\text { accelerometer. [Josh] explains the accelerometer and its functionality. }\end{array}$ \\
\hline
\end{tabular}




\begin{tabular}{|l|l|l|l|l|}
\hline & & & \multicolumn{3}{|l|}{$\begin{array}{l}\text { [Xavier] doesn't think the accelerometer will work because it would be } \\
\text { damaged by users. }\end{array}$} \\
\hline $\mathbf{7 . 4 1}$ & $4 \mid 5$ & $22 \mathrm{~s}$ & $\begin{array}{l}\text { [Bradley] and [Carla] test the sensors } \\
\text { inside the distribution box with } \\
\text { newspapers. }\end{array}$ & $\begin{array}{l}\text { [Olivia] and [Patricia] work on } \\
\text { writing code for the sensors. }\end{array}$ \\
\hline $\mathbf{1 . 4 2}$ & $2 \mid 4 \$ 5$ & $31 \mathrm{e}$ & $\begin{array}{l}\text { [Connor] talks through how time } \\
\text { stamps will needed and how the data } \\
\text { would be displayed and analysis } \\
\text { conducted with [Fiona] and [Susan]. }\end{array}$ & $\begin{array}{l}\text { [Paul] continues to write code } \\
\text { and occasionally test to see if } \\
\text { code is working. }\end{array}$ \\
\hline
\end{tabular}

\subsection{Validity}

Inter-rater reliability for design stage coding was established by having $20 \%$ of the overall number of segments coded by second coder. Three percent of those statements were coded jointly with the second coder as described before. The remaining $17 \%$ were coded independently and inter-rater agreement measured by computing Cohen's kappa coefficient, a commonly accepted method of assessing inter-coder reliability [47]-[49]. An agreement was defined as both coders assigning the same code to a transcript segment. The Cohen's kappa coefficient measured after independently coding the remaining $17 \%$ was 0.81 . Appendix $\mathrm{C}$ shows inter-rater agreement of coded segments. Team structure was easily identifiable from video and therefore was only rated by one person. 


\section{CONTEXTS OF DESIGN STAGE AND TEAM STRUCTURE}

The purpose of this chapter is to explain what happened during this study in reference to all student teams' work within the five engineering design stages and their utilization of team structure throughout this process. This chapter will accomplish the following:

- Show how student teams utilized the engineering design stages in reference to time throughout the entire study.

- Provide context for what working in a design stage entails, such as what type of activities students partook in and how those activities were classified within engineering design stages.

- Divide each design stage into sub-themes and further provide context on how many different ways students utilized each design stage.

- Show how student teams utilized team structure in reference to time throughout the entire study.

- Identify significant observations from the data presented on design stage usage and team structure utilization.

\subsection{Context on Design Stage}

Throughout this study, students utilized the five engineering design stages for varying amounts of time. It can be seen in Figure 6.1.1 that students spent the majority of their time $(\sim 48 \%)$ working on activities associated with prototyping, or stage 4 . The least amount of time was spent working on activities related to feasibility analysis, or stage 3 . When comparing time spent in the conceptual realm (stages 2 and 3) versus the 
implementation realm (stages 4 and 5) it can be seen approximately $20 \%$ was spent in the conceptual realm whereas nearly $60 \%$ was spent in the implementation realm. Most the remaining $20 \%$ was spent in activities not related to design (stage 0) such as team management. The total time (reflected in percentages in Figure 6.1.1) of all coded segments equaled 3046.6 minutes.

Figure 6.1.1 Overall Time Spent in Each Design Stage

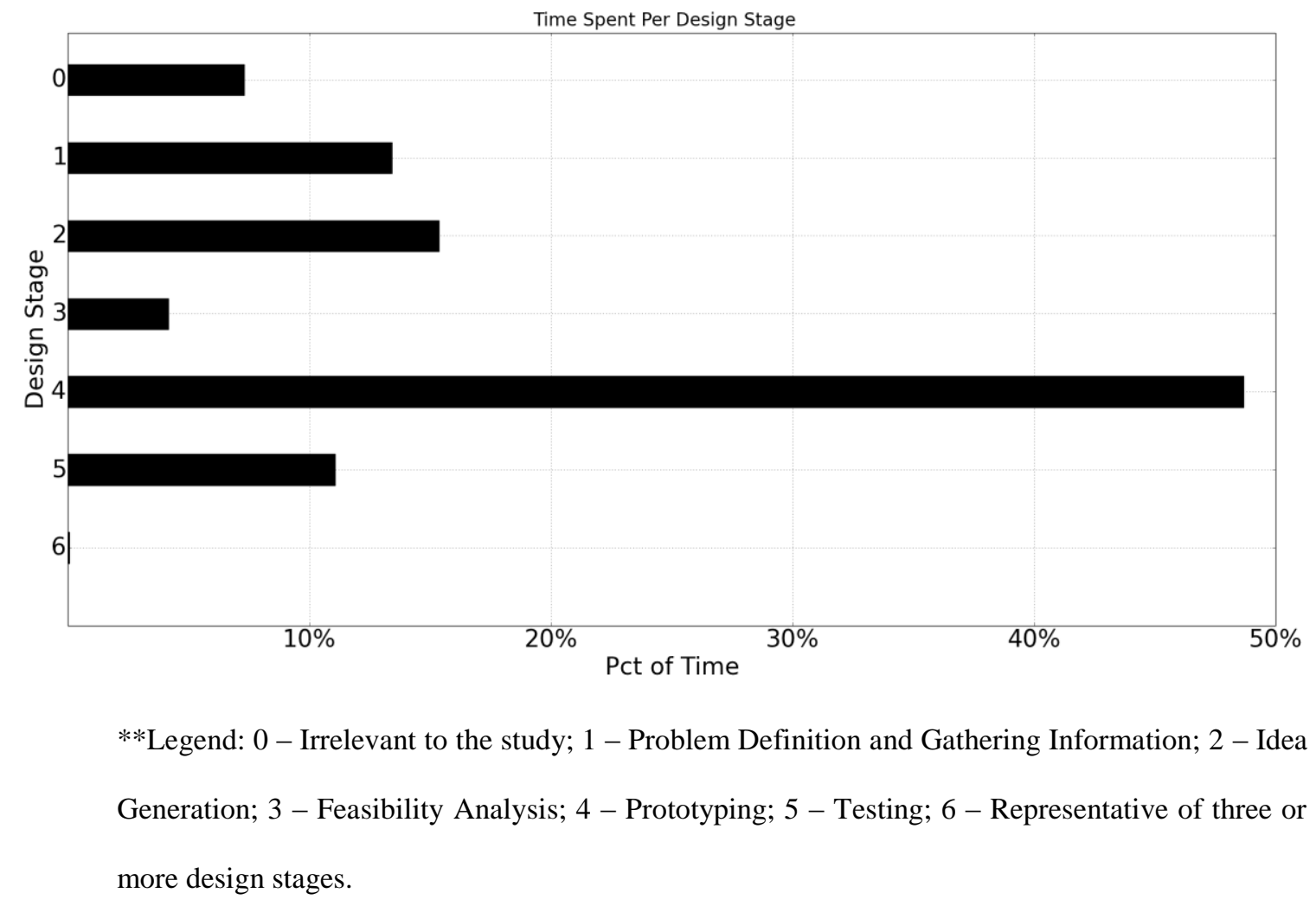

To provide understanding to what these percentages mean, the segments for each design stage were open coded to uncover the nature of activities that occurred. Those activities were then categorized into sub-themes to further give context to and develop the descriptions of each design stage. The nature of those activities and the associated subthemes that describe each design stage are as follows: 
Problem Definition and Gathering Information, Stage 1 encompasses conversations or actions pertaining to the defining of requirements, project scoping, and gathering information about the project, the needs of the stakeholder, or their available materials. Students' involvement in this stage was sub-categorized into the following:

- Client Engagement

When engaged with the client, the students did so in one of three ways, either by discussing the project requirements further, requesting data about client operations or ascertaining more information about the project purpose.

- Gather Information on Materials

When not engaged with the client, students spent their time gathering information through reading the design activity prompt, reading the specifications sheets provided for each sensor and by physically inspecting the features of the distribution box. Through utilization of these sources, students were then able to define requirements and set objectives for how to proceed with their design.

- Research Additional Information

Students also spent time within this stage researching areas related to the final implementation and production of their prototype. These areas including research on ways information can be transmitted or extracted 
from a device, external sources that can power a device, and the data storage capabilities of the sensors and other devices.

Figure 6.1.1 Sub-themes of Problem Definition and Gathering Information Stage

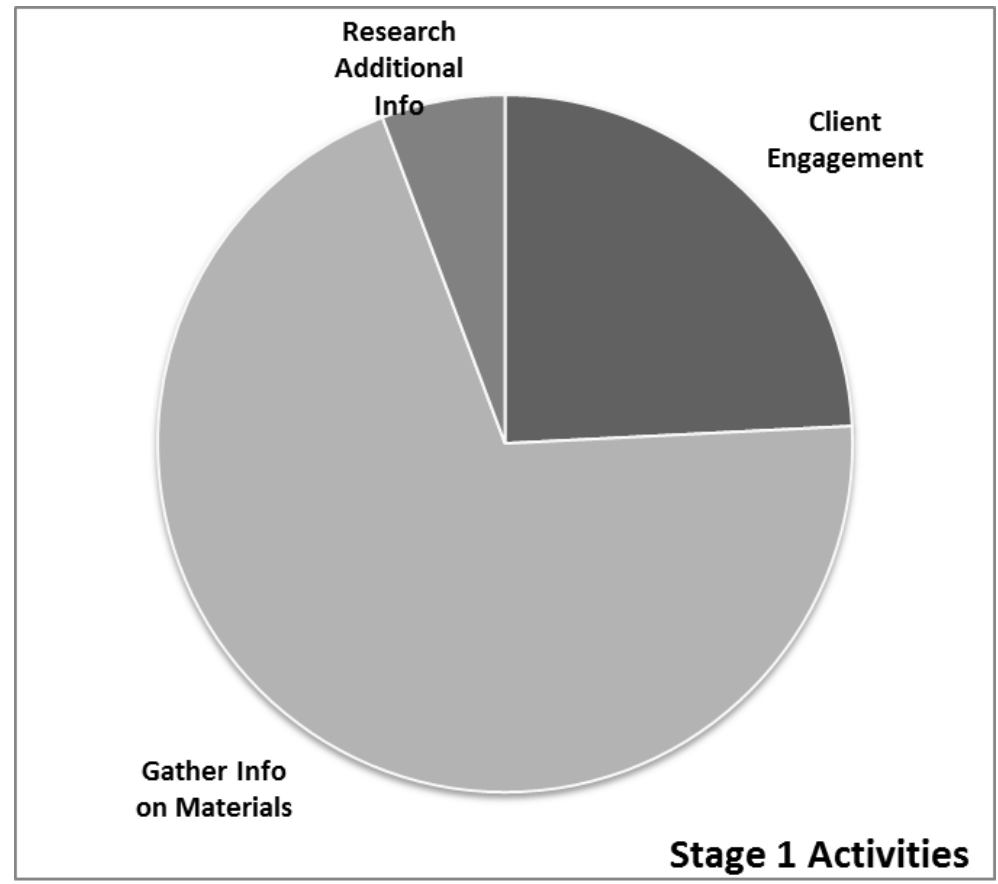

Idea Generation, Stage 2 encompasses conceptual conversations about new ideas for solutions or designs that pertain to the prototype, including brainstorming and other forms of idea generation (which could be applied prior to any implementation or in response to testing or implementation problems). The types of ideas generated in this stage can be sub-categorized into the following categories:

- General Solutions,

Ideas for ways to develop a prototype using the sensors to accomplish the project task, how to use the excess materials provided to construct add-ons that support the sensors and also ideas for the optimal location to construct 
the prototype inside the distribution box. This category also included organizational brainstorming methods used by the students such as the sketching out of a system design and its various components, and organizing ideas based on pricing constraints and requirements of the prototype.

- Add-on Features,

Ideas pertained to thoughts students had on additional features that could help support the accuracy of counting such as collecting over a specific time period, installation of a door counter or incorporation of time stamps into the data collected

- Prototype Programming,

Ideas related to the talking out of code for the prototype conceptually, before actually doing so, and the expectations of what the data collected from the code would look like in its outputted form

- Data Analysis

Ideas suggested by students for tools to display and explain the data collected from the prototype to the client in a way that is most beneficial to the client such as statistical simulations and graphical user interfaces.

- Self-sustaining Capabilities.

Ideas related to ways to make the prototype operate on its own without a laptop as the power and collection source. This category included ideas for 
data extraction, use of external power sources, data storage devices and other ideas that extended beyond the scope of the project. ..

Figure 6.1.2 Sub-themes of Idea Generation Stage

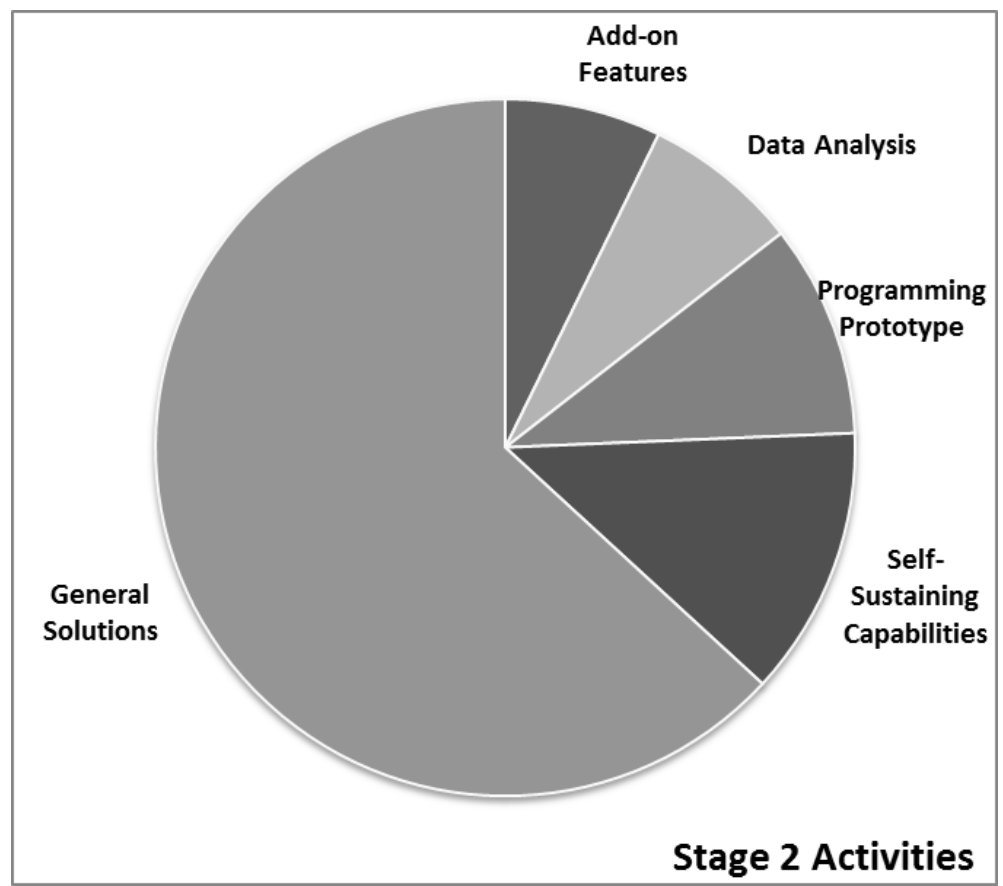

Feasibility Analysis, Stage 3 encompasses conceptual conversations about the feasibility of a proposed solution, including findings from analysis, simulations, and multi-attribute selection of a concept. This stage can be sub-categorized into two categories:

- Focus of the critique (or the target of assessment)

This category covered areas such as brainstormed general solutions, expected prototype performance at the system level, add-on features of the prototype and expected data collected from the prototype.

- Justification for the critique (or criteria used for assessment) 
The criteria in this category ranged including precision, accuracy, durability, price and specifications of the sensors, normal client operations, customer usage, and the background data and requirements provided by the client. There were also instances where an idea or potential prototype solution was accepted or rejected by the students without reasoning or justification.

Figure 6.1.3 Sub-themes of Feasibility Analysis Stage
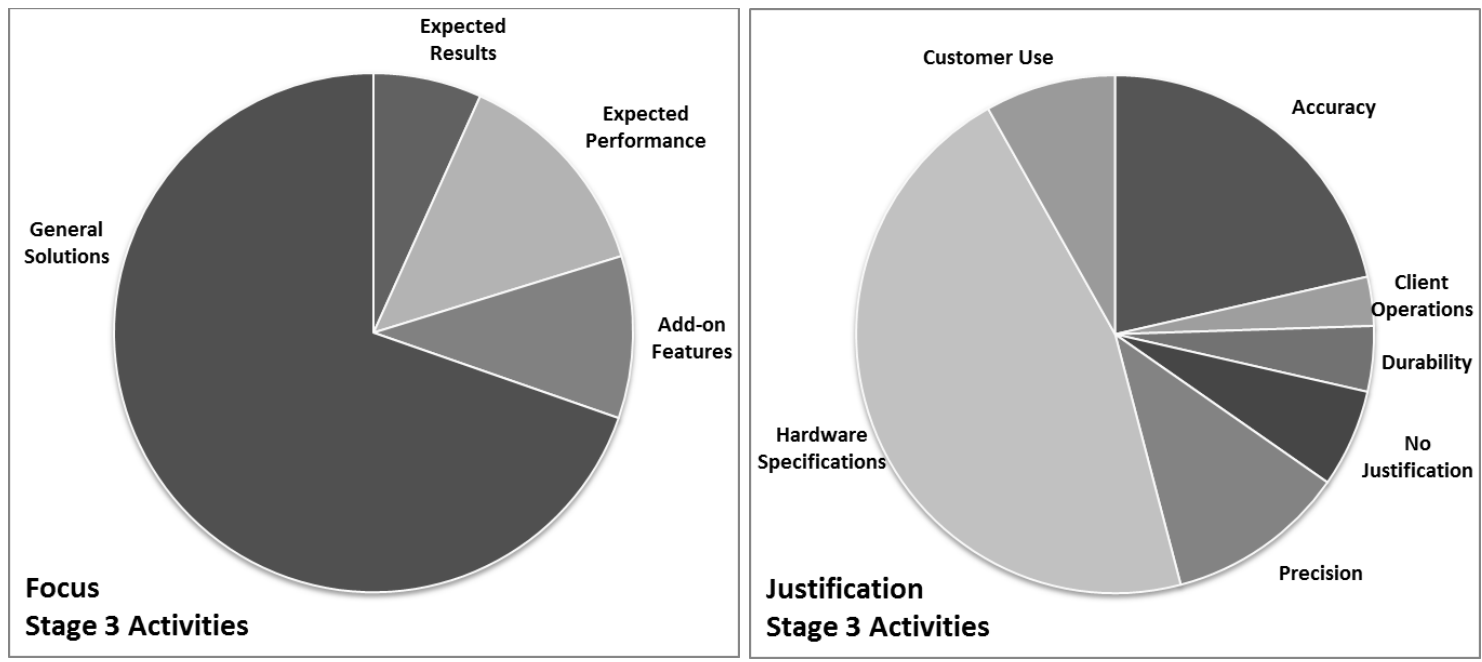

Prototyping, Stage 4 encompasses the actions and conversations associated with the constructing of a prototype including building and software coding. This stage can be divided into the following sub-categories that further explain the actions representative of this stage:

- Hardware Preparation

This sub-category describes the students' initial work to prepare the hardware or set up the sensors to work with the software. The activities 
included in this sub-category relate to the configuration of software needed to operate the sensors, positioning and attaching of hardware to the distribution box and construction of add-ons to the distribution box with the excess materials provided to support the sensor operation.

- Software Education

This sub-category describes actions the student took to orient themselves with the coding software and language. The activities included in this subcategory relate to time spent familiarizing themselves with the programming language, reading supporting documentation available through the sensor manufacturer and searching for other programming support material.

- Implementation

This sub-category describes the students' actual action of coding. The activities in this sub-category include writing out code into programming software, writing out code on paper due to students' inability to program and the troubleshooting of issues faced by either of the two coding actions. In most cases, students did not specify during the activity which part of the prototype they were currently coding, however, occasionally students did discuss coding specific features such as a door open alerts, timestamps and reset buttons.

- User-Interface 
This sub-category describes actions taken by students to make it easier for the client to understand the data being collected from the prototype. The activities in this sub-category include the production of statistical graphs and graphical user interfaces to aid in visual display and synthesis of the data output from the prototype.

Figure 6.1.4 Sub-themes of Stage 4 Prototyping Stage

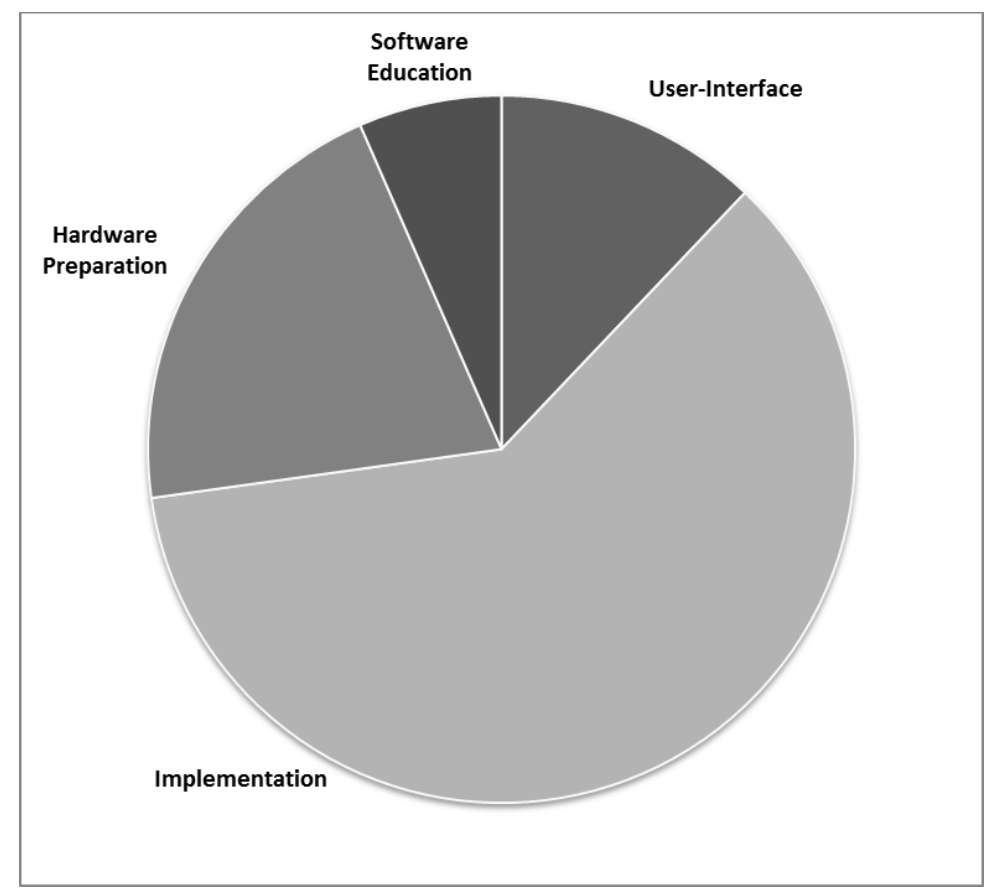

Testing, Stage 5 encompasses the actions or conversations associated with the testing of an implemented system. The activities in this category include testing for the purpose of understanding the functionality or capabilities of a sensor (Sensor Functionality), evaluating the accuracy of the prototype performance and evaluating an add-on feature of the prototype (Prototype Performance). This stage also included activities that related to 
discussions on the results of the data output and the error associated with its current results (Results Discussion).

Figure 6.1.5 Sub-themes of Stage 5

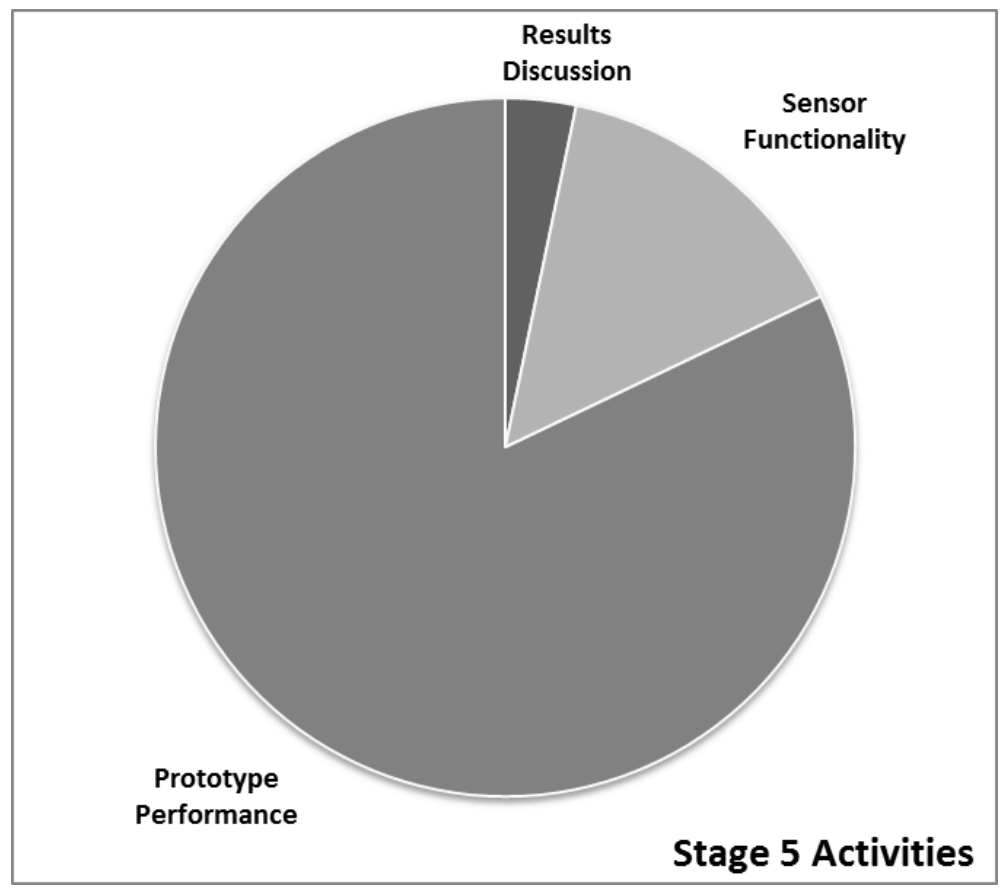

\subsection{Context on Team Structure}

The amount of time spent student teams spent working in each team structure was compiled into the following Figure 6.2.1. In order to accurately describe the amount of time spent in various team structures, two groups (G5 and G11) were omitted from the results shown in this section due to those groups being comprised of three students instead of four. Therefore, Figure 6.2.1 only shows the total amount of time spent in team structure by the remaining nine groups, which totaled 1570.86 minutes. 
Figure 6.2.1 Overall Time Spent in Each Team Structure

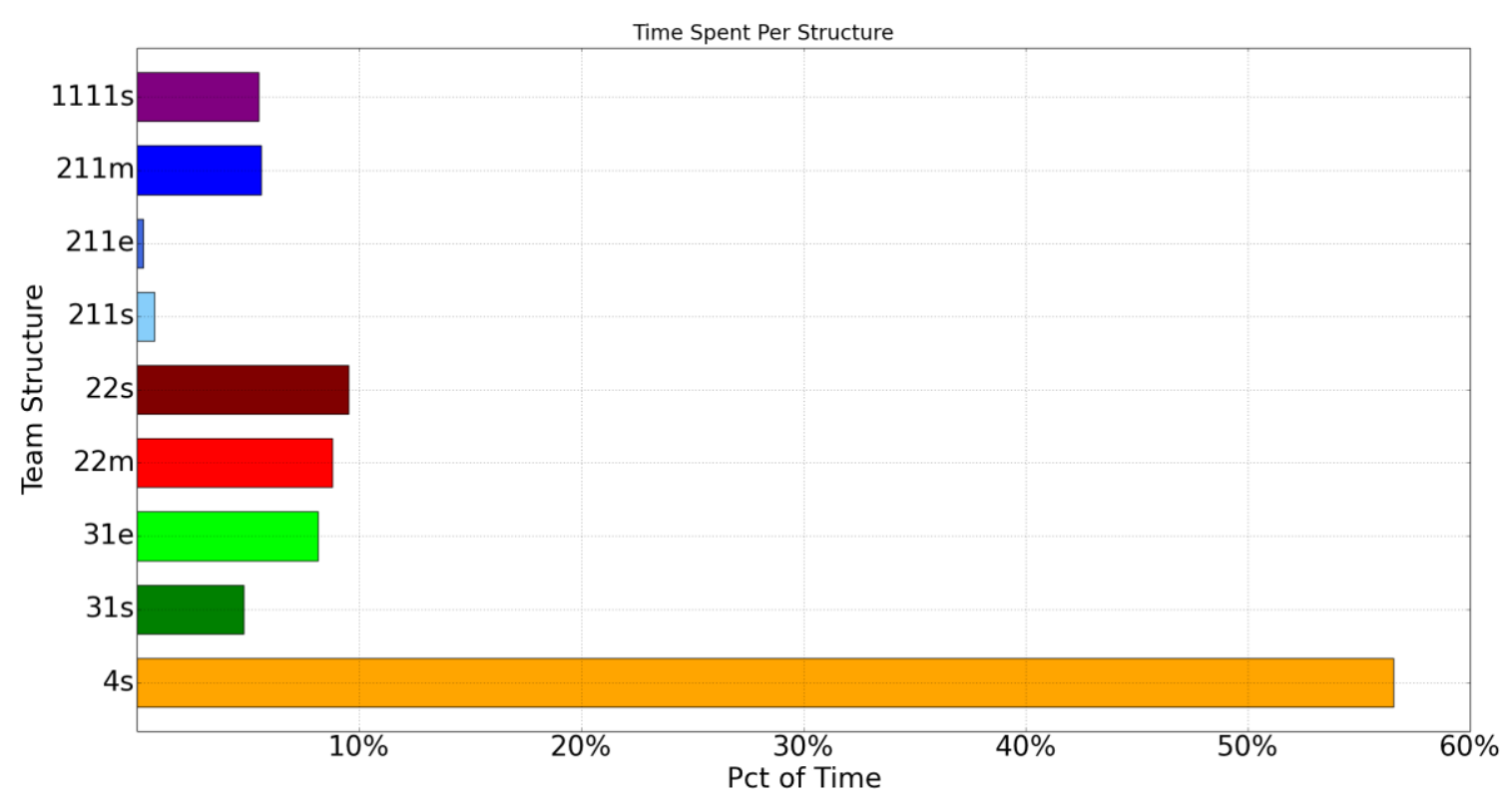

It can be seen from Figure 6.2.1 the majority of time $(56.5 \%)$ was spent working in a single group (4s) as opposed to working in some form of a sub-group combination. Among the time spent working in sub-groups, the most popular sub-group combinations were $22 \mathrm{~s}, 22 \mathrm{~m}$, and $31 \mathrm{e}$ which accounted for a combined $26.5 \%$ of the total time. The description of each team structure is provided in the coding schemes of team structure (Section 5.3.2).

\subsection{Discussion}

The results from the use of design stages show students spent the majority of their time working on activities related to the implementation realm of engineering design. Time spent doing implementation activities, stage 4 and stage 5, outweighed the time spent in conceptual activities, stage 2 and 3, by nearly $60 \%$. Of all the stages, students spent the majority of their time during this study working in stage 4, the prototyping stage. The 
dominant activity of this stage was the writing out of code for the prototype and its hardware. This is consistent with real-time observations taken by the researcher during the study. The act of coding or programming tended to be the most difficult task for students, which translated into students dedicating more time to coding during the activity. Stage 3, the feasibility analysis stage, was where students spent the least amount of time working during this study. The dominant activity of this stage was the act of critiquing proposed solutions using the information students gathered on the hardware specifications. This finding is also consistent with real-time observations as most teams spent little time debating ideas due to their ability to discard many of the sensors based off their stated functionality. The acknowledgement of how much time is spent prototyping is important to the contributions of this study. Many of the prior studies noted in the review of literature do not include implementation or testing. However, the findings from this chapter show the act of implementation and testing have a large influence and should be included when studying the behavior of design teams. Subsequent chapters will expand on these two areas and provide further insight into how the incorporation of implementation and testing influence the overall behavior of design teams. The purpose of this chapter was to explain in a general context what occurred during this study in terms of engineering design and teamwork. 


\section{INFLUENCE OF GROUP COMPOSITION ON STUDENT}

\section{BEHAVIOR}

The purpose of this chapter is to explain how group composition may have influenced what happened during this study. This chapter will accomplish the following:

- Show how each group composition utilized the engineering design stages in reference to time throughout the entire study.

- Provide context into the nature of activities undertaken by each group composition when working across the engineering design stages.

- Show how each group composition utilized team structure in reference to time throughout the entire study.

As noted in Section 3.4, each student team had two SIE students, two ECE students and was composed of five group compositions which varied in the number of TLP students. Table 7.0 shows the description of each group composition. GC4 and GC5 only had one four-person team to complete the study.

Table 7.0 Description of Group Compositions

\begin{tabular}{|l|l|}
\hline $\begin{array}{l}\text { Group } \\
\text { Composition }\end{array}$ & Description \\
\hline GC1 & Four TLP students (two SIE, two ECE) \\
\hline GC2 & Two traditional students (one SIE, one ECE), two TLP students (one SIE, one ECE) \\
\hline GC3 & Two traditional students (both ECE), two TLP students (both SIE) \\
\hline GC4 & Two traditional students (both SIE), two TLP students (both ECE) \\
\hline GC5 & Four traditional students (two SIE, two ECE) \\
\hline
\end{tabular}




\subsection{Influences on Design Stage in Reference to Time}

This section will describe how each group composition utilized their time during this study in reference to the design stages. Figure 7.1.1 shows the utilization of team structure in terms of time by each group composition. The data in the chart is presented in percentages of time to account for groups who did not use the full three hours allotted for the activity.

Figure 7.1.1: Time Spent in Design Stage by Group Composition

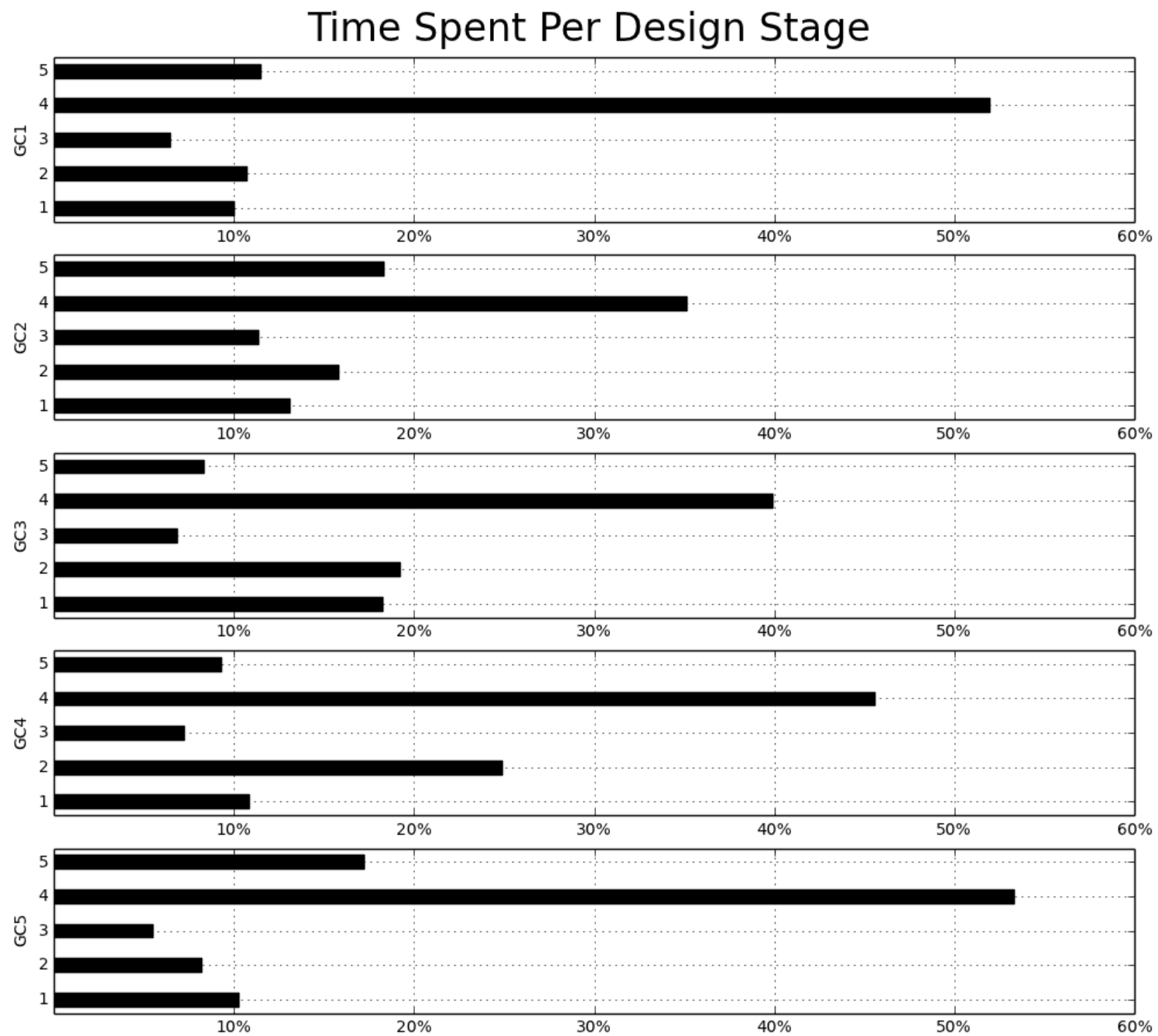


Figure 7.1.1 shows each group composition spent the majority of their time working in stage 4 . This is consistent with real-time observations as work in stage 4 seemed to be the most difficult for student teams which resulted in more time being dedicated to work in this stage. The least amount of time was spent working in stage 3 for each group composition. Therefore, it was observed group composition did not have influence the amount of time spent working in those two stages. A notable finding from this figure was the amount of time spent in the conceptual realm (stages 2 and 3) was much less for the GC1 and GC5 than the other group compositions. A chi-squared test was not run for the results shown in Figure 7.1.1 due to the metric being a continuous, not counted, variable. Further, due to each group composition only being replicated 2 or 3 times, parametric hypothesis tests such as ANOVA would also not be appropriate. This finding infers group composition, specifically groups with a mix of TLP and non-TLP students, affects how much time student teams spend on idea generation. Overall this figure does not offer strong evidence group composition influenced the amount of time students spent working in each engineering design stage, however, it does infer the presence of TLP students among non-TLP students influenced team activity in some way.

\subsection{Influences on Design Stage in Reference to Activity}

This section focuses on the different types of activities each group composition undertook during the study. Each stage is addressed in turn to show the distribution of work across that stage for each group composition. Chi-square tests were not run for this analysis due to the scarcity of data in multiple categories. 
Problem Definition and Gathering Information, Stage 1 encompasses conversations or actions pertaining to the defining of requirements, project scoping, and gathering information about the project or the needs of the stakeholder. Figure 7.2.1 shows how work was distributed across the sub-themes of stage 1 by each group composition.

Figure 7.2.1: Distribution of Work, in Terms of Number of Coded Segment, in Problem Definition and Gathering Information Stage
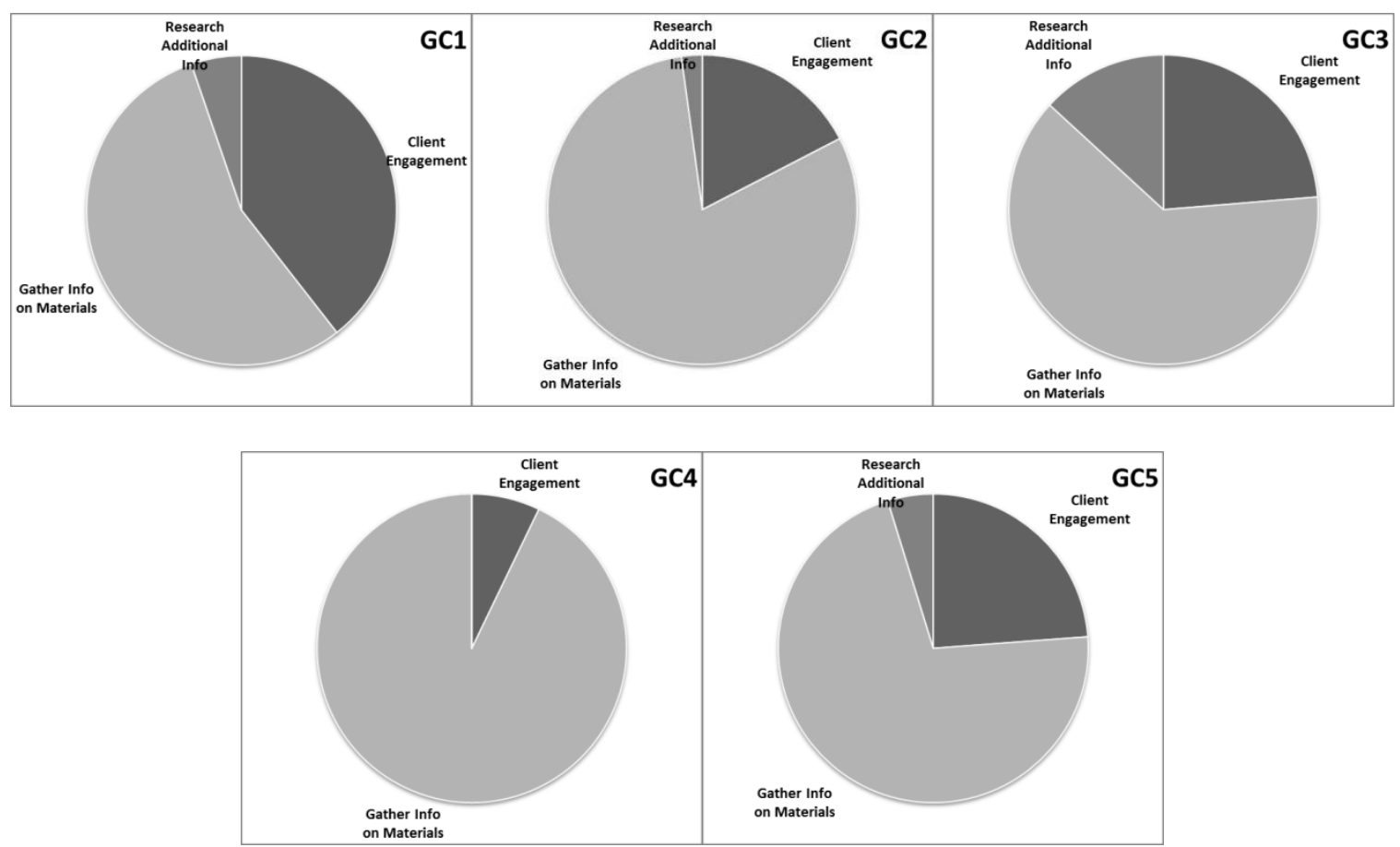

Figure 7.2.1 shows the majority of work done in stage 1 for each group composition related to the gathering of information on the materials provided for the activity. A notable observation was GC1 engaged the client more than the other group compositions which may be attributed to GC1 being comprised of all TLP students. In GC5, the nonTLP student group, the client engagement level was not less than the group compositions with both TLP and non-TLP students. Therefore, its students being members of the TLP might not have influenced the distribution of work within this stage for GC1. Another 
notable observation was GC4 engaged the client much less than the other group compositions. This could be a result of the absence of TLP SIE students in this group composition, however, due to the fact the all non-TLP group showed noticeable client involvement this inference may not be true. Overall it seems group composition could have influenced the distribution of work in stage 1 , specifically the frequency of client engagement.

Idea Generation, Stage 2 encompasses conceptual conversations about new ideas for solutions or designs that pertain to the prototype, including brainstorming and other forms of idea generation. As detailed in Section 6.1, the types of ideas generated in this stage can be sub-categorized into the following categories: general solutions, add-on features, prototype programming, data analysis and self-sustaining capabilities. Figure 7.2.2 shows how work was distributed across the sub-themes of stage 2 by each group composition.

Figure 7.2.2: Distribution of Work in Idea Generation Stage

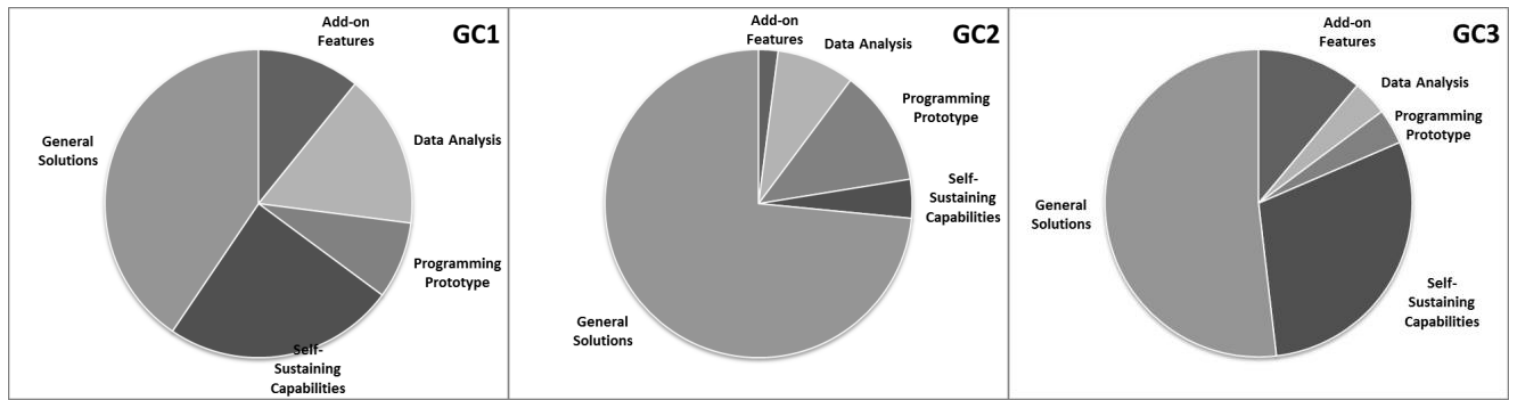




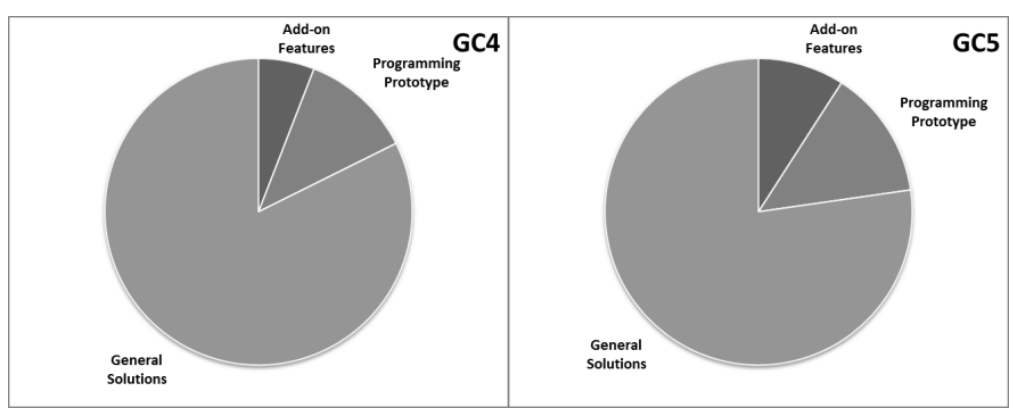

Figure 7.2.2 shows the majority of ideas generated during stage 2 for each group composition related to general solutions meet the requirement of counting newspapers. A notable observation is GC1's general solutions accounted for less than half of the total ideas in stage 2; GC1 spent non-trivial amounts of time to all types of ideation. While more than half of the time for GC2 and GC3 was used for general solution development, these two groups also both addressed all types of ideation. In particularly, GC3 (and GC1) each spent considerable time generating ideas for how to make the prototype a standalone device. GC4 and GC5, on the other hand, did not contribute any ideas to developing self-sustaining capabilities nor data analysis. These observations indicate that GC4 and GC5 were different in ideation activities compared to the other three, in particular to GC1 and GC3. GC1, and to a lesser degree GC3, focused on a broader range of ideation activities relating to designing a sound prototype than the other compositions. Both GC1 and GC3 had two SIE TLP students, with GC1 being composed of all TLP students. Overall, different group composition did different types of work in the ideation stage. These differences generally align with teams having significant TLP representation covering a more diverse range of design aspects during ideation. 
Feasibility Analysis, Stage 3 encompasses conceptual conversations about the feasibility of a proposed solution, including findings from analysis, simulations, and multi-attribute selection of a concept. This stage can be sub-categorized into the focus of the critique and the justification for the critique. Figure 7.2.3 shows how work was distributed across the critique focus sub-theme of stage 3 by each group composition.

Figure 7.2.3: Distribution of Work in Feasibility Analysis Stage, Focus of Critique
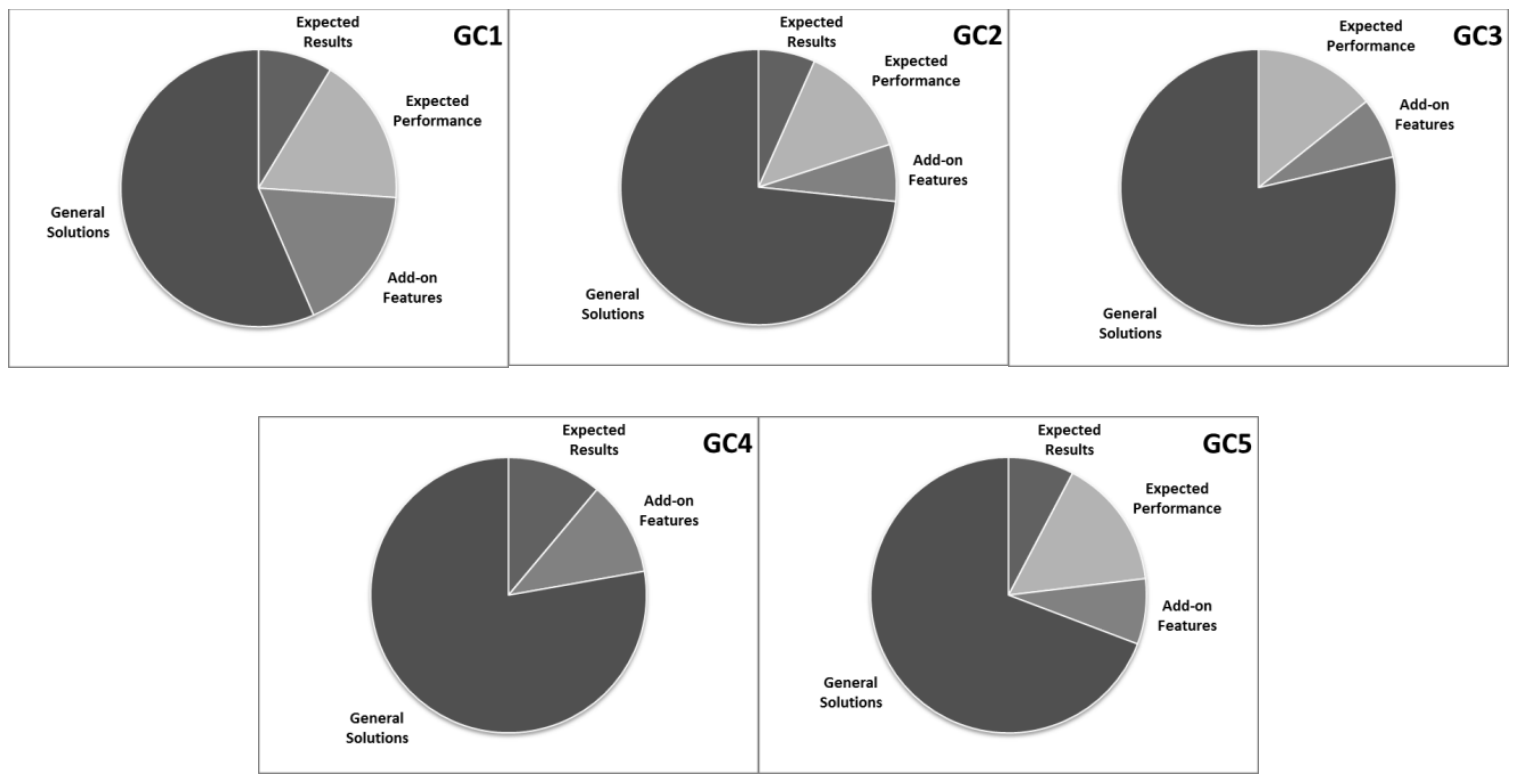

Figure 7.2.3 shows general ideas for the prototype were most critiqued by each of the group compositions. A notable observation is $\mathrm{GC} 1$ contributed roughly the same amount of work to critiquing general solutions as they did to the other areas combined. Another notable observation is GC2 and GC5 are similar to each other in distribution of work in this area Overall it does not seem that group composition influenced work in reference to the focus of critique in stage 3. Figure 7.2.4 shows how work was distributed across the justification sub-theme of stage 3 by each group composition. 
Figure 7.2.4: Distribution of Work in Feasibility Analysis Stage, Justification of Critique
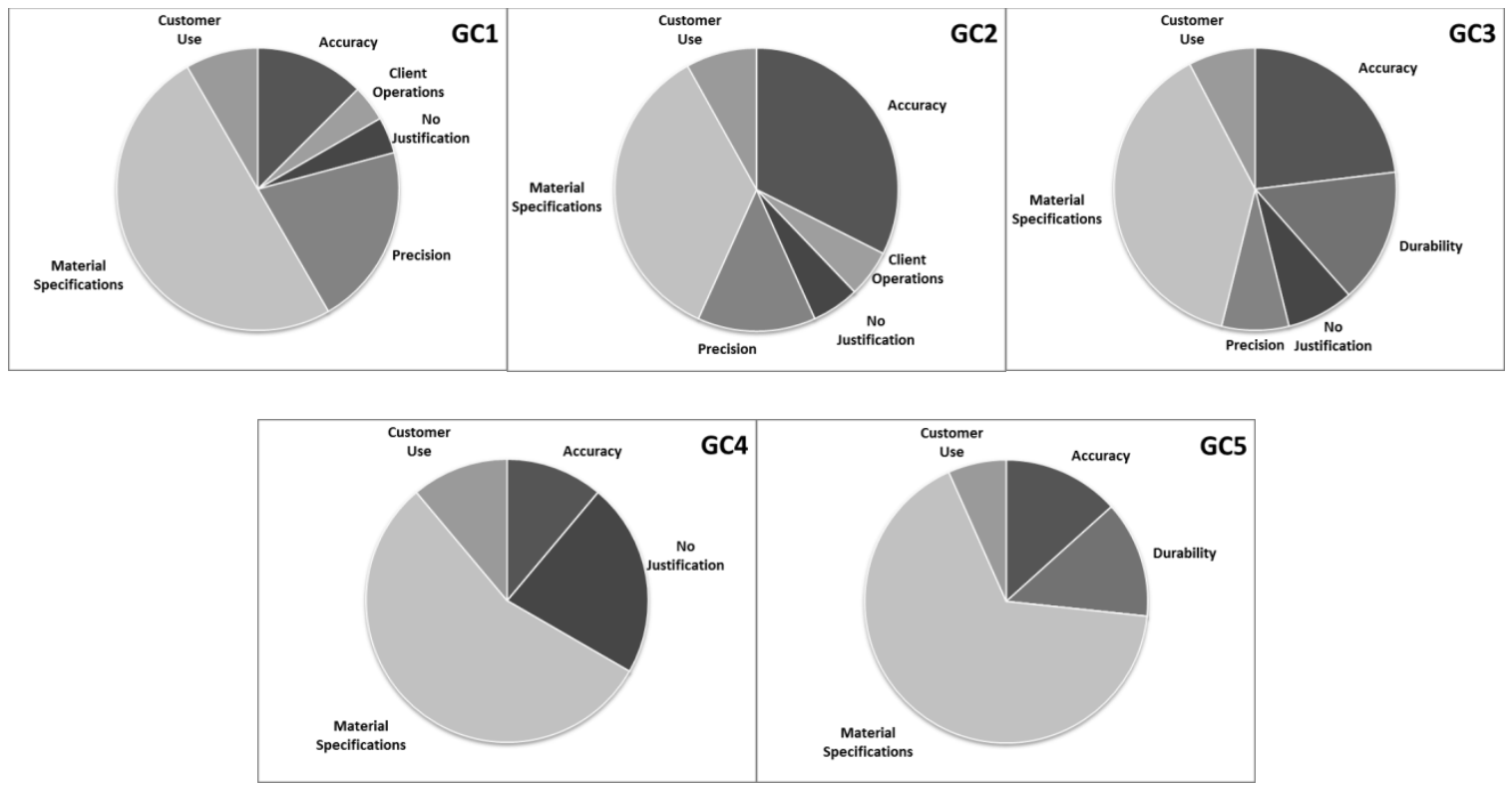

Figure 7.2.4 shows each group composition used material specifications as the primary justification of a design critique. It also shows that accuracy of the prototype was of greater importance to GC2 and GC3 whereas meeting the criteria of precision was more important for GC1. GC4 only used three criteria for their critiques while GC5 only used four. The results for this sub-theme show again GC4 and GC5 operate in similar manners and group composition influenced the use of criteria for assessment in this activity.

Prototyping, Stage 4 encompasses the actions and conversations associated with the constructing of a prototype including building and software coding. This stage can be divided into sub-categories that further explain the actions representative of this stage, which are: preparation, understanding, implementation and analysis. Figure 7.2.5 shows how work was distributed across the sub-themes of stage 4 by each group composition. 
Figure 7.2.5: Distribution of Work in Prototyping Stage 4
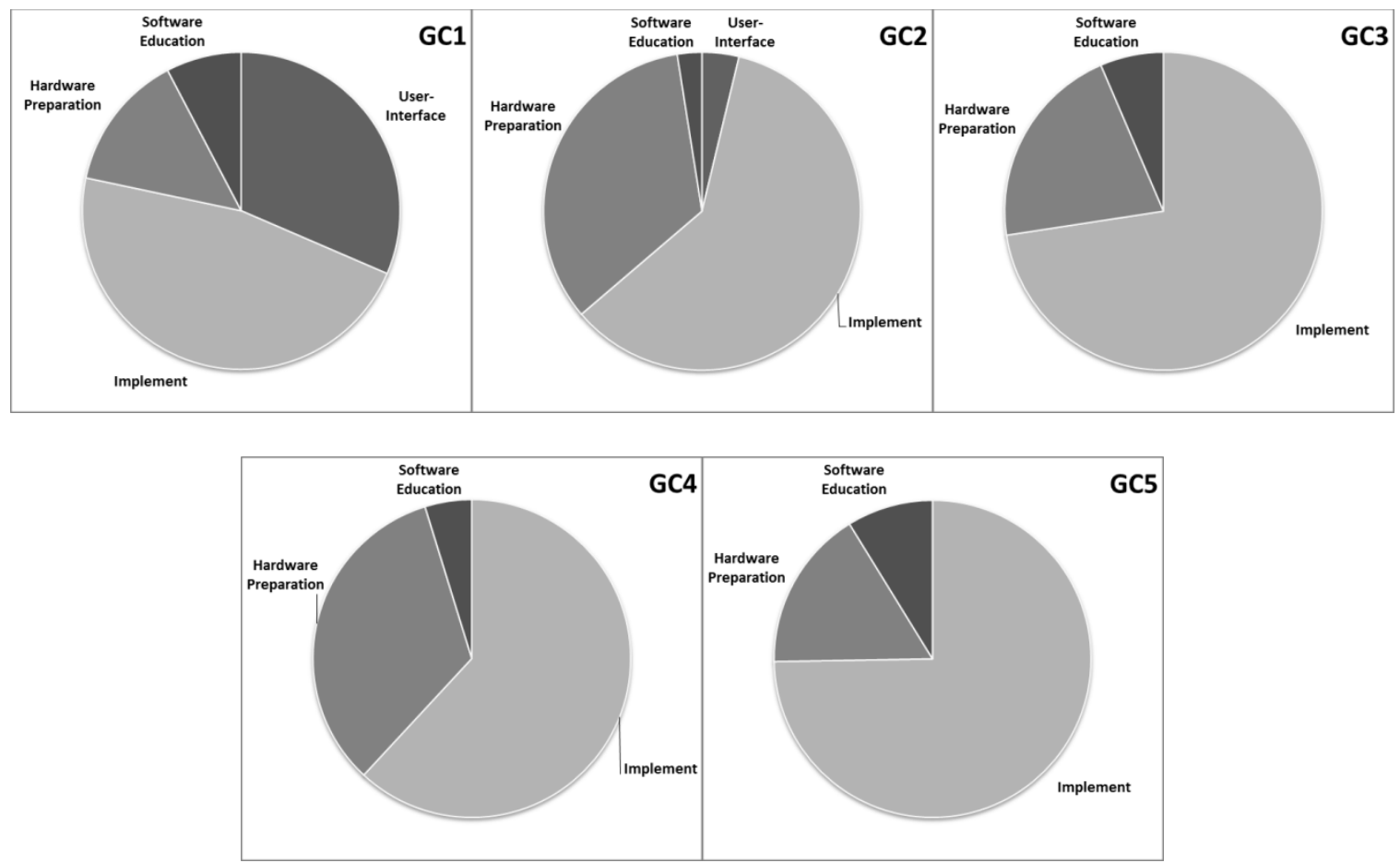

Figure 7.2.5 shows the act of coding dominated the distribution of work in this stage for all group compositions. GC1 was the only group composition to have a large amount of activity in analysis techniques, which involved programming software to run some sort of analysis on the data collected from the prototype. Aside from $\mathrm{GC} 1$, the only other group composition to have activity in this area was GC2. Given the GC3 and GC5 groups include all non-TLP ECE students, it is expected to see coding occurring more among these groups. It is also not surprising to see the all TLP groups function differently than the other groups in terms of the range of activities undertaken in this stage. Overall it can be inferred that group composition influenced the type of activity in this stage.

Testing, Stage 5 encompasses the actions or conversations associated with the testing of an implemented system. The activities in this category include testing for the purpose of 
understanding the functionality or capabilities of a sensor, evaluating the accuracy of the prototype performance and evaluating an add-on feature of the prototype. This stage also included activities that related to discussions on the results of the data output and the error associated with its current results. Figure 7.2.6 shows how work was distributed across the sub-themes of stage 4 by each group composition.

Figure 7.2.6: Distribution of Work in Testing Stage
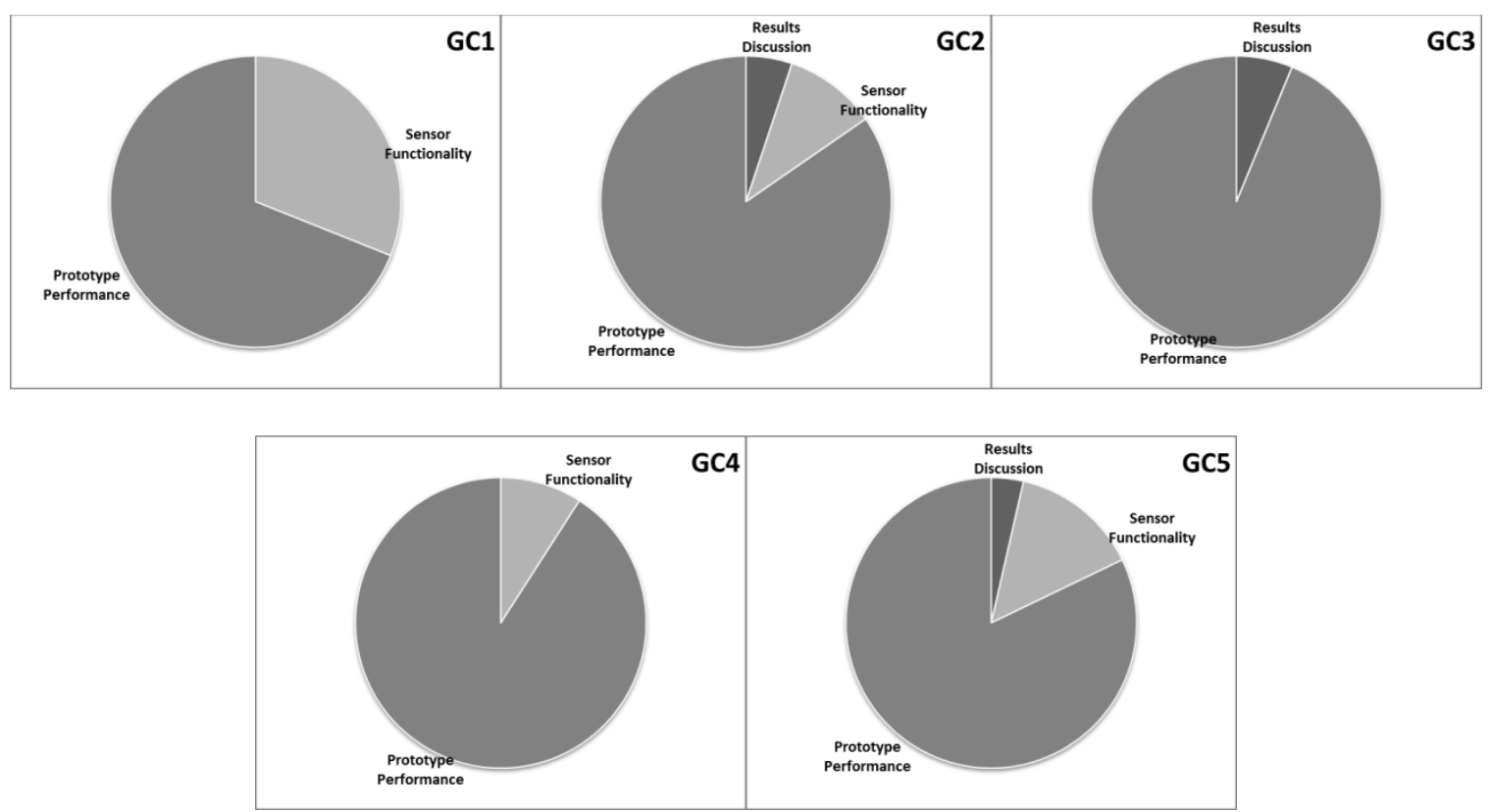

Figure 7.2.5 shows testing the performance of the prototype dominates the activity in this stage for all group compositions. In this stage it can be seen that once again GC1 operates differently from the other group compositions by doing more testing of sensor functionality. What might be surprising is the discussion of results is lacking in GC1 and GC4, and barely represented in GC5. There were other ways teams paid attention to what they saw from results by incorporating what they were seeing from initial testing into the new ideas they generated or in justifications of critiques. 


\subsection{Influences on Team Structure in Reference to Time}

This section will describe how each group composition utilized their time during this study in reference to team structure. In order to accurately represent the amount of time spent in various team structures, two groups, G5 (two non-TLP SIE / one TLP ECE group) and G11 (two non-TLP SIE / one non-TLP ECE) were omitted from the results shown in this section due to those groups being comprised of three students instead of four. The description of each team structure is provided in the coding schemes of team structure (Section 5.3.2). Figure 7.3.1 shows the utilization of team structure in terms of time by each group composition. 
Figure 7.3.1: Time Spent in Team Structure by Group Composition
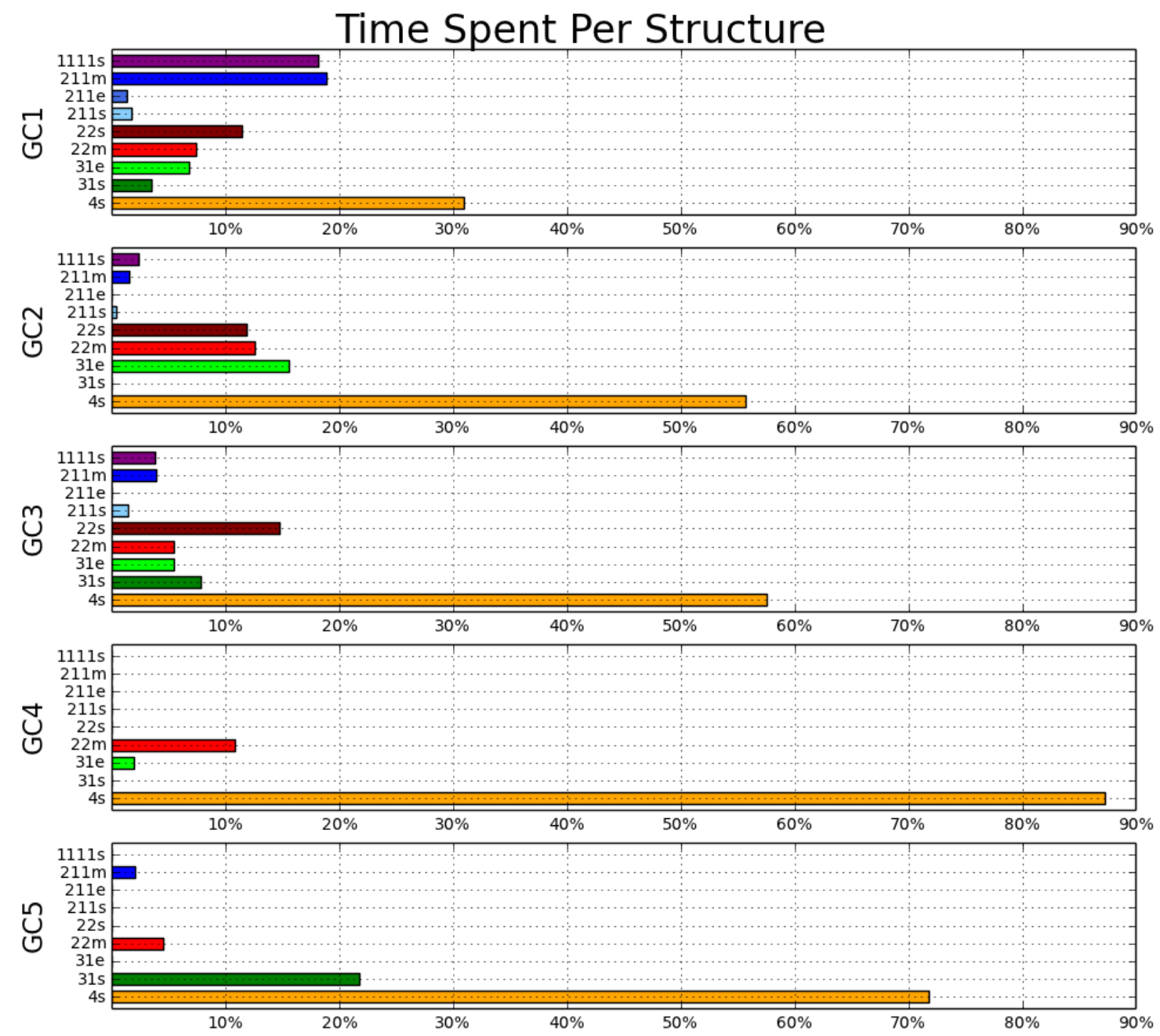

Figure 7.3.1 shows the time spent working in a single group (4s) accounted for the most time in each group composition. However, in only GC1 time spent in this structure accounted for less than half of the overall time. This may infer the TLP influenced how likely students were to split into subgroups since GC1 consisted of all TLP students. GC1 also spent the most amount of time working in the 1111s structure than any other group composition. Another observation from this figure was GC1, GC2 and GC3 utilized more types of team structures than GC4 or GC5. This may be due to the fact that only one 
group is accounted for in GC4 and GC5. This inference could be validated if there had been more four-person teams of those group compositions successfully included in this study. Other notable observations from this study relate to usage of the 2-2 and 3-1 combinations. Between the $22 \mathrm{~m}$ and $22 \mathrm{~s}$ structures, it seems across group compositions the preferred structure to work in was $22 \mathrm{~m}$, which is students of different majors splitting into subgroups. A chi-squared test was not run for the results shown in Figure 7.3.1 due to lack of time recorded in many team structures.

\subsection{Summary of Findings}

The purpose of this chapter is to explain how group composition may have influenced what happened during this study in reference to time and activity. In terms of time spent working in each design stage, there was not strong evidence that may suggest group composition had a major influence. It is notable that time working in stage 2 was much higher for GC2, GC3 and GC4 which suggest having a mix of TLP and non-TLP students influenced behavior.

In terms of the distribution of work in each design stage there were several observations noted from the comparison of group composition activity. It was observed group composition influenced the frequency of client engagement in stage 1 , the contribution of ideas pertaining to self-sustainment and data analysis in stage 2, the number of justifications used in a design critique in stage 3 and the use of data analysis techniques in stage 4. Specifically it could be seen the all TLP groups (GC1) showed a greater mix of activities across stages 1 through 4 . This could be attributed to pedagogy of the TLP, 
which emphasizes SIE students engaging more in technical activities (i.e. stage 4) and ECE students engaging more in the problem scoping and feasibility activities (i.e. stages 1 and 3) of an engineering design process. While efforts were made to place students on teams to minimize prior work together, the TLP students had worked together in prior courses moreso than non-TLP students. Therefore, it cannot be ruled out that this difference is due to team familiarity with each other. 


\section{RELATIONSHIP BETWEEN TEAM STRUCTURE AND DESIGN STAGE}

The purpose of this chapter is to explain the correlation between team structure and the behavior of student teams in the engineering design stages during this activity. This chapter will accomplish this by doing the following:

- Show how team structure and subgroup structures were utilized across the design stages in this study.

- Show, in terms of group composition, how team structure was utilized across the design stages in this study.

- Discuss notable observations and assumptions made pertaining to team structure, design stage and group composition.

\subsection{Relationship between Team Structure}

This section focuses on how team structure and subgroup structures were utilized across the engineering design stages. As noted in Section 5.3, all segments were assigned a code identifying team structure in addition to a code for design stage. Figure 8.1.1 shows the distribution of time across team structures for each design stage. 
Figure 8.1.1 Time Spent in Design Stage by Team Structure

\begin{tabular}{|c|c|c|c|c|c|c|c|c|c|c|}
\hline Stage & $\mathbf{1 1 1 1}$ & $\mathbf{2 1 1 e}$ & $\mathbf{2 1 1 m}$ & $\mathbf{2 1 1 s}$ & $\mathbf{2 2 m}$ & $\mathbf{2 2 s}$ & $\mathbf{3 1 e}$ & $\mathbf{3 1 s}$ & $\mathbf{4 s}$ & Total \\
\hline $\mathbf{1}$ & $17.7 \%$ & $0.0 \%$ & $8.7 \%$ & $1.9 \%$ & $13.1 \%$ & $4.9 \%$ & $7.3 \%$ & $2.0 \%$ & $44.5 \%$ & $100 \%$ \\
\hline $\mathbf{2}$ & $5.7 \%$ & $0.0 \%$ & $0.7 \%$ & $1.0 \%$ & $13.7 \%$ & $8.8 \%$ & $9.7 \%$ & $3.2 \%$ & $57.3 \%$ & $100 \%$ \\
\hline $\mathbf{3}$ & $0.0 \%$ & $0.0 \%$ & $1.8 \%$ & $0.0 \%$ & $0.9 \%$ & $3.3 \%$ & $10.6 \%$ & $3.9 \%$ & $79.4 \%$ & $100 \%$ \\
\hline $\mathbf{4}$ & $18.0 \%$ & $1.2 \%$ & $15.6 \%$ & $1.5 \%$ & $9.2 \%$ & $15.8 \%$ & $10.0 \%$ & $7.7 \%$ & $21.0 \%$ & $100 \%$ \\
\hline $\mathbf{5}$ & $7.4 \%$ & $0.0 \%$ & $8.7 \%$ & $0.8 \%$ & $13.6 \%$ & $9.6 \%$ & $7.5 \%$ & $6.3 \%$ & $45.9 \%$ & $100 \%$ \\
\hline
\end{tabular}

Results from Figure 8.1.1 show the $4 \mathrm{~s}$ structure was utilized the most among all the stages. In the case of the conceptual stages of 2 and 3, the time spent in the 4 s structure was more than the amount time spent in the other structures combined. Time spent in the 4s structure for stages 1 and 5 were close to half the amount of time spent in the other structures combined. However, for stage 4 , the time spent in $4 \mathrm{~s}$ was much less. Overall for the implementation stages of 4 and 5 it can be assumed it was preferred to work in a combination of subgroups. A chi-squared test was not run for the results shown in Figure 8.1.1 due to the metric being a continuous, not counted, variable.

To further understand how subgroups related to time spent working in the design stages Figure 8.1.2 shows the distribution of time across all design stages for each team subgroup. In this table "1e or $1 \mathrm{~s}$ " represents each time within a subgroup one ECE or one SIE student works alone (i.e. 31s, 31e, 211s, 211m, 1111s), "2e or 2s" represents each time within a subgroup two ECE or two SIE students work together (i.e 22s, 211e, 211s), " $2 \mathrm{~m}$ " represents every time within a subgroup one SIE and one ECE student work together (i.e. $22 \mathrm{~m}, 211 \mathrm{~m}$ ), " $3 \mathrm{~m}$ ” represents every time within a subgroup either two SIE / 
one ECE or two ECE / one SIE students work together (i.e. 31s, 31e) and " 4 s" represents all students working together as a single group.

Figure 8.1.2 Time Spent in Team Subgroup by Design Stage

\begin{tabular}{|c|c|c|c|c|c|c|c|}
\hline Stage & $\mathbf{1 e}$ & $\mathbf{1 s}$ & $\mathbf{2 e}$ & $\mathbf{2 s}$ & $\mathbf{2 m}$ & $\mathbf{3 m}$ & $\mathbf{4 s}$ \\
\hline 1 & $14.1 \%$ & $10.1 \%$ & $0.8 \%$ & $9.9 \%$ & $12.7 \%$ & $10.9 \%$ & $15.7 \%$ \\
\hline 2 & $5.0 \%$ & $2.9 \%$ & $7.3 \%$ & $16.3 \%$ & $14.4 \%$ & $20.9 \%$ & $23.0 \%$ \\
\hline 3 & $0.0 \%$ & $0.0 \%$ & $2.1 \%$ & $3.6 \%$ & $1.6 \%$ & $15.4 \%$ & $18.0 \%$ \\
\hline 4 & $55.2 \%$ & $76.5 \%$ & $83.4 \%$ & $37.8 \%$ & $46.0 \%$ & $28.6 \%$ & $22.6 \%$ \\
\hline 5 & $6.3 \%$ & $3.6 \%$ & $6.4 \%$ & $22.0 \%$ & $21.0 \%$ & $21.1 \%$ & $17.2 \%$ \\
\hline Other & $19.4 \%$ & $7.0 \%$ & $0.0 \%$ & $10.3 \%$ & $4.3 \%$ & $3.2 \%$ & $3.4 \%$ \\
\hline Total & $100 \%$ & $100 \%$ & $100 \%$ & $100 \%$ & $100 \%$ & $100 \%$ & $100 \%$ \\
\hline
\end{tabular}

Results from table 8.1.2 show students who worked alone (regardless of major) were most likely to conduct work related to stage 4. This is consistent with real-time observations from the study as when students worked alone they tended to be working on writing code. This suggests that major did not influence work when working solo and possibly did not influence the type of work chosen, in this case coding. A chi-squared test was not run for the results shown in Figure 8.1.2 due to the metric being a continuous, not counted, variable.

These findings, however, did not show to be the same for two-person teams. When two ECE students (2e) worked together the amount of time dedicated to stage 4 increased whereas for two SIE students (2s) working together the time decreased. Results from the mixed major two-person teams $(2 \mathrm{~m})$ resemble the $2 \mathrm{~s}$ structure. In those structures, time was more spread out across all five of the design stages and not just concentrated on stage 4. These findings suggest major might have influenced the behavior of two-person teams. 
Specifically they suggest the ECE students are more likely to work in stage 4. From inperson observations and previous findings presented in Figure 6.1.4 time spent in stage 4 was most commonly associated with coding. Therefore, it was observed ECE students are more likely to take on the work of coding on a team. The reason why time in the $2 \mathrm{~s}$ subgroup is spread across all the stages could be to account for the large focus on stage 4 by the 2e subgroup. It could also infer that SIE students were more flexible in type of work they could do during this study.

For the three-person and four-person subgroups, the results are very similar. Both subgroups varied their time equally across all five design stages. For the $3 \mathrm{~m}$ structure the cause of this may be due to the fact the $1 \mathrm{~s}$ and 1e subgroups both favored stage 4 . Similar to the two-person team combinations, to account for the large amount of time dedicated to stage 4 by the $1 \mathrm{~s}$ and 1 e subgroups, the mixed major subgroup $(3 \mathrm{~m})$ instead focused on completing work across all the stages. However, it should be noted that these subgroups were the only two to show a large amount of time spent in stage 3 . This is most likely due to the way students critiqued each other's ideas; based on observations, critiquing ideas and suggestions in a group seemed to be most effective since each student had a different view on how a proposed idea would operate. Also, due to the nature of the study, the results might show students who worked solo did not work in stage 3 because those students did not talk aloud when doing so. There also were not any concrete physical actions students demonstrated to show they were working in stage 3. 


\subsection{Influence of Group Composition}

This section will describe how group composition related to work completed in design stages by comparing and contrasting time spent in each team structure across each group composition for each design stage.

Stage 1 encompasses conversations or actions pertaining to the defining of requirements, project scoping, and gathering information about the project or the needs of the stakeholder. Figure 8.2.1 shows distribution time spent in stage 1 across each structure per group composition.

Figure 8.2.1: Stage 1 Time Spent in Each Structure per Group Composition

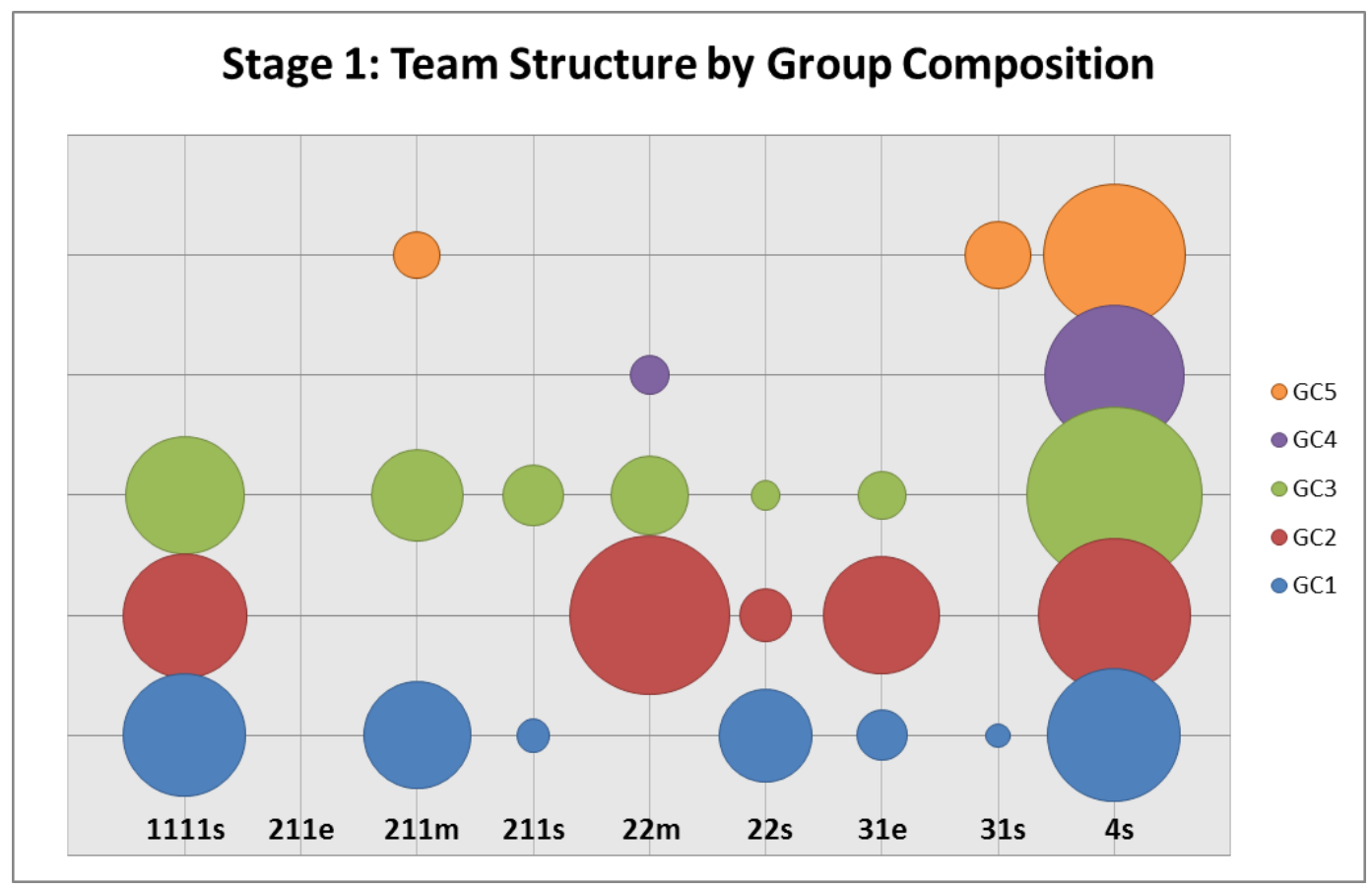

Figure 8.2.1 shows the $4 \mathrm{~s}$ structure was utilized most across all group compositions in stage 1 . There were other structures that were used heavily in this stage such as the $1111 \mathrm{~s}$ structure that was only used by GC1, GC2 and GC3. CG1 also spent slightly less time 
working in the 1111 s structure as in the 4 s structure while GC2 slightly less time working in the $22 \mathrm{~m}$ structure as it did in the $4 \mathrm{~s}$ structure. GC4 and GC5 spent at least three quarters of their time working in the $4 \mathrm{~s}$ structure. Out of the two-person team structures GC2 and GC3 were the only group compositions to utilize both $22 \mathrm{~m}$ and $22 \mathrm{~s}$ in this stage. GC4 only used the $22 \mathrm{~m}$ structure. GC1 only used the $22 \mathrm{~s}$ structure. GC5 did not use the two-person team structure during the study. In general, GC1, GC2 and GC3 used more types of structures than GC4 or GC5 in this stage.

Stage 2 encompasses conceptual conversations about new ideas for solutions or designs that pertain to the prototype, including brainstorming and other forms of idea generation (which could be applied prior to any implementation or in response to testing or implementation problems). Figure 8.2.2 shows distribution time spent in stage 2 across each structure per group composition. 
Figure 8.2.2: Stage 2 Time Spent in Each Structure per Group Composition

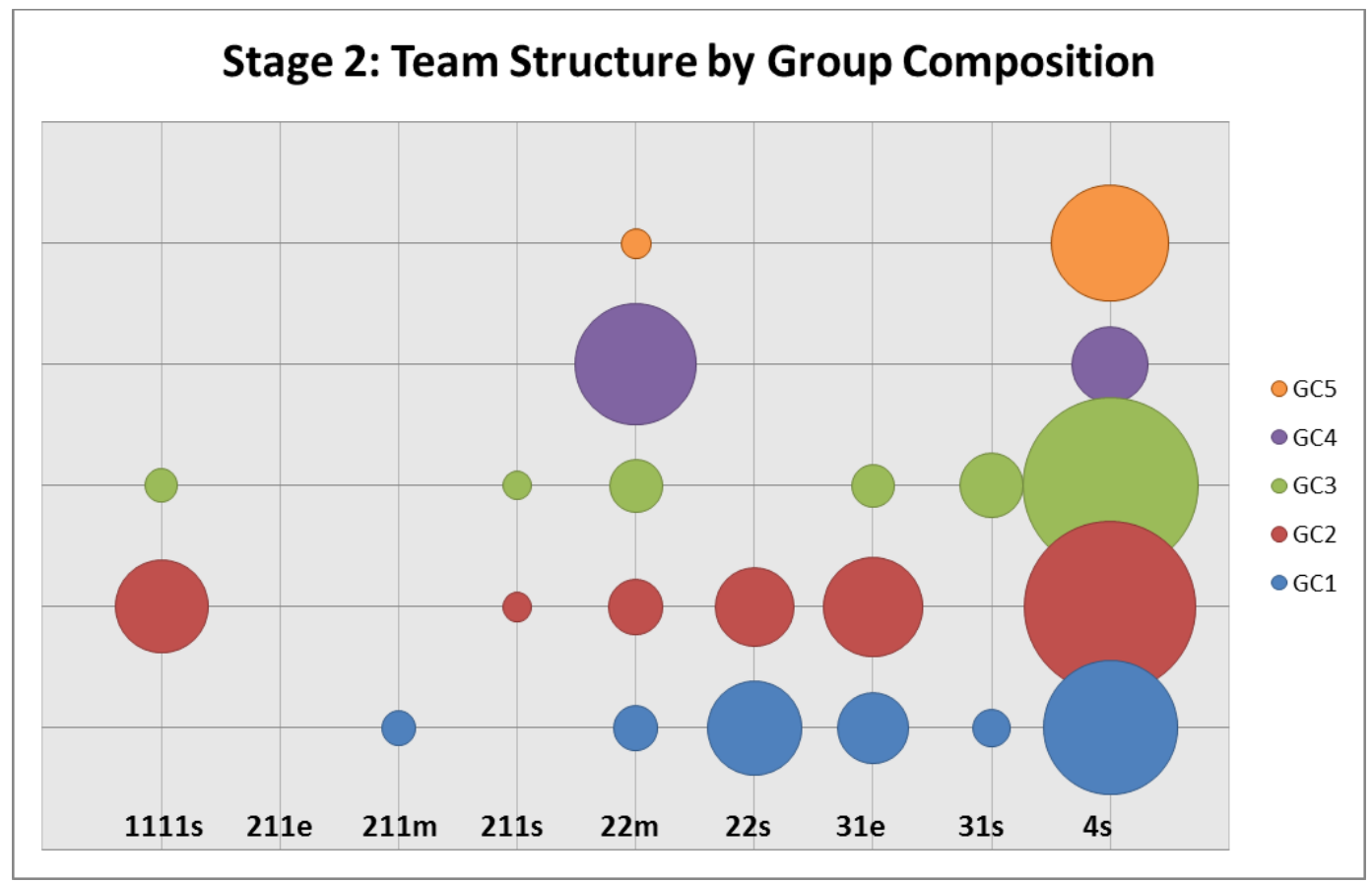

Figure 8.2.2 shows the dominant structure used in this stage was the $4 \mathrm{~s}$ structure. GC3 and GC5 spent three quarters or more of the time in the 4s structure. GC1 and GC2 only spent about half their time in this structure. GC4 spent about a quarter of the time in this structure. The remainder of GC4's time was spent in the $22 \mathrm{~m}$ structure. GC2 was the only set of groups to spend a large amount of time in the 1111s structure. GC1 was the only set of groups to spend a large amount of time in the $22 \mathrm{~s}$. In general, just like in stage 1 , GC1, GC2 and GC3 used more types of structures than GC4 and GC5 in this stage. GC1 and GC2 were very identical in the distribution of time across team structures. Overall, these findings suggest group composition did not have a major influence on the structures selected to complete work in this stage. 
Stage 3 encompasses conceptual conversations about the feasibility of a proposed solution, including findings from analysis, simulations, and multi-attribute selection of a concept. Figure 8.2.3 shows distribution time spent in stage 3 across each structure per group composition.

Figure 8.2.3: Stage 3 Time Spent in Each Structure per Group Composition

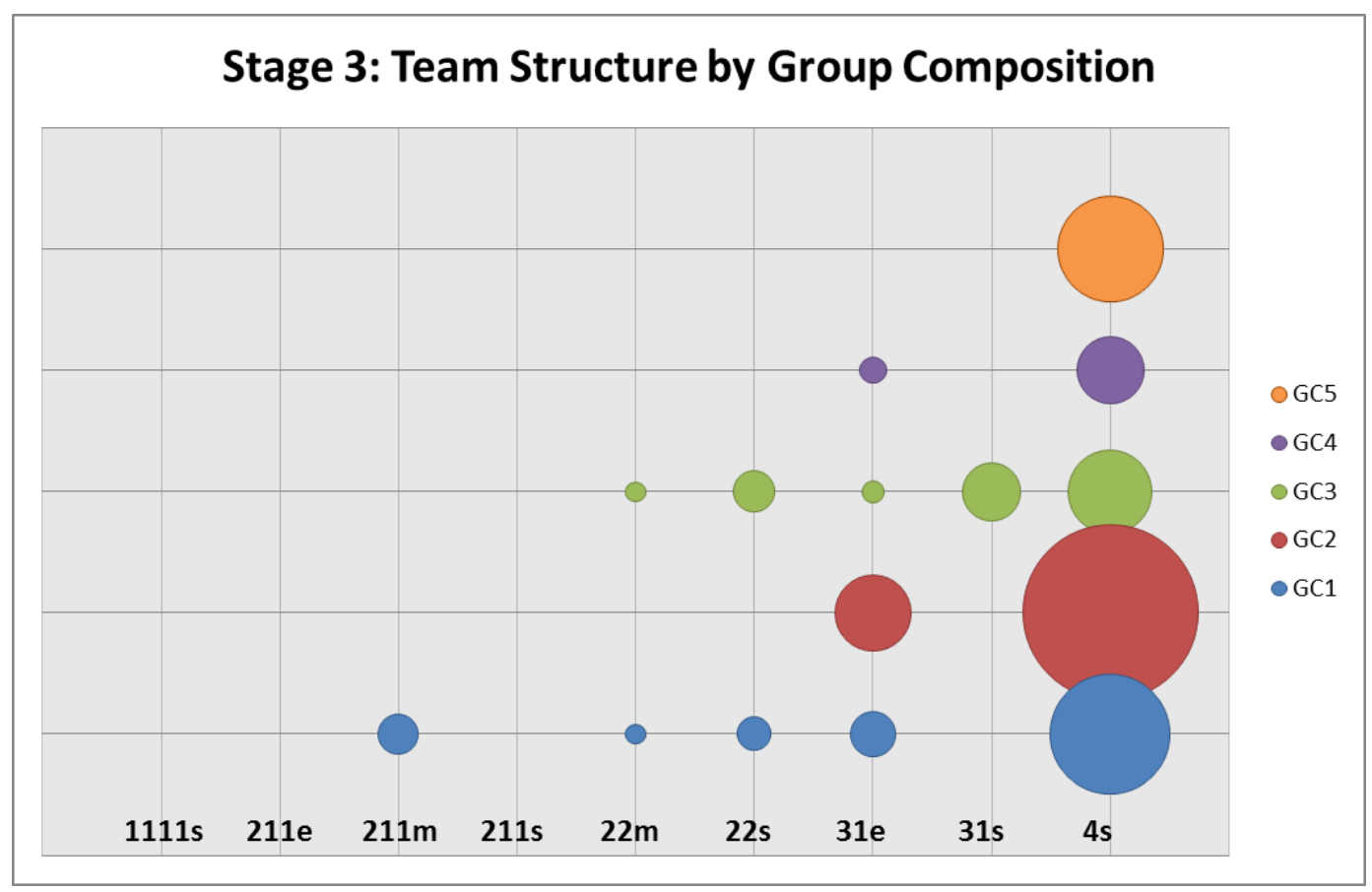

Figure 8.2.3 shows the $4 \mathrm{~s}$ structure is the preferred structure of choice for this stage among the different group compositions. For GC5 this was the only structured in this stage. GC2 and GC5 are very identical both using the $4 \mathrm{~s}$ and $31 \mathrm{e}$ structure for the same proportion of their time. GC1 and GC3 are identical in the number of structures they utilize in this stage. These two group compositions were the most active in using various structures in this stage. 
Stage 4 encompasses the actions and conversations associated with the constructing of a prototype including building and software coding. Figure 8.2.4 shows distribution time spent in stage 4 across each structure per group composition.

Figure 8.2.4: Stage 4 Time Spent in Each Structure per Group Composition

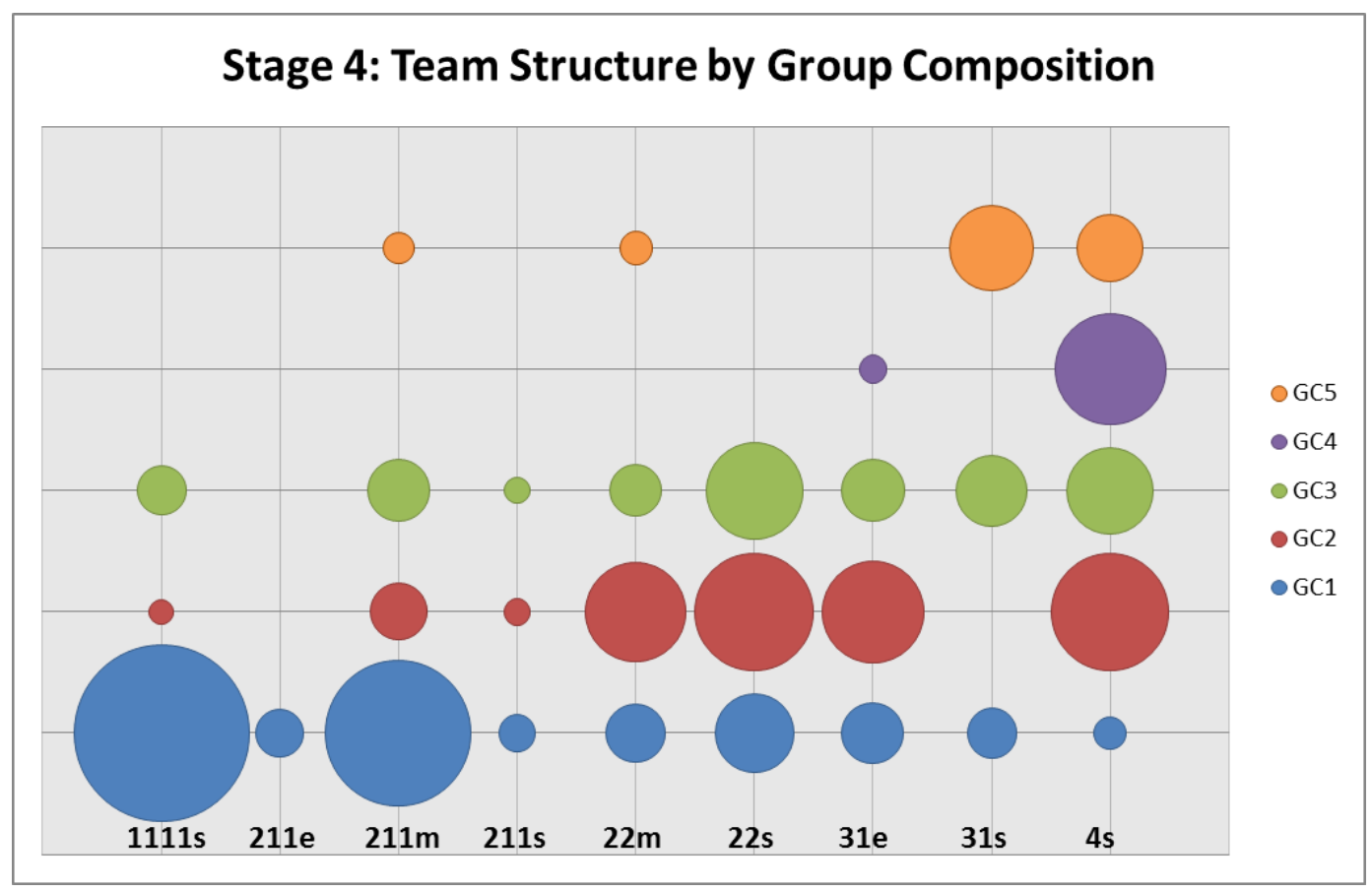

Figure 8.2.4 shows this stage experienced the most use of different team structures than any other stage. GC1 was the only set of groups to use all nine of the team structures. GC2, GC3 and GC5 used 4 or more structures during this stage. GC4 only used one structure in addition to the $4 \mathrm{~s}$ structure and for a small amount of time. GC1 used $4 \mathrm{~s}$ the least out of all other structures in this stage. The two structures that were used the most by $\mathrm{GC} 1$ were the $1111 \mathrm{~s}$ and $211 \mathrm{~m}$ structures. 
Stage 5 encompasses the actions or conversations associated with the testing of an implemented system. Figure 8.2.5 shows distribution time spent in stage 5 across each structure per group composition.

Figure 8.2.5: Stage 5 Time Spent in Each Structure per Group Composition

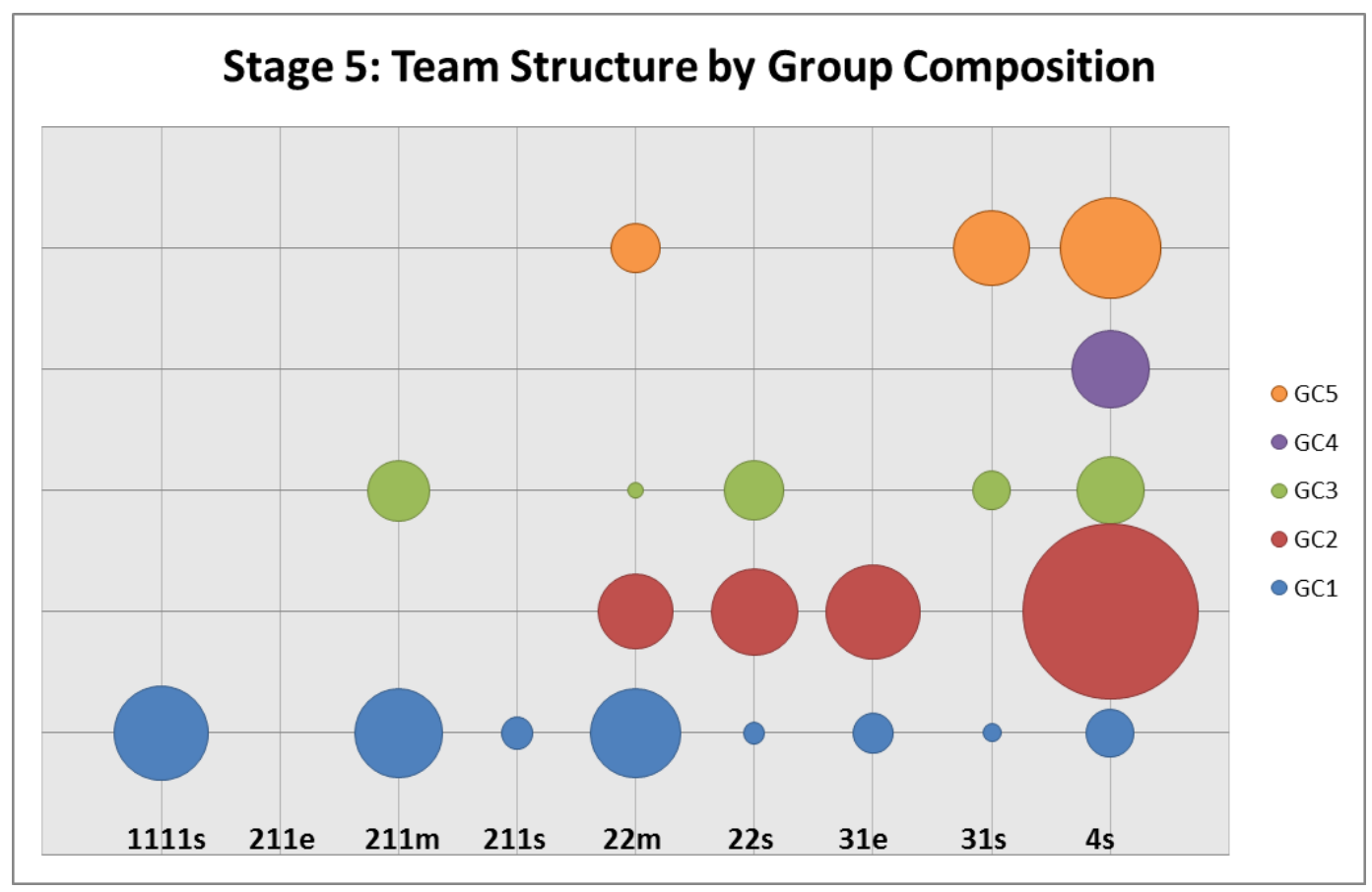

Figure 8.2.5 shows the dominant structure of choice for most of the group compositions is the $4 \mathrm{~s}$ structure. GC1 was the only set of groups not to use the 4s structure for a large amount of time and instead used the $1111 \mathrm{~s}, 211 \mathrm{~m}$ and $22 \mathrm{~m}$ structures. GC1 was also the set of groups to use the most number of team structures in this stage. GC4 only used one the $4 \mathrm{~s}$ structure during this stage.

In summary, many of the group compositions showed distributions that resembled the assumptions from Section 8.1. For stage 1 results showed the majority of time was spent working in the $4 \mathrm{~s}$ structure but that was not the case for GC1 or GC2. These two sets of 
groups spent a large amount of time working in that structure but the majority of their time was distributed across subgroup structures. For stage 2 the assumption was that groups spent half their time in $4 \mathrm{~s}$ structure and the other half split across subgroups. This assumption was correct for GC1 and GC2. However, GC3 and GC5 spent over three quarters of their time in the 4 s stage and GC4 only spent a little over a quarter. The results for stage 3 were as expected. All group compositions used the $4 \mathrm{~s}$ structure the majority of the time for stage 3 . For stage 4 the assumption was the majority of time was spent working in subgroups. This was true for all sets of groups except GC4 which spent the majority of their time working in the $4 \mathrm{~s}$ structure. For stage 5 the assumption was about half the time was spent working in the $4 \mathrm{~s}$ structure and the other half split across other subgroup structures. The only sets of groups that resembled this expected distribution was GC2, GC3 and GC5. GC1 barely used the 4s structure during this stage and GC4 only used the 4s structure in this stage. A chi-squared test was not run for the previous shown pie charts due to the metric being a continuous, not counted, variable and due to lack of any time recorded for many team structures. 


\section{PATTERNS IN DESIGN STAGE USE AND TEAM STRUCTURE}

The purpose of this chapter is to explain the type of patterns that student teams take throughout this study to reach a solution and ultimately a working prototype. This chapter will accomplish this by doing the following:

- Show each student team's path through the engineering design process in terms of time and team structure.

- Explain each group's usage of design stage and team structure during this activity.

- Identify patterns in design stage and team structure use that emerged from graphically analyzing the data.

- Discuss notable observations of those patterns and how group composition might have influenced the patterns used during this study.

\subsection{Individual Group Patterns}

This section will show how each group navigated the design stages of this activity and in what ways they utilized team structure. Each segment block on the following charts represents a coded segment from the activity summary transcripts. All segments were coded in the manner explained in Section 5.3, Coding Schemes. Each color on the charts represent a particular team structure. The color scheme used for four-person team structures was purple for $1111 \mathrm{~s}$, royal blue for $211 \mathrm{e}$, blue for $211 \mathrm{~m}$, light sky blue for $211 \mathrm{~s}$, red for $22 \mathrm{~m}$, maroon for $22 \mathrm{~s}$, lime for $31 \mathrm{e}$, green for $31 \mathrm{~s}$ and orange for $4 \mathrm{~s}$. The color scheme used for three-person team structures was purple for $111 \mathrm{~s}$, lime for $21 \mathrm{e}$, green for 21s and orange for 3s. Figure 9.1.0 shows the patterns of all 11 groups in 
reference to team structure use over time. Figures showing the patterns of each group over time in reference to team structure and design stage are presented in Appendix D.

Figure 9.1.0 Overall Group Structure Over Time

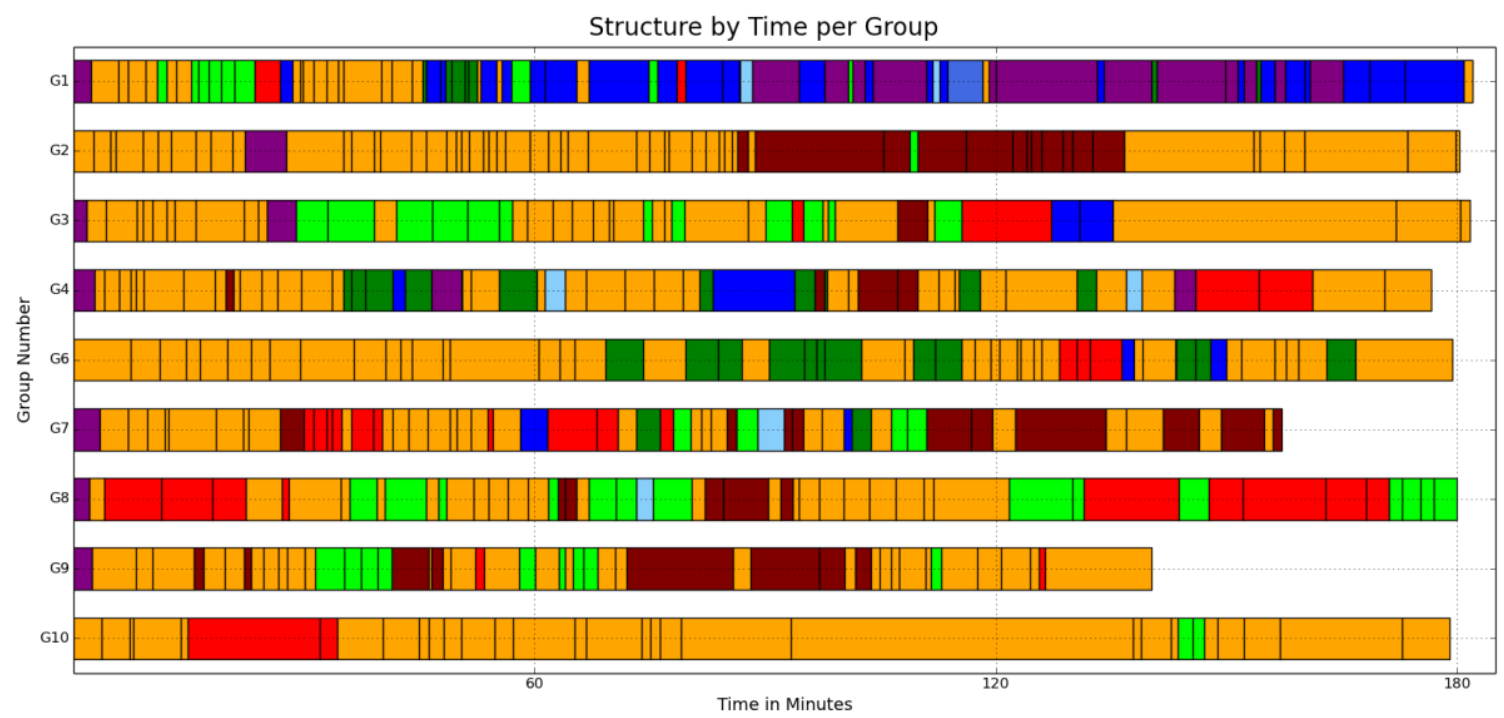

\subsection{Observed Patterns through Design Stages}

There were five types of patterns of movement through design stages that emerged from analysis of the charts above:

(DSP-1) The first pattern and most popular that emerged was the pattern of conducting work in the gathering information and conceptual stages early in the activity then spending the remaining amount of time focusing on work in the implementation stages. The groups that operated in this manner were G1, G2, G3, G9, G10 and G11.

(DSP-2) The second pattern, similar to the first, consisted of conducting work in the gathering information and conceptual stages upfront, moving into work focusing on the 
implementation stages, but then in the last hour conducting work across all five stages. The groups that operated in this manner were G6 and G7.

(DSP-3) The third pattern consisted of switching back and forth between the conceptual stages and implementation stages repeatedly throughout the activity. The group that operated in this manner was G5.

(DSP-4) The fourth pattern consisted of working concurrently through both the conceptual and implementation stages throughout the activity. This means a group primarily split into subgroups for the majority of the activity with each subgroup working in a different design stage. The group that operated in this manner was G4.

(DSP-5) The fifth pattern consisted of beginning work in the conceptual stages, then moving to working concurrently in the conceptual and implementation stages, to finally just working in the implementation stages. This pattern was more of a gradual move from conceptual to implementation whereas the first pattern was quick move. The group that operated in this manner was G8.

\subsection{Observed Patterns through Team Structure}

There were four patterns of movement through team structure that emerged from analysis of the charts above: 
(TSP-1) The first pattern consisted of starting the activity working as a group, usually in the gathering information and conceptual stages, then splitting into subgroups to work in the implementation stages. The groups that operated in this manner were G1 and G7.

(TSP-2) The second pattern consisted of starting the activity working as a group, moving to a period of working as in subgroups, and then ending the activity working as a single group again. Similar to the first pattern, the period where groups split into subgroups was also the period where work in the implementation stages began. The groups that operated in this manner were $\mathrm{G} 2, \mathrm{G} 9$, and G11.

(TSP-3) The third pattern, similar to the second, consisted of constant switching back and forth between working as a single group and working as a subgroup. This pattern is different from the second pattern as it involves multiple switches of single group to subgroups whereas the second pattern only consisted of one switch. The groups that operated in this manner were G3, G4, G6 and G8.

(TSP-4) The fourth pattern consisted of working through most of the activity as a group, with little to no time spent working as a subgroup. The groups that operated in this pattern were G5 and G10.

\subsection{Discussion of Results}

There were several patterns that student teams took throughout the design stages. Most of them consisted of the students initially starting out the activity working in the gathering information and conceptual stages and ending in the implementation stages. It is also 
noticeable that teams preferred to split into subgroups to do work in the implementation stages. It is also noticeable that not very many groups worked in both the implementation and conceptual stages concurrently. There were only two groups that utilized at least a portion of their time in this manner, G4 and G1. For the majority of groups, when split into subgroups, the subgroups both worked concurrently in the implementation stages.

Table 9.4.1 Group Patterns on Design Stage and Team Structure

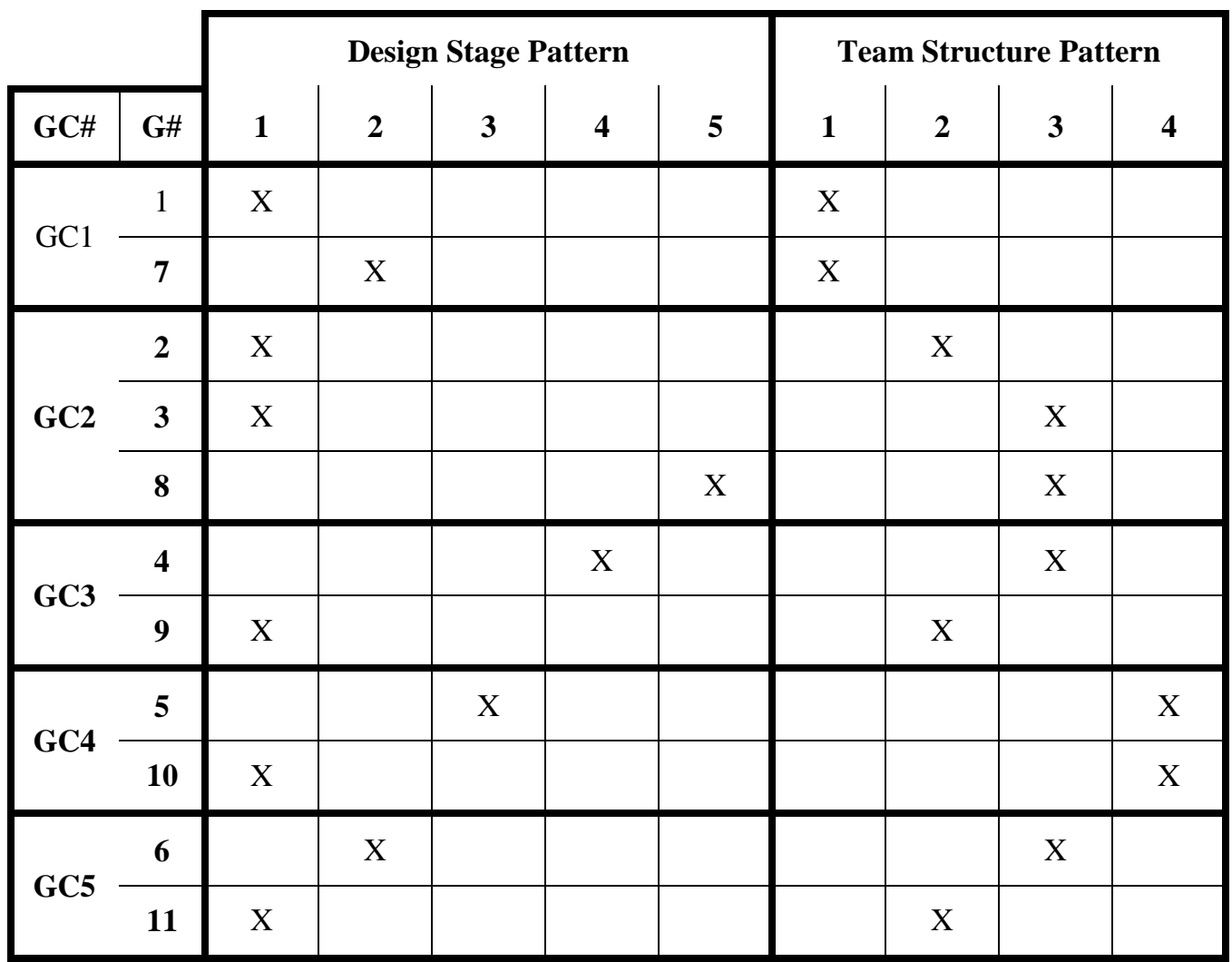

Based on observations in Table 9.4.1, group composition did not have a major influence on the pattern of work in design stages undertaken by each team. GC2 teams $(\mathrm{G} 2, \mathrm{G} 3$, and G8) did show similarities in pattern, however, their choice of design stage patterns (DSP-1 and DSP-5) were also represented in other group compositions. On the other hand, patterns found in use of team structure were possibly influenced by group 
composition. GC1 teams (G1 and G7) were the only teams to follow the TSP-1 pattern of starting out in a group for the conceptual stages before splitting into subgroups for the implementation stages. GC2 (G2, G3, and G8) was the only group composition in which all the teams followed the similar TSP-2 and TSP-3 patterns of starting out work as a single group, then splitting into some form a subgroup, then ending the activity back in a single group. GC4 teams (G5 and G10) were the only teams to follow the TSP-4 pattern of working in a single group the majority of the study with little time spent working in a subgroup. However, it must be noted that G5 (and G11) only consisted of three students which could have influenced their behavior. An additional observation is GC1 teams were the only teams not to return to the single group structure (or stay in it). This suggests the presence of non-TLP students caused teams to stay in or return to the single group structure. As noted in the limitations, the TLP students had prior experience working on projects together which could have attributed to their decision to work more in subgroups. 


\section{CONCLUSIONS}

\subsection{Response to Research Questions of Interest}

1. How do interdisciplinary teams engage in the engineering design process? Is there a difference in how teams of differing student composition engage in the engineering design process?

Findings from chapter 6 developed rich descriptions of the type of work students completed during this engineering activity. This contribution of rich descriptions adds to prior work Cross [23] conducted centered around the elements of teamwork. Cross characterized teamwork as consisting of six elements, one of which being a "planning process and actions relative to the plan." The overall findings from this chapter provide a description for what actions take place in a design process and show student teams primarily place a major emphasis on actions related to prototyping. This is especially important to know given that the prior studies noted in the review of literature exclude implementation and testing from their methods. Therefore the answer to the first part of this research question is in the rich descriptions of activities that were developed as a result of this study and the findings from the distribution of time across design stages.

When studying the results at the group composition level, chapter 7 , the distribution of activities within each stage showed interesting results as well. Findings showed the two TLP ECE / two SIE non-TLP groups (GC4) and the non-TLP groups (GC5) tended to operate in the same manner in regards to distribution of work within each design stage. 
What this suggests is the absence of SIE TLP students causes similar behavior among student teams. This suggestion is supported by the fact the all TLP teams (GC1) tended to show a greater variety of distribution of work across all stages. Therefore, there is a difference in how teams of differing student compositions engage in an engineering design activity, and this difference is based on the combination of TLP students.

2. How do interdisciplinary teams distribute their time with respect to the engineering design stages and team structure? Is there a difference in the distribution of time when comparing teams of differing student compositions?

Results from chapter 6 show interdisciplinary teams spend the majority of their time in the implementation stages when engaging in an engineering design process. The reason why this occurred could be attributed to the difficultly students faced with programming which translated into a dedication of more time. This in return resulted in groups conducting a large portion of the work in this stage in conjunction with other activities throughout the activity time. The least amount of time was spent conceptually critiquing proposed ideas for solutions (stage 3) which was a large part of Atman's study [18]. This finding perhaps suggest when implementation of a prototype is included in the deliverables, students tend to spend less time conceptually analyzing ideas and instead use the act of testing as a substitute. When evaluating at the group composition level (chapter 7) the results were no different. Work in stage 4 accrued the most time across all group compositions and work in stage 3 the least. 
In terms of team structure results from chapter 6 show students are just as likely to work in a subgroup as in a single group. However, at the group composition level, results in chapter 7 show certain group compositions are more likely than others to work in subgroups. This could be attributed to the total number of TLP students on each team as the four-person TLP teams (GC1) spent the least amount of time working in subgroups. Further analysis at the student level would provide insight into how each student influenced the results of this study.

3. When interdisciplinary teams split into subgroups, how do those subgroups contribute to the engineering design stages? Are those subgroups determined by majors, curriculum or other factors?

Chapter 8 showed the way interdisciplinary teams contributed to the engineering design stages varied by subgroup structure. When students worked alone, regardless of their individual engineering discipline, their work primarily related to the coding of the prototype. As noted in chapter 2, results from the study conducted by Richter [7] inferred students are not able to think beyond their discipline. Findings from Borrego's [38] work suggested engineers are unlikely to participate in interdisciplinary work and instead trust in the expertise of others' to do their own work. The behavior observed by one-person teams provides counter-evidence to such prior work and infers, especially in the case of SIE students, that students can expand beyond their specific discipline and take on work that others on the have deeper expertise in. The primarily reason why students split up to work alone was to do work in stage 4. Based on observed conversations between 
students, the student who generally completed the most work in this stage tended to be the one who felt most comfortable with coding (or learning to code).

However, when students worked in two-person teams, depending on the combination, results inferred two ECE students are more likely to strictly function in the implementation realm of stages 4 and 5. Those two stages involved more of the hands-on technical tasks that ECE students were expected to heavily engage in due to their curriculum. Whereas when two SIE students worked together they spent more time than their counterparts in the information gathering and brainstorming stages in the conceptual realm and the testing stage in the implementation realm. From chapter 6 it was determined that work in these stages has less electrical engineering and coding than does stage 4. Stage 5 was hands-on in terms of testing the prototype but much of the discussion that occurred in this stage revolved around the data collected from testing the prototype. In addition to those stages, two-person SIE teams also spent a substantial amount of time working in stage 4, but this time was small compared to their counterparts. Therefore, when teams split into two-person subgroups split by major, the subgroups tended to focus more on work that aligned with their major.

When teams split into the three-person / one-person subgroup, the work of three-person subgroups tended to be distributed across all five design stages fairly evenly. This may be due to the fact the single person of this subgroup tended to work primarily in the prototyping stage. Therefore the three-person subgroup was responsible for completing the work spanning the other stages. Therefore, the decision to split into this subgroup 
structure (i.e., 3-1) was a byproduct of choosing a single student to work on software coding.

4. What patterns of behavior with respect to design stage and team structure do interdisciplinary teams exhibit during an engineering design activity?

As noted in chapter 2, prior work of Song [31] showed that high performing design teams cycle between divergent and convergent patterns of thinking and questioning. This pattern is consistent with the patterns observed from this study. Nearly every group at some point continually cycled between the five design stages before primarily focusing on one, usually stage 4 the prototyping stage. In some cases this pattern of cycling was recorded and represented by those segments that were coded as oscillating between stages 2 / 3 and stages 4 / 5. There were other instances of oscillating quickly between two design stages in this study but the most often design stages moved between quickly paired divergent and convergent work. A unique aspect of this study was the ability to track how teams utilized the design stages while split into sub groups which made it easy to see teams often worked in different stages concurrently.

Also noted in chapter 2, results from Olson's [32] study found that design meetings, although as an observer seem scattered and disorganized, are actually quite organized. This is consistent with the findings of this study. When looking at the individual team maps in chapter 9, the activity of each group looks disorganized at first glance. But, on further analysis, several consistent patterns emerged. Those patterns both showed how 
student teams navigated the design stages and how they used team structure throughout the study to build a working prototype. The most popular pattern of team structure groups followed was to first start out in a single group, switch to some form of subgroup (or multiple) and end working in a single group again. The most popular design stage pattern was spending time working in the information gathering and conceptual stages upfront before spending the majority of time working on prototyping and testing.

\subsection{Closing}

There are many studies that individually study how individuals engage in design, interdisciplinarity or teamwork environments, but none of the aforementioned studies incorporate all three into one. This study ultimately adds value by studying the intersection between design, interdisciplinary and teamwork and elements of its findings can be utilized in both academia and professional practice. One of its practical contributions to academia is an example of a medium through which assessment of teamwork using video data can be done. This work also provides an example of an assessment strategy that can be used for engineering design and teamwork in general. Even the engineering design process defined in this study is not unique and can be further isolated into specific areas or generalized into larger themes.

There was also a wealth of data collected through this study in addition to video footage that was not analyzed including audio from focus group sessions and responses to individual surveys. Future work could study those additional data points for the purpose of understanding further at the individual team and student level the impacts of 
interdisciplinary engineering work on undergraduate students. More specifically, through the individual survey responses the perception and value of student contribution can be analyzed to determine if students of the TLP shared the same viewpoints as students not in the program during this study. Also, for more analysis at the individual student level, the individual contributions of students to conversations on interdisciplinary topics can be studied using the audio recorded from the focus group sessions. 


\section{REFERENCES}

[1] C. Dym, A. Agogino, O. Eris, D. Frey, and L. Leifer, "Engineering design thinking, teaching, and learning," J. Eng. Educ., no. January, pp. 103-120, 2005.

[2] C. Dym, "Design and design centers in engineering education," AI EDAM, vol. 12, no. 01, pp. 43-46, 1998.

[3] R. S. Adams, L. Mann, S. Jordan, and S. Daly, "Exploring the Boundaries: Language, Roles and Structures in Cross-Disciplinary Design Teams," in About: Designing: Analysing Design Meetings, 2009, pp. 339-361.

[4] M. Lih, "Educating future executives," ASEE Prism, 1997.

[5] National Academy of Engineering of the National Academies, Educating the engineer of 2020 : adapting engineering education to the new century. Washington, DC, 2005.

[6] National Academy of Engineering of the National Academies, The engineer of 2020 : visions of engineering in the new century. Washington, DC: National Academies Press, 2004.

[7] D. M. Richter and M. C. Paretti, "Identifying barriers to and outcomes of interdisciplinarity in the engineering classroom," Eur. J. Eng. Educ., vol. 34, no. 1, pp. 29-45, Mar. 2009. 
[8] M. Borrego and S. Cutler, "Constructive alignment of interdisciplinary graduate curriculum in engineering and science: An analysis of successful IGERT proposals," J. Eng. Educ., 2010.

[9] C. Dym, Engineering design: a synthesis of views. Press Syndicate of the University of Cambridge, 1994.

[10] C. L. Dym, M. M. Gilkeson, and J. R. Phillips, "Engineering Design at Harvey Mudd College: Innovation Institutionalized, Lessons Learned," J. Mech. Des., vol. 134, no. 8, p. 080202, 2012.

[11] "Department of Engineering at James Madison University: CISE." [Online]. Available: http://www.jmu.edu/engineering/curriculumoverview.html.

[12] "Purdue University: EPICS.” [Online]. Available: https://engineering.purdue.edu/EPICS/About.

[13] "Undergraduate Programs: Multidisciplinary Engineering and Interdisciplinary Engineering Studies.” [Online]. Available: https://engineering.purdue.edu/ENE/Academics/Undergrad.

[14] “UVA - SEAS - Technology Leaders Program.” [Online]. Available: http://www.seas.virginia.edu/acad/programs/tlp/. [Accessed: 25-Jul-2013]. 
[15] C. J. Atman, M. E. Cardella, J. Turns, and R. Adams, "Comparing freshman and senior engineering design processes: an in-depth follow-up study," Des. Stud., vol. 26, no. 4, pp. 325-357, Jul. 2005.

[16] C. J. Atman, R. S. Adams, M. E. Cardella, J. Turns, S. Mosborg, and J. Saleem, "Engineering design processes: A comparison of students and expert practitioners," J. Eng. Educ., no. October, pp. 359-379, 2007.

[17] C. J. Atman, J. R. Chimka, K. M. Bursic, and H. L. Nachtmann, “A comparison of freshman and senior engineering design processes," Des. Stud., vol. 20, no. 2, pp. 131-152, Mar. 1999.

[18] C. Atman, J. Borgford-Parnell, and K. Deibel, "Matters of context in design," in About: Designing: Analysing Design Meetings, 2009, pp. 399-416.

[19] N. Cross, H. Christiaans, and K. Dorst, Analysing design activity. John Wiley \& Sons, 1996.

[20] J. A. MacDonnell and P. Lloyd, About: Designing: Analysing Design Meetings. CRC Press, 2009.

[21] G. Goldschmidt, "The Designer as a Team of One," in Analysing design activity, 1996, pp. 65-92. 
[22] S. Dwarakanath and L. Blessing, "Ingredients of the Design Process: a Comparison Between Group and Individual Work," in Analysing design activity, 1996, pp. 93-116.

[23] N. Cross and A. C. Cross, "Observations of teamwork and social processes in design," Des. Stud., vol. 16, no. April, pp. 143-170, 1995.

[24] M. F. Brereton, D. M. Cannon, A. Mabogunje, and L. J. Leifer, "Collaboration in Design Teams: How Social Interaction Shapes the Product," in Analysing design activity, 1996, pp. 319-342.

[25] D. F. Radcliffe, “Concurrency of Actions, Ideas and Knowledge Displays within a Design Team," in Analysing design activity, 1996, pp. 343-364.

[26] P. Badke-Schaub, K. Lauche, A. Neumann, and S. Ahmed, “Task, Team, Process: The Development of Shared Representations in an Engineering Design Team," in About: Designing: Analysing Design Meetings, 2009, pp. 153-170.

[27] L. J. Ball and B. T. Christensen, "Analogical Reasoning and Mental Simulation in Design: Two Strategies Linked to Uncertainty Resolution," in About: Designing: Analysing Design Meetings, 2009, pp. 137-152.

[28] M. Stacey, C. Eckert, and C. Earl, "From Ronchamp by Sledge: On the Pragmatics of Object References," in About: Designing: Analysing Design Meetings, 2009, pp. $361-380$. 
[29] E. S. Arikoglu, E. Blanco, and F. Pourroy, "Keeping Traces of Design Meetings through Intermediary Objects," in About: Designing: Analysing Design Meetings, 2009, pp. 381-398.

[30] A. Dong, A. H. Hill, and A. M. Agogino, "Document analysis as a means for predicting design team performance," ASME J. Mech. Des., 2004.

[31] S. Song, A. Dong, and A. M. Agogino, "Time Variance of Design 'Story Telling' in Engineering Design Teams," in International Conference on Engineering Design (ICED), 2003.

[32] G. Olson and J. Olson, "Small group design meetings: An analysis of collaboration," Human-Computer Interact., vol. 7, pp. 347-374, 1992.

[33] D. Richter, M. Paretti, L. Mcnair, and M. Borrego, “AC 2009-1592: ASSESSING STUDENT PERSPECTIVES OF INTERDISCIPLINARY COLLABORATION,” 2009.

[34] L. Lattuca and D. Knight, “AC 2010-1537: IN THE EYE OF THE BEHOLDER: DEFINING AND STUDYING INTERDISCIPLINARITY IN ENGINEERING EDUCATION,” 2010.

[35] M. Borrego and L. K. Newswander, "Definitions of Interdisciplinary Research: Toward Graduate-Level Interdisciplinary Learning Outcomes," Rev. High. Educ., vol. 34, no. 1, pp. 61-84, 2010. 
[36] A. E. Coso, "Measuring Undergraduate Engineering Students ' Interdisciplinary Understanding," University of Virginia, 2010.

[37] R. Adams, "Cross-disciplinary practice in engineering contexts," 17th Int. Conf. Eng. Des., no. August, 2009.

[38] M. Borrego and L. Newswander, "Characteristics of Successful Cross-disciplinary Engineering Education Collaborations," J. Eng. Educ., no. April, 2008.

[39] J. T. Klein, "Evaluation of interdisciplinary and transdisciplinary research: a literature review.," Am. J. Prev. Med., vol. 35, no. 2 Suppl, pp. S116-23, Aug. 2008.

[40] M. Borrego, "Discipline-based views of collaboration in engineering education research partnerships," in Frontiers in Education Annual Conference, 2006.

[41] K. Börner, N. Contractor, H. J. Falk-Krzesinski, S. M. Fiore, K. L. Hall, J. Keyton, B. Spring, D. Stokols, W. Trochim, and B. Uzzi, “A multi-level systems perspective for the science of team science.," Sci. Transl. Med., vol. 2, no. 49, p. 49cm24, Sep. 2010.

[42] H. J. Falk-Krzesinski, N. Contractor, S. M. Fiore, K. L. Hall, C. Kane, J. Keyton, J. T. Klein, B. Spring, D. Stokols, and W. Trochim, "Mapping a research agenda for the science of team science.," Res. Eval., vol. 20, no. 2, pp. 145-158, Jun. 2011. 
[43] K. A. Ericsson and H. A. Simon, Protocol analysis verbal reports as data. Cambridge, MA: MIT Press, 1993.

[44] M. T. Orne, "Demand characteristics and the concept of quasi-controls," in Artifacts in Behavioral Research: Robert Rosenthal and Ralph L. Rosnow's Classic Books, 2009, pp. 110-137.

[45] V. Kumar, 101 Design methods: A structured approach for driving innovation in your organization. Wiley, 2012.

[46] Flash-Integro, "VSDC Free Video Editor." www.CNET.com.

[47] D. Kilgore, C. J. Atman, K. Yasuhara, T. J. Barker, and A. Morozov, "Considering Context : A Study of First-Year,” J. Eng. Educ., vol. 96, no. 4, pp. 321-334, 2007.

[48] D. H. Jonassen and Y. H. Cho, "Fostering Argumentation While Solving Engineering Ethics Problems," J. Eng. Educ., vol. 100, no. 4, pp. 680-702, Oct. 2011.

[49] N. Genco, K. Holtta-Otto, and C. C. Seepersad, “An Experimental Investigation of the Innovation Capabilities of Undergraduate," J. Eng. Educ., vol. 101, no. 1, pp. 60-81, 2012. 


\section{APPENDICES}

\section{APPENDIX A: Study Room Set-up Description and Layout}

Appendix A shows a diagram and provides a description of the room setup used for this study. This study took place inside a classroom designed for interactive learning. The room setup included three six foot tables, four desk chairs, various arts and craft materials, loose-leaf paper, mechanical pencils, two white boards and one replica of the newspaper distribution box. Two cameras were positioned in adjacent corners of the room to capture the overall and main table view student participants working during the pilot study. A tape recorder was positioned on the main table to capture any discussion between the students that were not picked up by the cameras. Figure A shows a diagram of the room set-up.

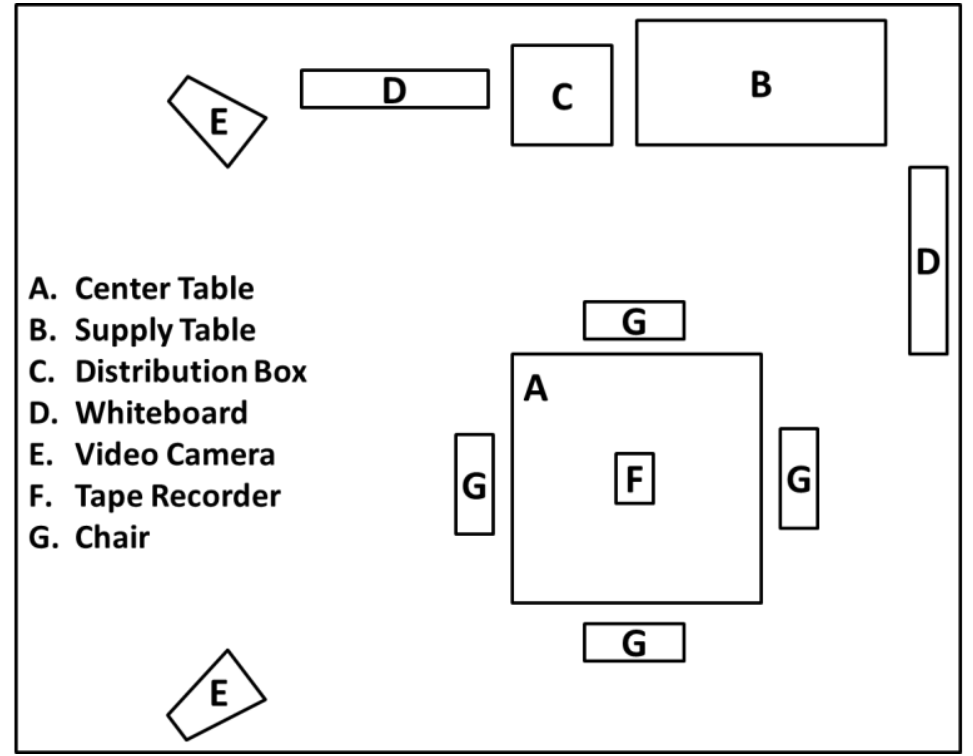

Figure A: Diagram of Room Set-up 


\section{APPENDIX B: Design Activity Prompt and Cavalier Daily Additional Information}

Appendix B shows the activity prompt used for this study and the sample sets of data provided to student upon request in the activity.

\section{$\underline{\text { Introduction }}$}

The Cavalier Daily, with its 120+ history, is undoubtedly a big UVA tradition, as noted by the following from www.cavalierdaily.com:

"Founded in 1890 under the name College Topics, The Cavalier Daily is the independent daily newspaper at the University of Virginia. The Cavalier Daily is Virginia's oldest collegiate daily and the oldest daily newspaper in Charlottesville, Va. Since the summer of 1996, The Cavalier Daily has been the only daily newspaper at the University, with a print circulation of 10,000 distributed on Grounds and in the surrounding Charlottesville area. The Cavalier Daily is an entirely student-run, non-profit organization with an operating budget accrued solely through advertising. "

Despite claims of reaching over 10,000 people per day, a recent study found that an average of only 3,800 print copies are removed by readers from distribution points each day. In order to better understand the distribution of its papers across campus, the Cavalier Daily would like to know more information about the time and amount of newspapers picked up throughout the day. They have hired your team to construct a mechanism that records the time each newspaper is taken and the amount of newspapers taken at that time. The mechanism should be easily attachable to the distribution box, not 
hinder the consumer in anyway and allow for easy extraction of the data recorded by the mechanism. From this data the Cavalier Daily hopes ultimately to create an optimal distribution plan to reach more readers (and consequently be able to increase the price of ads) but also, being an environmentally responsible organization, avoid any outcry over the huge number of papers recycled each day.

\section{$\underline{\text { Project Details }}$}

For ease of prototyping the Cavalier Daily has provided an exact replica of their distribution box along with a stack of old newspapers. Your team will also be provided with a mixture of hardware (i.e. electronic sensors, microprocessors, analog to digital converters, etc.) to complete the task. The hardware provided are the only materials the Cavalier Daily will use for mass production of your finished prototype. In addition, to save time in designing your prototype, your team will be provided with a laptop that can be connected to the system. However, as a team, do your best to consider a realistic situation where leaving a laptop with the distribution box is not an option and there are no power sources available for use. Your end product should be a standalone mechanism that can be constructed inside of one distribution box for a minimum period of 3 days. However, your priority for right now is to create a demo prototype using a laptop and power source if necessary. Also, an important part of this prototype design is the ability to easily extract the collected data. Your prototype should allow for the Cavalier Daily staff to easily obtain and view the data for analysis. Assume you have a maximum budget of $\$ 300$ to produce one prototype. 


\section{Documentation Included with Prompt}

1. CavDaily Data Sheet (cavdaily_data.xls): Sheet 1 includes data of papers in box at the beginning and end of business hours, sheet 2 includes listing of locations with boxes marked.

2. Material List (Material_list.doc): Document includes listing of electrical hardware available for use with prototype. Document also includes pictures of hardware for ease of identification with some basic.

\section{Additional Information: CavDaily Distribution Data (Data Set A)}

You are provided with data from a previous one-time study of 70 distribution points during 4 business days. The data shows the number of papers at 8:00a and at 5:00p. Based on prior studies, roughly $75 \%$ of papers (that are to be taken) are taken by 1:00p and $90 \%$ are taken by 4:00p. The data included is actual data collected by Cavalier Daily staff over a year ago and as such, it is not perfect. UVA Recycling recycles papers sometime late in the day (the exact time is not known). If a distribution point is listed as empty at 5:00p, there is some chance that this is due to the papers being recycled, not due to readers picking up the papers.

Additional Information: Data on Why Distribution Box Opens (Data Set B)

*** (Based on 5 hours* of observation at two distribution points)

$87 \%$ - one newspaper is taken 
$5 \%$ - nothing is taken, sometimes due to no newspapers left in the box

- Of this $5 \%, 80 \%$ of consumers eventually went to another box that same day

$4 \%$ - more than one newspaper was taken

$3 \%$ - Other

- A consumer put back a newspaper.

- A consumer accidentally let the box close before grabbing a newspaper, so reopened the box to grab one.

- A child or someone is playing around with the door.

$1 \%$ - someone restocking or collecting newspapers for recycling.

*The following five hours is the time frame within which the majority of the papers are taken ( 8 am to $1 \mathrm{pm})$, as mentioned above in the Additional Information section.

\section{Additional Information: Video Footage of Distribution Box Usage (Data Set C)}

The video clip provided is of several individuals picking up a CavDaily newspaper from a distribution box located on grounds. The video clip shows individuals from two different angles retrieving newspapers from the distribution box. Each segment was filmed separately at various during the day and do not display the frequency of use of one box over the video time span. 


\section{APPENDIX C: Inter-rater Reliability using Cohen's Kappa}

Appendix $\mathrm{C}$ shows in table form the how many times the researcher and reviewer agreed when conducting the inter-rater reliability test on all coded segments. It also shows how the values used in the calculation of Cohen's Kappa.

\begin{tabular}{|c|c|c|c|c|c|c|c|c|c|c|c|c|c|}
\hline \multirow{2}{*}{ App.1 } & \multicolumn{13}{|c|}{ Reviewer Codes } \\
\hline & 0 & 1 & 2 & 3 & 4 & 5 & 6 & $1 \$ 2$ & $1 \$ 4$ & $2 \$ 3$ & $2 \$ 5$ & $3 \$ 5$ & $4 \$ 5$ \\
\hline 0 & 6 & 3 & 1 & 1 & - & - & 1 & - & - & - & - & - & - \\
\hline 1 & 1 & 18 & 1 & 1 & 1 & 1 & - & - & - & - & - & - & - \\
\hline 2 & - & - & 14 & - & 1 & - & 1 & - & - & - & 1 & - & - \\
\hline 3 & - & - & - & 6 & - & - & - & - & - & - & - & - & - \\
\hline 4 & - & - & 1 & - & 58 & - & - & - & - & - & - & - & - \\
\hline 5 & - & - & - & 1 & - & 17 & - & - & - & - & - & - & 1 \\
\hline 6 & - & - & - & - & - & - & - & - & - & - & - & - & - \\
\hline $1 \$ 2$ & - & - & - & - & - & - & - & - & - & 1 & - & - & - \\
\hline $1 \$ 4$ & - & - & - & - & 1 & - & - & - & - & - & - & - & - \\
\hline $2 \$ 3$ & - & - & 1 & 1 & - & - & - & - & - & 5 & - & - & - \\
\hline $2 \$ 5$ & - & - & - & - & - & - & - & - & - & - & - & - & - \\
\hline $3 \$ 5$ & - & - & - & - & - & 1 & - & - & - & - & - & - & - \\
\hline $4 \$ 5$ & - & - & - & - & - & - & - & - & - & - & - & - & 3 \\
\hline
\end{tabular}

\begin{tabular}{|l|l|}
\hline pr-a & 0.852 \\
\hline pr-e & 0.223 \\
\hline kappa & 0.810 \\
\hline
\end{tabular}




\section{APPENDIX D: Patterns of Activity for Each Group}

Appendix D shows the figures displaying the patterns of each group over time in reference to team structure and design stage are presented in Appendix D.

\subsubsection{Group \#1}

G1 was comprised of four TLP students (two SIE, two ECE). The following Figure 9.1.1 shows how G1 navigated this study in reference to design stage and team structure.

Figure 9.1.1 Group 1 (GC1) Engineering Design Activity

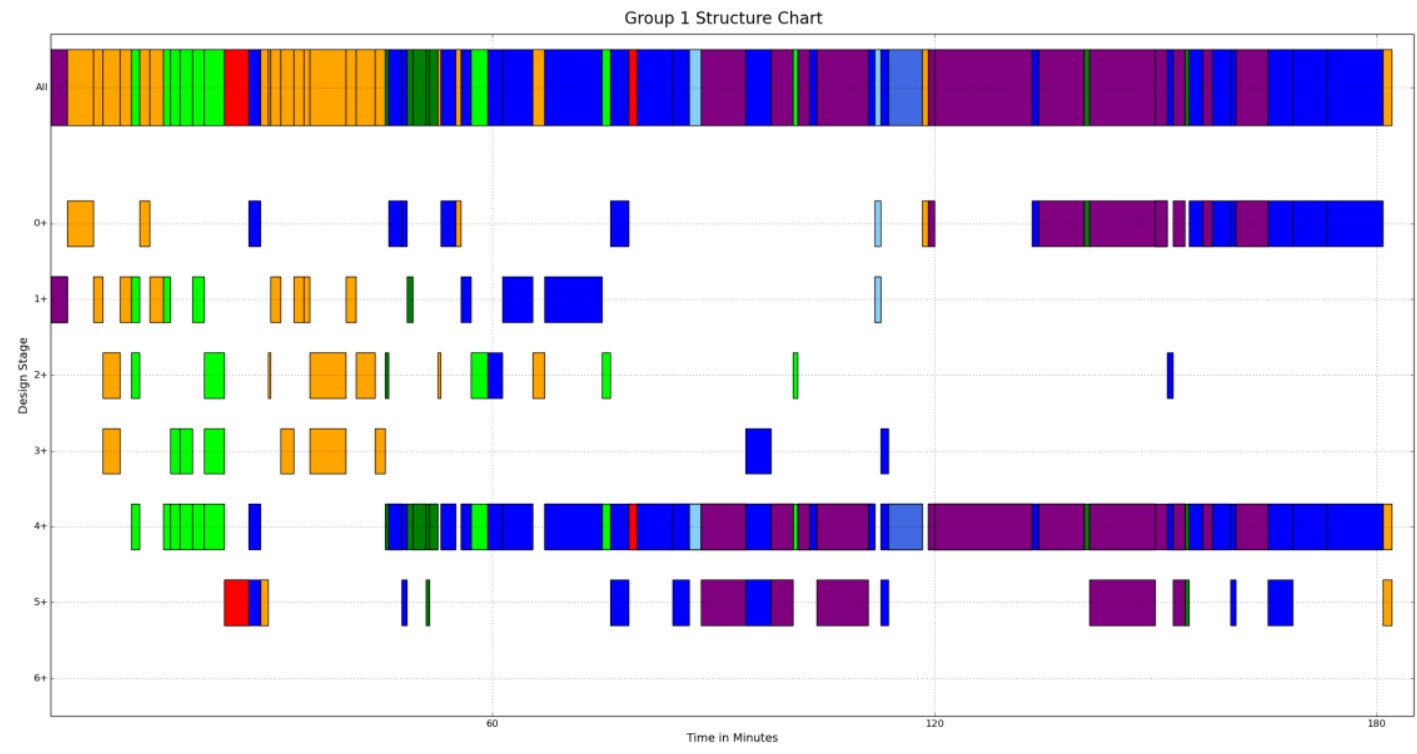

Design Stage: During the first 30 minutes of the activity G1 cycled through work in all 5 stages starting with stage 1 . The least amount of time was spent in stage 5 during this period. In the last 30 minutes of the first hour G1 cycled through the stages again but this time stopping at stage 4 . Stage 4 is where the majority of the type work conducted by G1 fell into for the rest of the study. During the first 20 minutes of the second hour work in stage 1 and briefly in stage 2 was done in conjunction with work in stage 4 . During the 
remaining 40 minutes of the second hour work in those stages stopped and switched to work in stage 5 being done in conjunction with stage 4 . During the final hour work in stage 5 was occasionally done in conjunction with work in stage 4 until the end of the activity.

Team Structure: During the first 45 minutes of the activity, G1 spent the majority of this time working in either the $4 \mathrm{~s}$ or $31 \mathrm{e}$ structure. There were brief moments during this time period where G1 utilized the $22 \mathrm{~m}$ and $211 \mathrm{~m}$ structures. For the remaining 2 hours and 15 minutes of the activity primarily work in either the $1111 \mathrm{~s}$ or $211 \mathrm{~m}$ structure, often alternating between the two repeatedly. There were brief moments where G1 work in the $22 \mathrm{~m}, 211 \mathrm{~s}$, and $211 \mathrm{e}$ structures. The very last minute ending the activity was spent in the 4s structure.

\subsubsection{Group \#2}

G2 was comprised of two traditional students (one SIE, one ECE) and two TLP students (one SIE, one ECE). The following Figure 9.1.2 shows how G2 navigated this study in reference to design stage and team structure. 
Figure 9.1.2 Group 2 (GC2) Engineering Design Activity

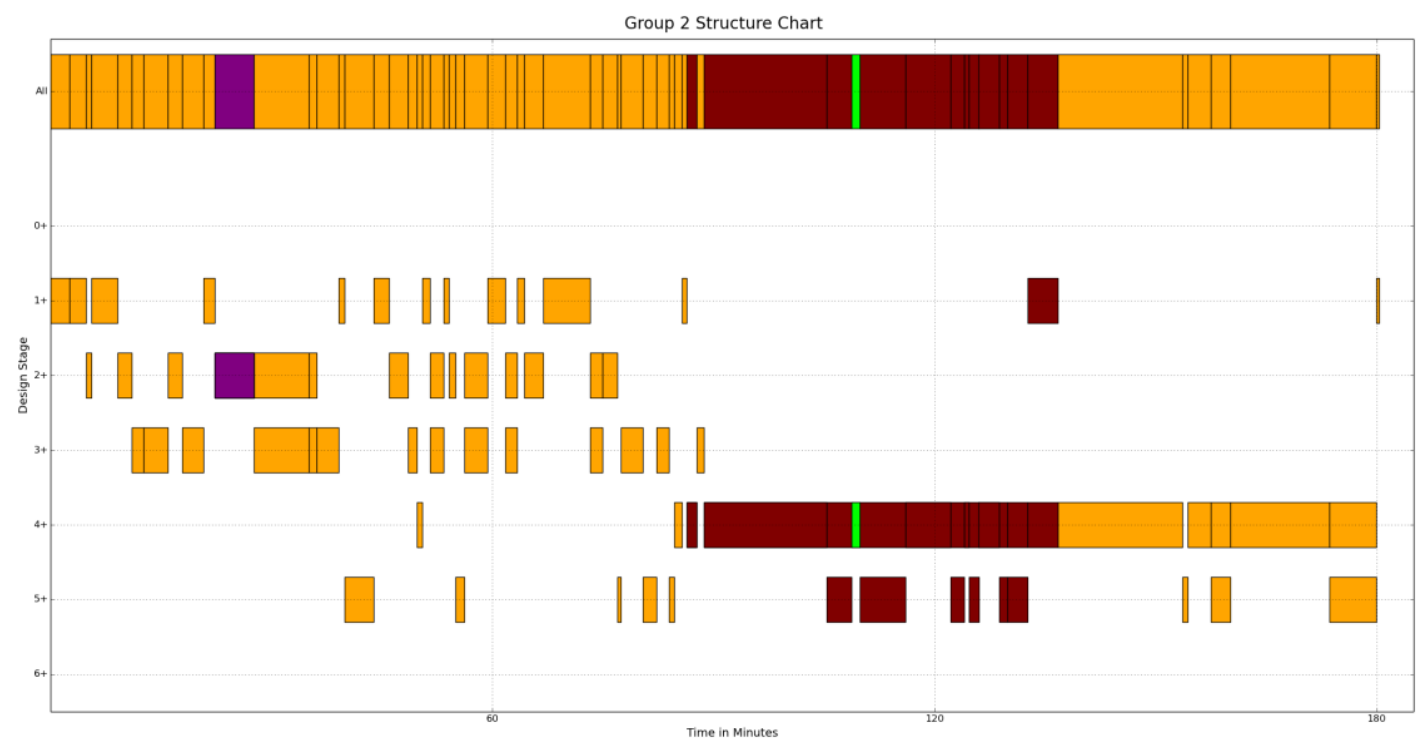

Design Stage: G2 spent the first hour and a half of the activity cycling through work from stages 1,2, and 3 repeatedly. During this time period, most work done in stage 3 seems to be done in conjunction with stage 2 . The amount of time spent in these three stages during this time period seems to be about equal. There is also occasional work done in stage 5 during this time but most work in stage 5 doesn't begin until about 2 hours into the activity. For the second half of the activity G2 spends the entire time working in stage 4. Any other work done during this time (which is primarily stage 5) of the activity was done concurrently with stage 4 .

Team Structure: G2 utilized the 4s structure for the majority of the activity. There was a small period of time (about 10 minutes) spent in the 1111s structure during the first hour of the study, otherwise the entire first hour and a half of the activity was spent in the $4 \mathrm{~s}$ structure. The second half of the activity was mainly split between two structures, $22 \mathrm{~s}$ 
and $4 \mathrm{~s}$. Both were used for about 45 minutes during this time, with the $22 \mathrm{~s}$ structure being first followed by the $4 \mathrm{~s}$ structure.

\subsubsection{Group \#3}

G3 was comprised of two traditional students (one SIE, one ECE) and two TLP students (one SIE, one ECE). The following Figure 9.1.3 shows how G3 navigated this study in reference to design stage and team structure.

Figure 9.1.3 Group 3 (GC2) Engineering Design Activity

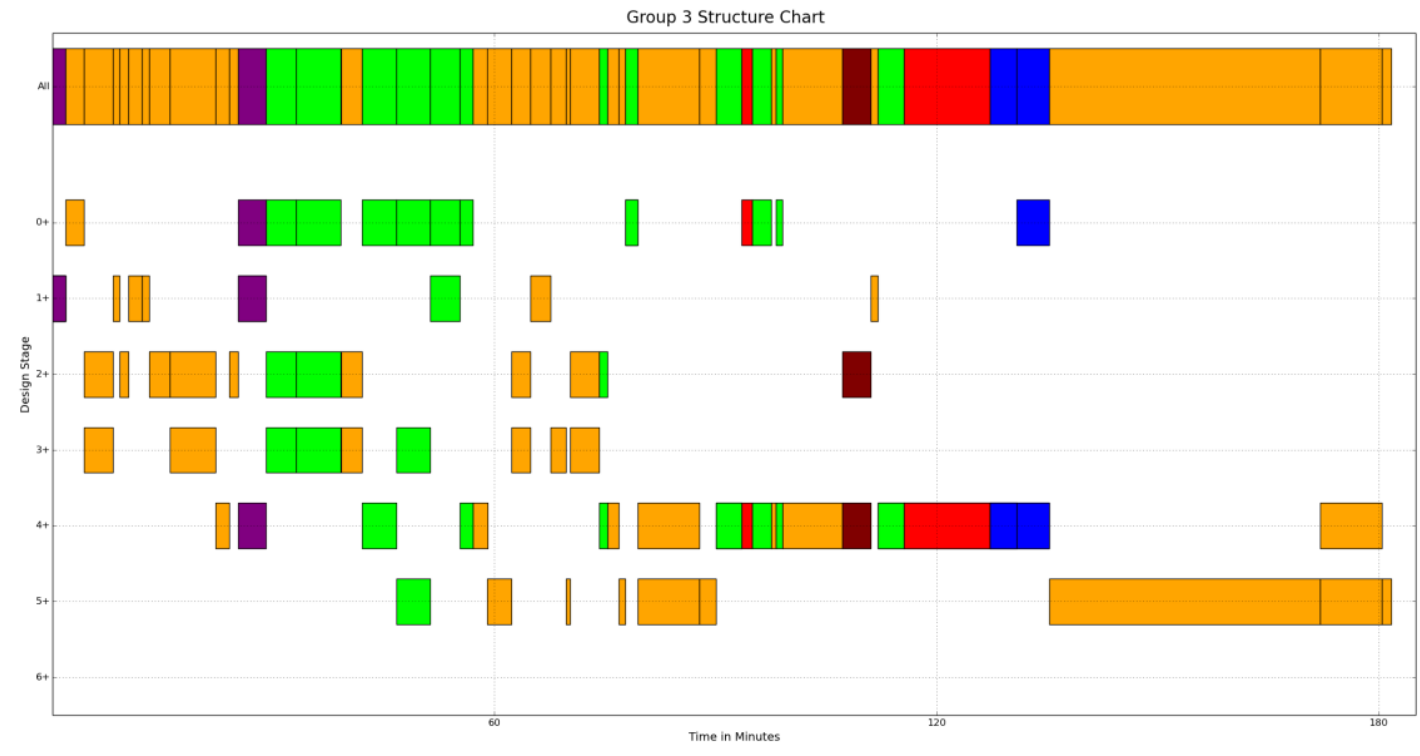

Design Stages: Within the first hour G3 cycles through all 5 stages starting with stage 1 and progressing through to stage 5. Most of the work done during this hour was in stages 2 and 3. The least amount of work was done in stage 5. During the first 20 minutes of the second hour G3 again cycled through all 5 stages starting with stage 1 again and ending with stage 5 . The remainder of this hour was primarily spent working in stage 4 . There were also segments of time where work in stages 5, 2 and 1 were also conducted but 
jointly with stage 4 . For the final hour of the activity G3 started out the first 20 minutes working in stage 4 and the rest working primarily in stage 5. G3 ended the last 10 minutes working both in stages 4 and 5 concurrently.

Team Structure: G3 starts off working in a single group for the first 30 minutes doing work primarily in stages 1 through 3 . G3 then splits into the 31e structure primarily for the remainder of the first hour doing work across all 5 stages. Then the groups come back together for roughly 30 more minutes or so to do more work ranging across all 5 stages. Then G3 splits out into the $31 \mathrm{e}, 22 \mathrm{~m}$ and $211 \mathrm{~m}$ structures for roughly 45 minutes to primarily work in stage 4 . Then the remaining 45 minutes G3 spent back working as a group in stage 5 .

\subsubsection{Group \#4}

G4 was comprised of two traditional students (both ECE) and two TLP students (both SIE). The following Figure 9.1.4 shows how G4 navigated this study in reference to design stage and team structure. 
Figure 9.1.4 Group 4 (GC3) Engineering Design Activity

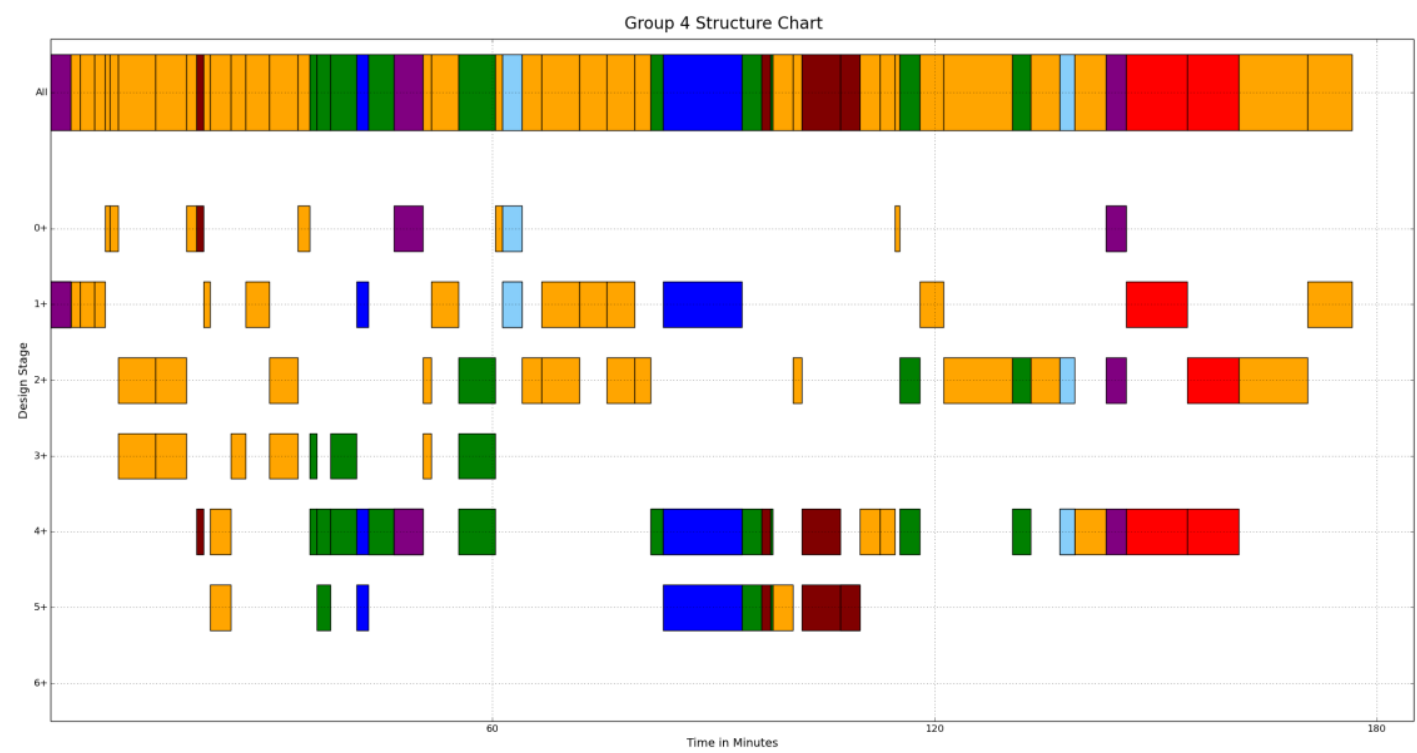

Design Stage: During the first hour of the activity G1 was very active across all 5 stages completing a large amount of time all but stage 5 . The first two minutes of work was primarily in stages 1 and 2 . The next 40 minutes saw work inclusive of all the stages with most being in stages 3 and 4 . The first 20 minutes of the second hour was spent working in stages 1 and 2 once again before moving to predominantly work in stages 4 and 5 the rest of this time period. The final hour of this activity was predominantly spent working in stages 2 and 4 . There was also work occasionally done in stage 1 . All work related to stage 3 ceased after the first hour of the study. Work in stage 5 was only done during the last 40 minutes of the second hour.

Team Structure: During the first 30 minutes of the activity G4 worked in the 4s structure and briefly in the 1111s structure at the very beginning. The latter half of the first hour was spent in several structures, primarily in $31 \mathrm{~s}$ but also briefly in $211 \mathrm{~m}, 1111 \mathrm{~s}$ and $4 \mathrm{~s}$. 
The first 20 minutes of the second hour was spent primarily working in $4 \mathrm{~s}$ and briefly in $211 \mathrm{~s}$. The remainder of the second hour was primarily spent in the $211 \mathrm{~m}$ structure but also briefly in the $22 \mathrm{~s}, 4 \mathrm{~s}$ and $31 \mathrm{~s}$ structures. The final hour primarily started with G4 working in the $4 \mathrm{~s}$ structure for the first third of this period. During the middle third of this time frame $\mathrm{G} 4$ worked in the $22 \mathrm{~m}$ structure before ending the activity in the $4 \mathrm{~s}$ structure. The 1111s, 211s, and 31s was also used briefly during this hour as well in addition to the $4 \mathrm{~s}$ and $22 \mathrm{~m}$ structures.

\subsubsection{Group \#5}

G5 was comprised of two traditional students (both SIE) and one TLP student (one Computer Science). The following Figure 9.1.5 shows how G5 navigated this study in reference to design stage and team structure.

Figure 9.1.5 Group 5 (GC4) Engineering Design Activity

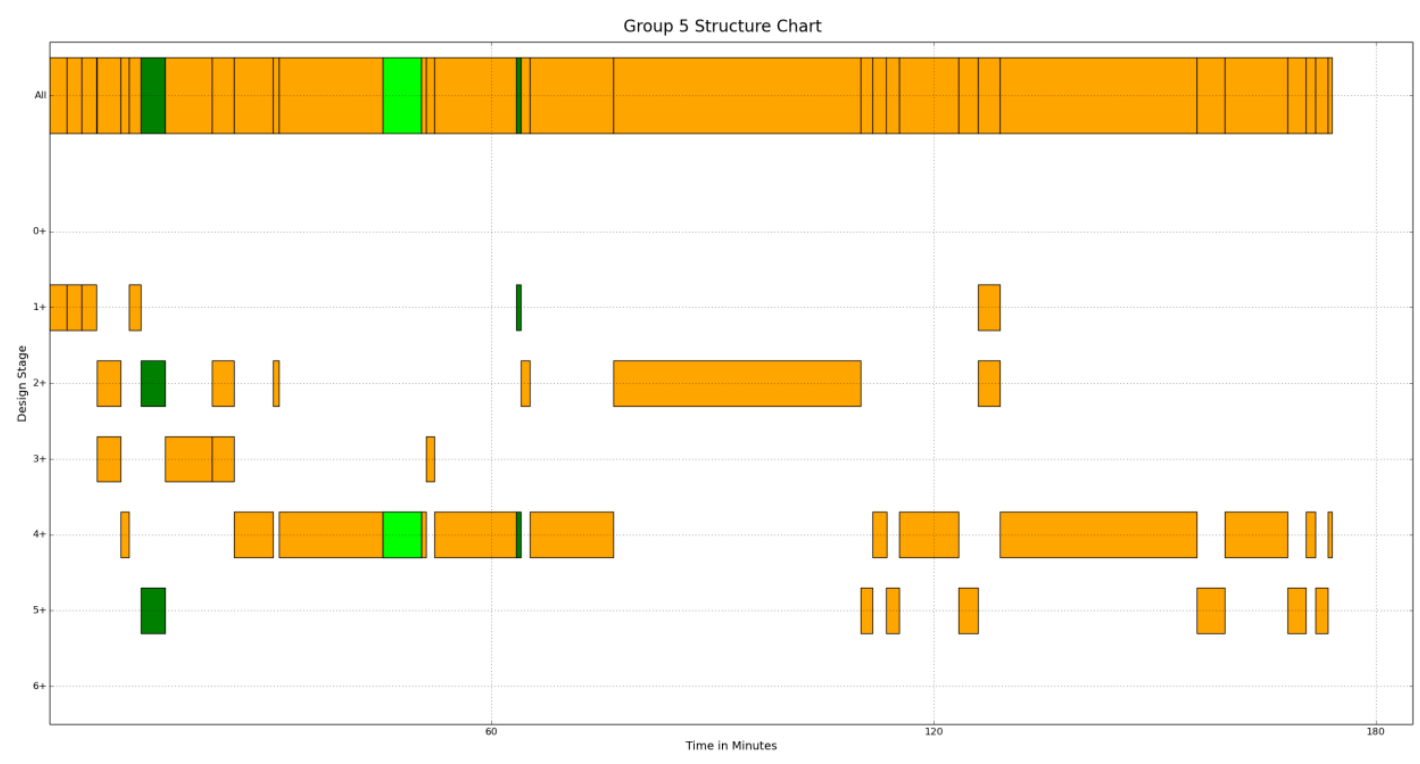


Design Stage: During the first 30 minutes of the activity G5 spends time doing work in each of the 5 stages, with work done in stage 5 being the least. The remaining 30 minutes and moving into the first 20 minutes of the second hour was spent primarily working in stage 4 . The rest of the second hour up until about 10 minutes left in the hour was spent primarily working in stage 2 . The last 10 minutes of the second hour was spent working in stages 4 and 5. The third hour starts off in stages 4, 5, 1 and 2 each for a few minutes before moving into stage 4 for the majority of the remaining time. There was some work done in stage 5 within the last 20 minutes of stage 3.

Team Structure: G5 spent the majority of their time working as a single group. However there were brief moments where G5 worked in the 31s and 31e team structures.

\subsubsection{Group \#6}

G6 was comprised of four traditional students (two SIE, two ECE). The following Figure 9.1.6 shows how G6 navigated this study in reference to design stage and team structure. 
Figure 9.1.6 Group 6 (GC5) Engineering Design Activity

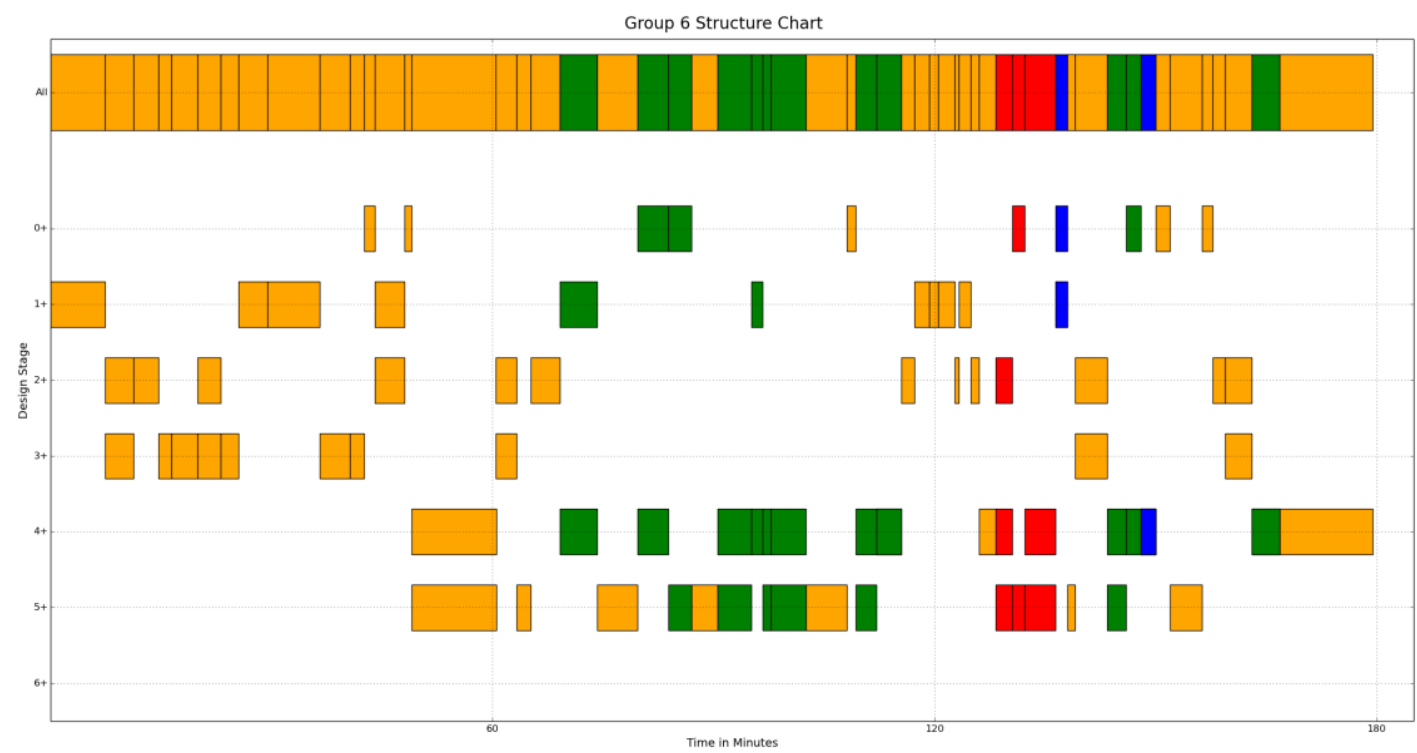

Design Stage: G6 spent the first 45 minutes of this activity cycling through work in stages 1, 2 and 3. The last 10 minutes of this hour was spent conducting work jointly in stages 4 and 5 . Work in the second hour was primarily conducted in stages 4 and 5 with little being done in the other stages. During this time work in stages 4 and 5 traded back and forth, only being done jointly for a few minutes. The final hour was also dominated by work in stages 4 and 5 but work in stages 1,2, and 3 also existed in small increments of time.

Structure: For all of the first hour of this activity G6 worked in the 4s structure. During the majority of the second hour G6 utilized the 31s subgroup structure. G6 spent the remainder of its time working in the 4 s structure during this time period. During the third hour G6 utilized several structures such as 22m, 31s, 211m and 4s. Neither of the 
structures were utilized for an extended period of time until the last 15 minutes which was spent in the $4 \mathrm{~s}$ structure.

\subsubsection{Group \#7}

G7 was comprised of four TLP students (two SIE, two ECE). The following Figure 9.1.7 shows how G7 navigated this study in reference to design stage and team structure.

Figure 9.1.7 Group 7 (GC1) Engineering Design Activity

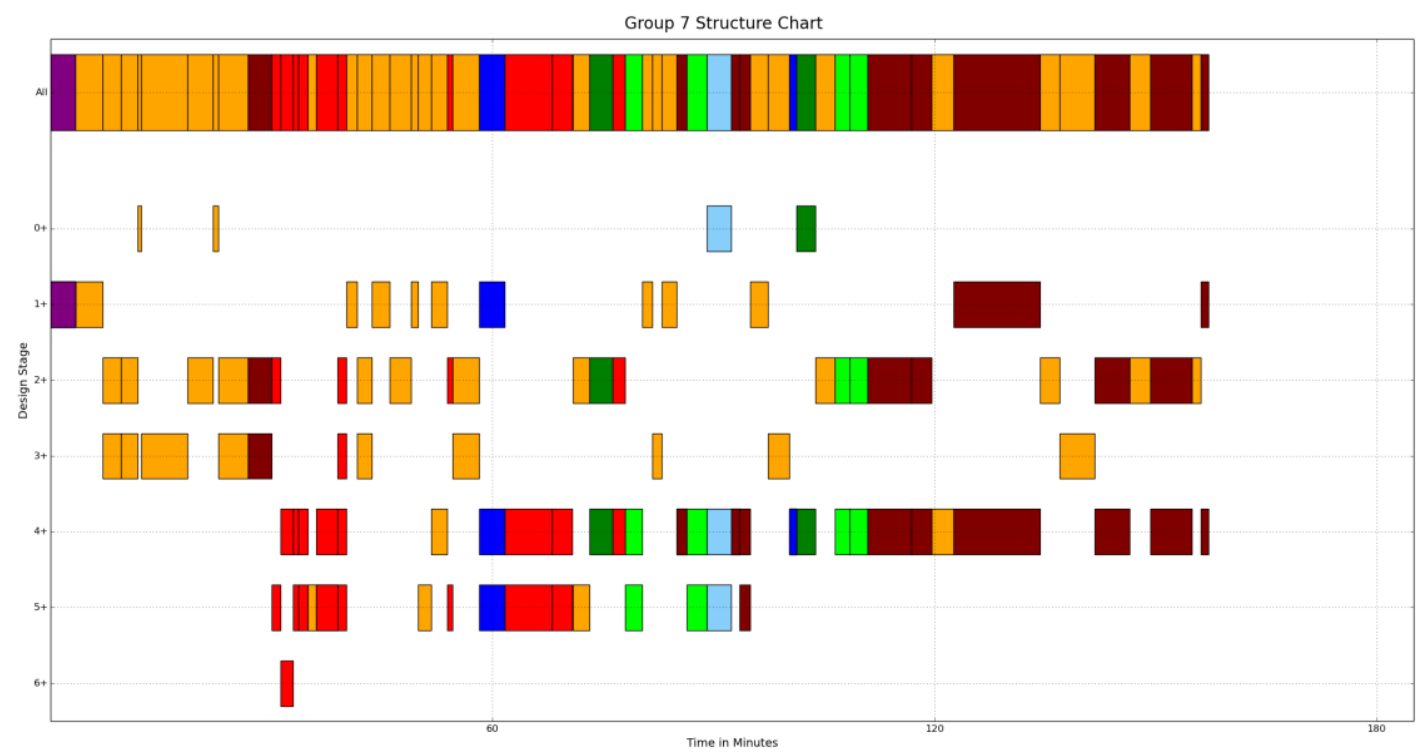

Design Stage: G7 started out this activity working in stage 1 for about 15 minutes before starting work in stage 2 and 3 concurrently. Around the middle of the first hour G7 began to work jointly in stages 4 and 5 for about 10 minutes before returning to work in stages 1,2 , and 3 the rest of the hour. To begin the second hour G7 worked jointly in stages 4 and 5 and continued doing so for the first half of the second hour. After the first half of the second hour work in stage 5 ceased for the remainder of the activity. The remainder 
of the time was primarily spent working in stage 4 joint with either stage 2 or stage $1 . \mathrm{G} 7$ spent the last twenty minutes of the activity working jointly in stages 2 and 4 .

Team Structure: During the first hour G7 utilized multiple structures including 1111s, 4s, $22 \mathrm{~m}$ and $22 \mathrm{~s}$. During this time period the $4 \mathrm{~s}$ structure was utilized the most whereas the others were only used for a few minutes. During the second hour G7 utilized multiple structures again including 4s, 22m, 31e, 31s, 211s and $211 \mathrm{~m}$. The beginning of the hour started off using $211 \mathrm{~m}$ and $22 \mathrm{~m}$, and then moved into a period of 20 minutes where the structure changed sporadically. The last 20 minutes of the second hour ended with G7 working in the $22 \mathrm{~m}$ structure. The final 45 minutes of G7's activity was spent primarily in the $22 \mathrm{~m}$ structure with a few instances of switching to the 4 s structure.

\subsubsection{Group \#8}

G8 was comprised of two traditional students (one SIE, one ECE) and two TLP students (one SIE, one ECE). The following Figure 9.1.8 shows how G8 navigated this study in reference to design stage and team structure. 


\section{Figure 9.1.8 Group 8 (GC2) Engineering Design Activity}

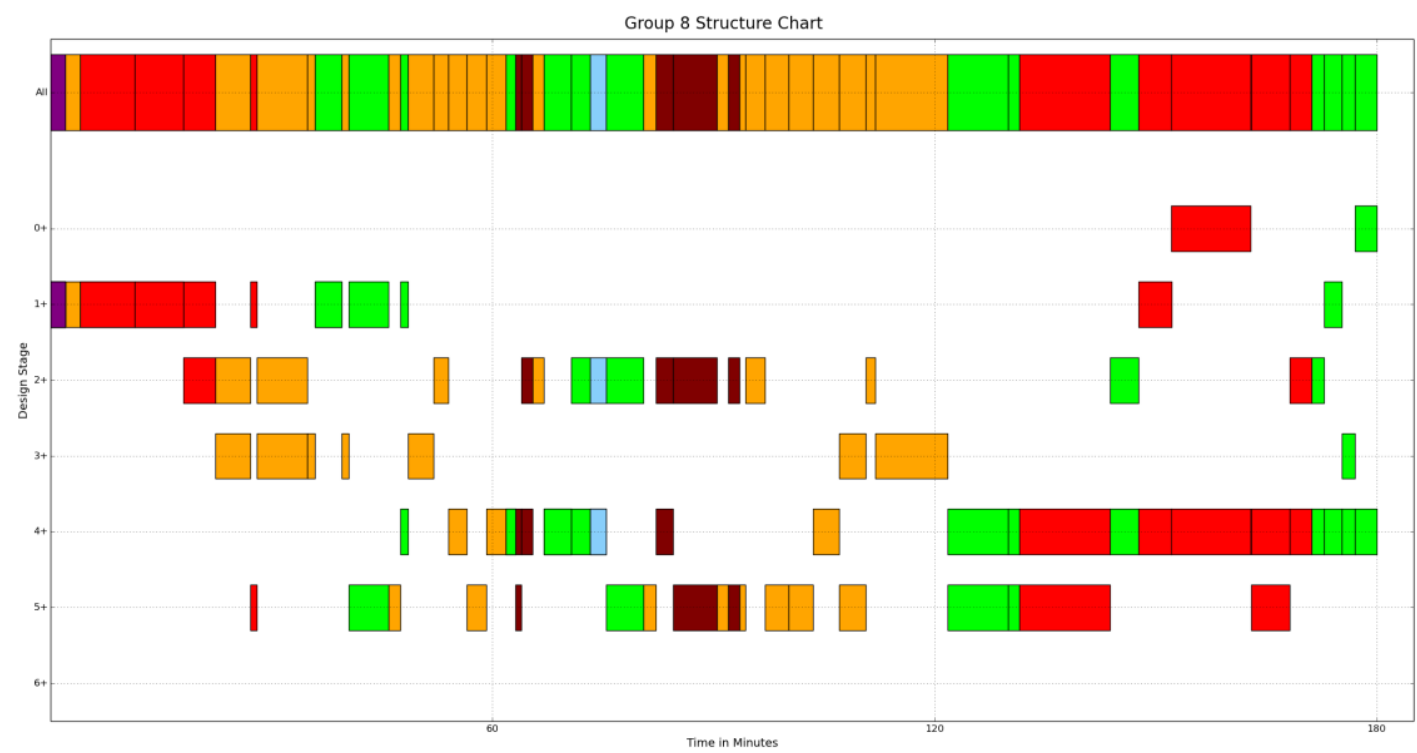

Design Stage: For the first 45 minutes of the activity G8 conducted work in stages 1,2 and 3 , starting out in stage 1 , then moving to stage 2 , then to stage 3 before going back to stage 1. Towards the end of the first hour G8 began work in stage 4 and stage 5 . Work done during the second hour mainly fell into stages 2, 4 and 5. During this time period it seems as if stages 2 and 5 were done concurrently. At the end of the second hour work in stage 3 occurred for about 15 minutes. In the third hour, most work was done in stage 4 . There was occasional work done in stages 1, 2 and 3 and large amount in stage 5 but all of this work was done concurrently with stage 4 .

Team Structure: G8 started out the activity working in 1111s structure briefly before switching to the $22 \mathrm{~m}$ structure for the remainder of the first 30 minutes. In the second half of the first hour G8 primarily worked in the 4s and 31e structure. During the first half of the second hour of this activity G8 utilized several subgroup structures including 22s, 
$31 \mathrm{e}$, and $211 \mathrm{~s}$. The second half of the second hour was primarily spent working in the $4 \mathrm{~s}$ structure. During the final hour of this activity G8 only used the $31 \mathrm{e}$ and $22 \mathrm{~m}$, spending about 30 minutes in each.

\subsubsection{Group \#9}

G9 was comprised of two traditional students (both ECE) and two TLP students (both SIE). The following Figure 9.1.9 shows how G9 navigated this study in reference to design stage and team structure.

Figure 9.1.9 Group 9 (GC3) Engineering Design Activity

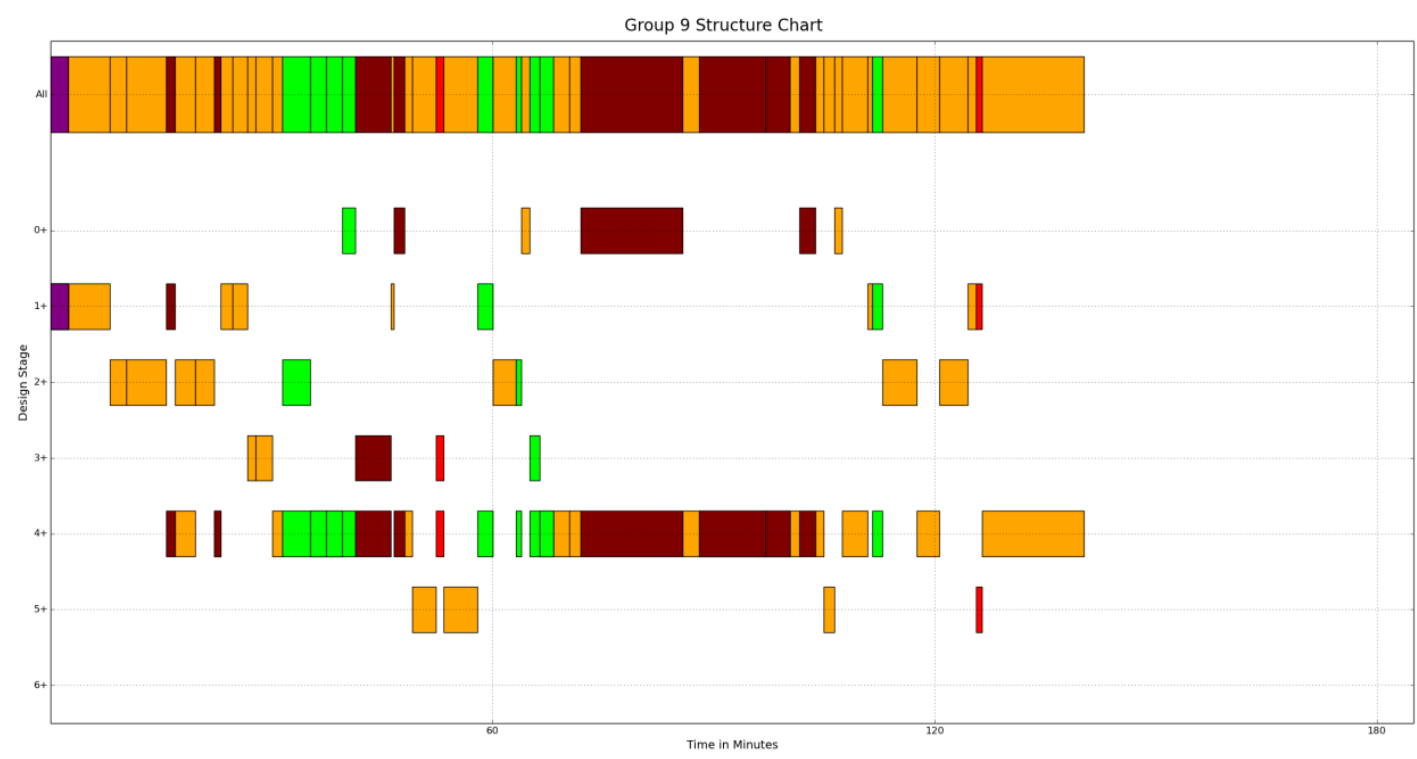

Design Stage: G9 cycles through all 5 stages once within the first hour of the activity, spending the most time in stage 4 . Then within the first 10 minutes of the second hour G9 cycles from stage 1 to 4 , where G9 spends the majority of the second hour. Towards the end of the second hour G9 conducts some work in stages 5,1 and 2 as the activity 
continues into the final 20 minutes. G9 closes out the final 20 minutes of the activity working in stage 4 .

Team Structure: G9 begins the activity working in the 1111s structure briefly before beginning work in the single group structure. The majority of the first 30 minutes was spent working in the $4 \mathrm{~s}$ structure. The remaining 30 minutes of the activity was spent in a mixture of structures primarily $4 \mathrm{~s}, 31 \mathrm{e}$ and $22 \mathrm{~s}$. These three structures were used for the remainder of the activity. $31 \mathrm{e}$ and 22 s were mostly used during the second hour. The end of the second hour moving into the final 20 minutes activity were primarily spent in the 4 s structure.

\subsubsection{Group \#10}

G10 was comprised of two traditional students (both SIE) and two TLP students (both ECE). The following Figure 9.1.10 shows how G10 navigated this study in reference to design stage and team structure. 
Figure 9.1.10 Group 10 (GC4) Engineering Design Activity

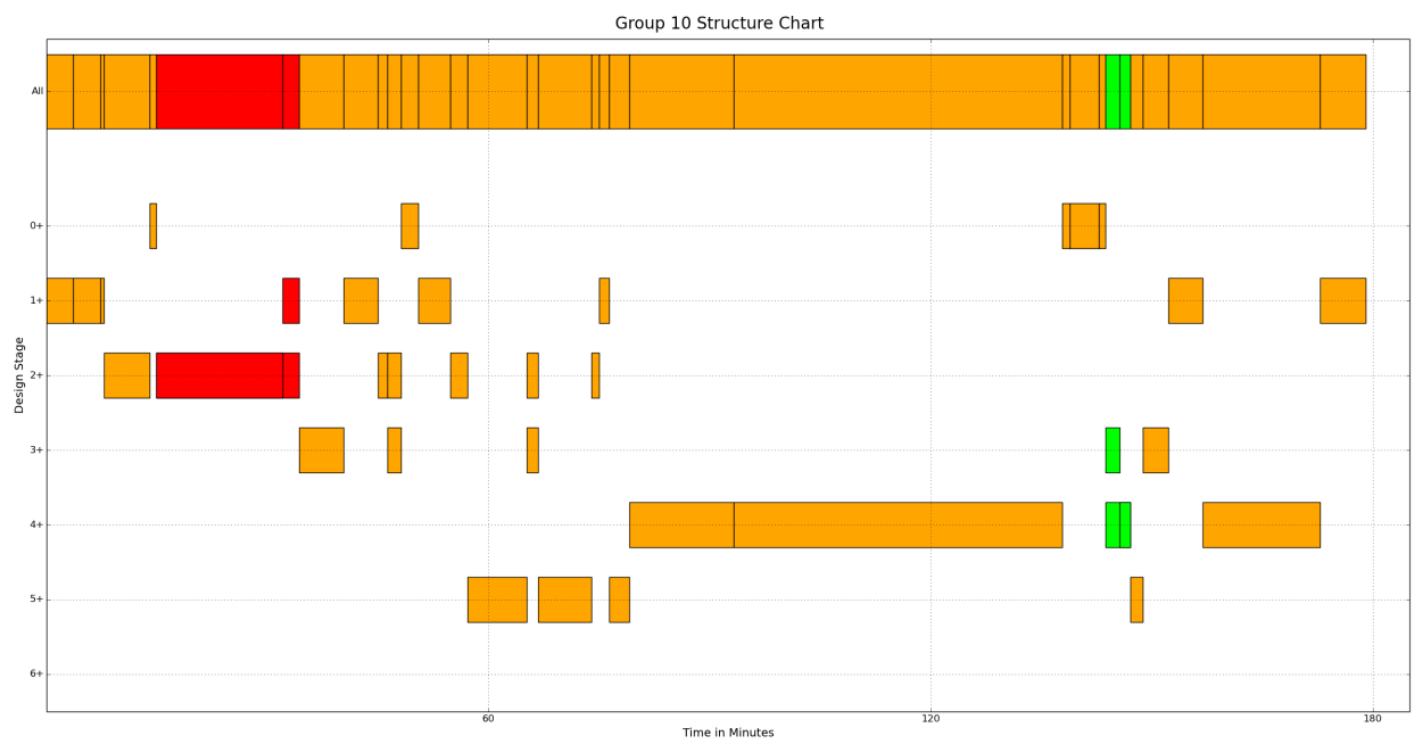

Design Stage: G10 started off the first 30 minutes conducting work first in stage 1 for a few minutes followed by stage 2 for the remaining time. In the second half of the first hour work done ranges across stages 1,2 and 3. At the very end of the first hour work in stage 5 begins and carries into the first 20 minutes of the second hour. During this time work occasionally occurs in the stages 1 through 3 as well. The remainder of the second hour moving into the first 20 minutes of the final hour was only spent working in stage 4 . The remainder of the final hour (40 minutes) consisted of work done in stages 1, 3, 4 and 5 with most work being done in stage 4. G10 ended the activity working in stage 1 .

Team Structure: G10 only used three structures throughout the entire activity, 4s, 22m, and 31e. The structure used for the majority of the activity was $4 \mathrm{~s}$. The subgroup structure $22 \mathrm{~m}$ was used for about 20 minutes during the middle of the first hour. The subgroup structure 31e was used for a few minutes in the middle of T3. 


\subsubsection{Group \#11}

G11 was comprised of three traditional students (two SIE, one ECE). The following Figure 9.1.11 shows how G11 navigated this study in reference to design stage and team structure.

Figure 9.1.6 Group 11 (GC5) Engineering Design Activity

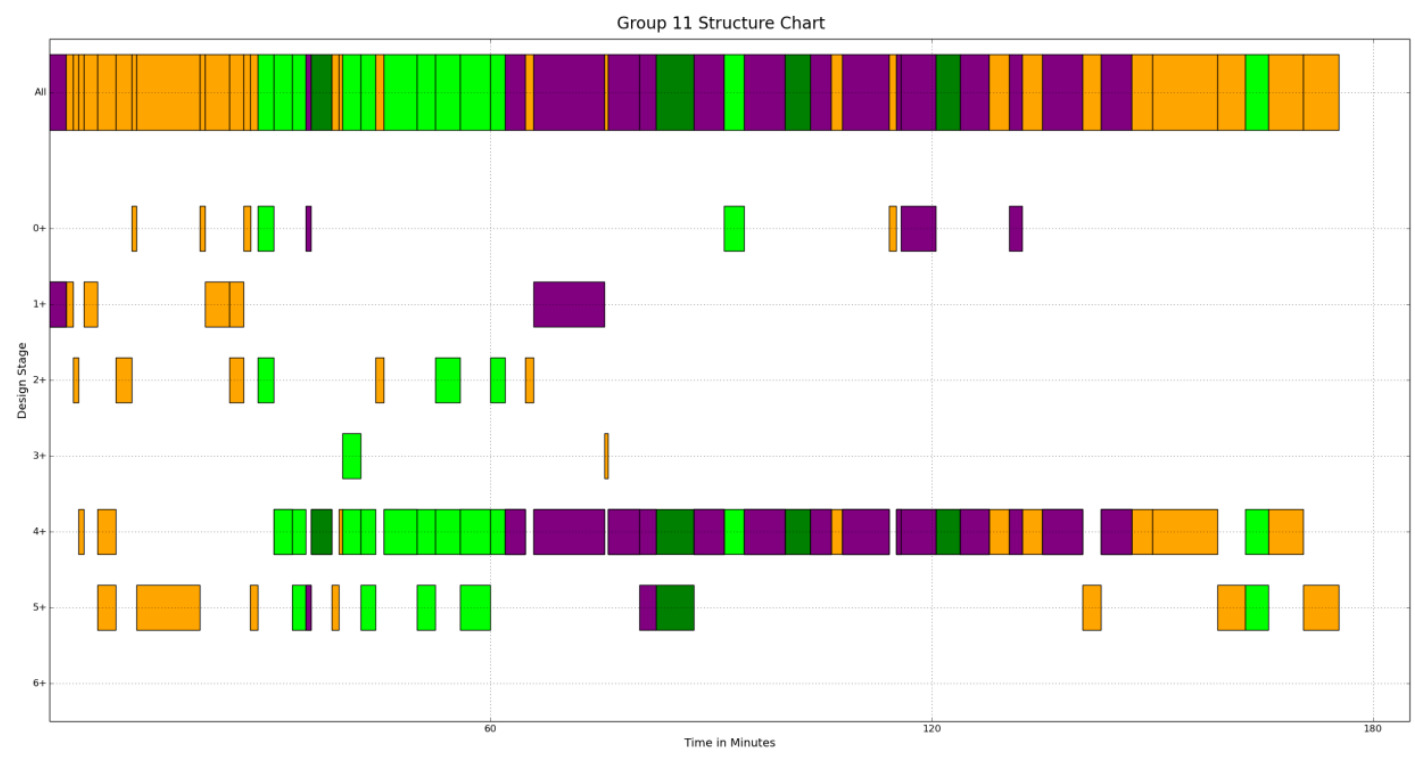

Design Stage: Within the first hour of the activity G11 conducted work across all the stages, however, very little to none was done in stage 3 . The most work was done in stages 4 and 5. Work in stage 4 dominated the last 30 minutes of the first hour. Work in Stage 5 was done fairly early, starting 15 minutes into the activity and carrying through much of the first hour. During the second hour most work was done in stage 4 with a little being done in stages 1 and 5, and little to none in stages 2 and 3. During the final 
hour G11 spent the majority of their time in stage 4 with a little work being done in stage 5 towards the very end of the time.

Team Structure: G11 spent the very first few minutes of this activity in the $1111 \mathrm{~s}$ structure before working in the $4 \mathrm{~s}$ structure for much of the first 30 minutes. The remaining 30 minutes of the first hour were spent working in the 31e structure. Most of the second hour and beginning of the third was spent working in the 1111s structure with occasional periods of time spent in the $31 \mathrm{e}$ and $31 \mathrm{~s}$ structures. The majority of the third hour was spent back working in the $4 \mathrm{~s}$ structure. 